\title{
Um Estudo Comparativo de Métodos de Segmentação de Documentos Antigos
}

Nury Yuleny Arosquipa Yanque

\author{
DISSERTAÇÃO APRESENTADA AO \\ Instituto de MATEMÁtica E Estatística \\ da Universidade de São Paulo \\ PARA OBTENÇÃO DO TÍTULO DE \\ Mestra EM CiêNCIAS
}

Programa: Ciência da Computação

Orientador: Prof. Dr. Roberto Hirata Junior

Durante o desenvolvimento deste trabalho o autor recebeu auxílio financeiro da CAPES

São Paulo

Novembro de 2018 



\title{
Um Estudo Comparativo de Métodos de Segmentação de Documentos Antigos
}

\author{
Nury Yuleny Arosquipa Yanque
}

Esta versão da dissertação contém as correções e alterações sugeridas pela Comissão Julgadora durante a defesa da versão original do trabalho, realizada em Novembro de 2018.

Uma cópia da versão original está disponível no Instituto de Matemática e Estatística da Universidade de São Paulo.

Comissão Julgadora:

- Prof. Dr. Roberto Hirata Junior (orientador) - IME-USP

- Prof. Dr. Edson Gomi - Poli-USP

- Prof. Dr. Gustavo Enrique Salazar Torres - UNIFESP 
Autorizo a reprodução e divulgação total ou parcial deste trabalho, por qualquer meio convencional ou eletrônico, para fins de estudo e pesquisa, desde que citada a fonte. 


\section{Agradecimentos}

Este trabalho não teria sido possível sem a ajuda e colaboração de inumeras pessoas. Agradeço aos meus pais Yuri e Deicy, que me mostraram desde cedo a importância dos estudos na vida de uma pessoa, pelo apoio, coragem e carinho que me deram e agora são a minha força de vida. A meu irmão Nin pelo contínuo incentivo e acreditar sempre em mim. A Alex, por suas recomendações e por sempre me estimular na contínua aprendizagem.

Agradeço profundamente ao meu orientador, professor Roberto Hirata Júnior, pela sua disposição, comentários, correções, ensinamentos e principalmente por dar-me a oportunidade de pesquisar na área. Agradeço aos professores Ronaldo Fumio Hashimoto e Edson Gomi por todas as recomendações e correções dadas na qualificação.

Agradeço aos amigos e colegas do laboratório de visão: Grover, Hans, Evelyn, Miguel, Mariela, Carlos e Maciel por suas opiniões, comentários e correções. Aos meus colegas de pesquisa e orientados do professor Hirata e da professora Nina: Caio, Matheus, Igor, Leandro e Antonio, pelas críticas e sugestões.

Aos meus amigos Julissa, Marcos e Milton por sua amizade e companhia desde o início da aventura do mestrado. E a todos que de alguma forma contribuíram e me incentivaram para a conclusão do trabalho. 



\section{Resumo}

\section{Nury Yuleny Arosquipa Yanque. Um Estudo Comparativo de Métodos de Segmentação} de Documentos Antigos. Dissertação (Mestrado). Instituto de Matemática e Estatística, Universidade de São Paulo, São Paulo, 2018.

Há uma vasta quantidade de informação nos textos antigos manuscritos e tipografados, e grandes esforços para a digitalização e disponibilização desses documentos têm sido feitos nos últimos anos. No entanto, os sistemas de Reconhecimento Óptico de Caracteres (OCR) não têm grande sucesso nesses documentos por diversas razões, por exemplo, devido a defeitos por envelhecimento do papel, manchas, iluminação desigual, dobras, escrita do verso transparecendo na frente, pouco contraste entre texto e fundo, entre outros. Uma das etapas importantes para o sucesso de um OCR é a boa segmentação da parte escrita e do fundo da imagem (binarização) e essa etapa é particularmente sensível a esses defeitos que são próprios de documentos históricos. Tanto assim que nos últimos oito anos foram realizadas competições de métodos de binarização de documentos históricos ${ }^{1}$ que levaram ao avanço do estado da arte na área. Neste trabalho fizemos um estudo comparativo de diversos métodos de segmentação de documentos antigos e propusemos um método baseado em aprendizado de máquina que resgata as vantagens dos métodos heurísticos. Esse estudo abrangeu documentos históricos manuscritos e tipografados e foi comparado com os métodos do estado da arte via métricas usuais e via um sistema de OCR de código aberto. Os resultados obtidos pelo método proposto são comparáveis com os métodos do estado da arte respeito no resultado do OCR, mostrando algumas vantagens em imagens específicas.

Palavras-chave: Segmentação de documentos. Binarização de imagens. Limiarização. OCR. Documentos Históricos. Análise de Documentos

\footnotetext{
${ }^{1}$ https://vc.ee.duth.gr/h-dibco2018/
} 



\begin{abstract}
Nury Yuleny Arosquipa Yanque. A comparative study of segmentation methods of historical documents. Thesis (Masters). Institute of Mathematics and Statistics, University of São Paulo, São Paulo, 2018.

There is a vast amount of information in the ancient handwritten and machine-printed texts, and great efforts for the digitization and availability of these documents have been made in recent years. However, Optical Character Recognition (OCR) systems do not have much success in these documents for a variety of reasons, for example, due to paper aging defects, faded ink, stains, uneven lighting, folds, bleed-through, gosthing, poor contrast between text and background, among others. One of the important steps for the success of an OCR system is the good segmentation of the written part and the background of the image (binarization) and this step is particularly sensitive to those defects that are typical of historical documents. So much so that in the last eight years a competition for the binarization methods of historical documents have been held ${ }^{2}$ which led to the advance of the state of the art in the area. In this work we have done a comparative study of several methods of segmentation of historical documents and propose a method based on machine learning that rescues the advantages of the heuristic methods. This study covered both handwritten and typography historical documents and was compared to state-of-the-art methods via DIBCO standard metrics and via an open source OCR system. The results obtained by the proposed method are comparable with the methods of the state of the art respect in the OCR result, showing some advantages in specific images.
\end{abstract}

Keywords: Segmentation of documents. Binarization of images. Thresholding. OCR Historical Documents. Document Analysis

\footnotetext{
${ }^{2}$ https://vc.ee.duth.gr/h-dibco2018/
} 



\section{Lista de Abreviaturas}

OCR Reconhecimento Ótico de Caracteres (Optical Character Recognition)

DIARS Document Image Analysis and Retrieval System

(Sistema de Análise de Imagens e Recuperação de Documentos)

DIBCO Concurso de Binarização de Imagens de Documentos

(Document Image Binarization Contest)

H-DIBCO Concurso de Binarização de Imagens de Documentos Manuscritos

(Handwritten Document Image Binarization Contest)

ICDAR Conferência Internacional sobre Análise e Reconhecimento de Documentos

(International Conference on Document Analysis and Recognition)

ICFHR Conferência Internacional sobre fronteiras no reconhecimento de manuscrito

(International Conference on Frontiers in Handwriting Recognition)

GT Ground Thruth

RDI Índice de Escuridão Relativa (Relative Darkness Index)

LTP Padrões Ternários Locais (Local Ternary Patterns)

LBP Padrões Binários Locais (Local Binary Patterns)

SGD Gradiente Descendente Estocástico

(Stochastic Gradient Descent)

GT Padrão ouro (ground truth)

LSTM Redes de Memória de Longo Prazo

(Long Short Term Memory)

CNN Rede neural convolucional (Convolutional Neural Network)

DSN Red Profunda Supervisionada (Deep Supervised Network)

IME Instituto de Matemática e Estatística

USP Universidade de São Paulo 


\section{Lista de Figuras}

1.1 Etapas envolvidas no processo de análise de documentos . . . . . . . . . 1

1.2 Variação da parte escrita que sobrevém do autor do documento. . . . . . . 2

1.3 Efeitos da pluma, da tinta e do papel no documento. . . . . . . . . . 2

1.4 Exemplos de degradações de documentos antigos . . . . . . . . . . . . . 3

1.5 Diversas características em conjunto que os documentos antigos que apresentam. ......................... 3

1.6 Efeitos da binarização no OCR . . . . . . . . . . . . . . . . 4

1.7 Resultados da binarização de métodos consolidados do estado da arte para uma imagem manuscrita e para uma imagem tipografada . . . . . . . . . 6

3.1 Fluxo de informações (workflow) da metodología proposta. . . . . . . . . 16

3.2 Estratégia de combinação das características. . . . . . . . . . . . . . . . . 17

3.3 Dados do nosso espaço de características projetados em um plano usando o LDA . . . . . . . . . . . . . . . . . . . . . . . . . . 21

4.1 Tipos de documentos históricos e as suas correspondentes segmentações verificadas(GT) . . . . . . . . . . . . . . . . . . 24

4.2 Documentos manuscritos do DIBCO 2013 e os seus correspondentes GT . 25

4.3 Documentos tipografados do DIBCO 2013 e os seus correspondentes GT 25

4.4 Métrica de avaliação para o resultado do OCR . . . . . . . . . . . . . 30

5.1 Caso 3.1: Resultados das métricas do DIBCO por conjunto de características 37

5.2 Caso 3.1: Porcentagem de casamento obtida a partir da comparação de caracteres dos textos extraídos pelo Tesseract das imagens binarias e da imagem original . . . . . . . . . . . . . . . . . . . . . 39

5.3 Caso 3.2: Resultados das métricas do DIBCO por conjunto de características. 40

5.4 Caso 3.2: Porcentagem de casamentos obtidos a partir da comparação de caracteres dos textos extraídos pelo Tesseract das imagens binarias e da imagem original . . . . . . . . . . . . . . . . . . 4 41

5.5 Desempenho dos classificadores segundo F-Measure $(F M)$. . . . . . . . . 46

5.6 Desempenho dos classificadores Pseudo-FMeasure (pFM) . . . . . . . . . . 47 
5.7 Desempenho dos classificadores segundo Peak Signal to Noise Ratio (PSNR) 47

5.8 Desempenho dos classificadores segundo Distance Reciprocal Distortion Metric $(D R D) \ldots \ldots \ldots \ldots$. . . . . . . . . . . . . . . 48

5.9 Comparação das porcentagens de casamento dos textos extraídos pelo Tesseract das imagens binarias tipografadas obtidos por cada classificador para os Casos 3.1 e 3.2, e também a comparação do texto extraido diretamente da imagem original . . . . . . . . . . . . . 48

5.10 Desempenho dos métodos do estado da arte e o proposto segundo o F-Measure 49

5.11 Desempenho dos métodos do estado da arte e o proposto segundo o PseudoFMeasure .......................... 50

5.12 Comparação dos metodos do estado da arte e o proposto segundo o PSNR 50

5.13 Porcentagem de casamento de texto obtido do método proposto e os métodos do estado da arte. . . . . . . . . . . . . 51

5.14 Imagem tipografada, o seu Ground Truth e as suas binarizações pelos métodos do estado da arte e o método proposto. . . . . . . . . . . . 53

A.1 Tela inicial do visualizador . . . . . . . . . . . . . . . . . 57

A.2 Tela inicial com a configuração para vizualizar uma imagem manuscrita. 58

A.3 Visualização e zoom de uma imagem manuscrita . . . . . . . . . . . . . . 59

A.4 Configuração da tela inicial para a visualização da diferença de imagens. $\quad 59$

A.5 Visualização da diferença de imagens. . . . . . . . . . . . . . . . . . 60

A.6 Visualização da diferença de imagens com uma apliação de uma certa região. 60

A.7 Tela inicial para visualizar uma imagem tipografada. . . . . . . . . . . . 61

A.8 Visualização e diferença para uma imagem tipografada. . . . . . . . . . . 61 


\section{Lista de Tabelas}

2.1 Categorias das técnicas de binarização . . . . . . . . . . . . . . . . . 11

4.1 Quantidade e tipo de documentos históricos nas competições DIBCO . . 25

5.1 Casos avaliados segundo as combinações de tipos de documentos históricos para o treinamento e para teste do modelo. . . . . . . . . . . . 34

5.2 Grade de hiper-parâmetros a avaliar . . . . . . . . . . . . . 35

5.3 Caso 3.1: Combinação de valores dos hiper-parâmetros que obtiveram a maior revocação por tipo de característica . . . . . . . . . . 36

5.4 Caso 3.1: Resultados quantitativos das imagens binarizadas usando as mêtricas do DIBCO para as imagens 71 imagens de teste. . . . . . . . . 42

5.5 Porcentagem de matching(comparação) entre dois textos . . . . . . . . . 43

5.6 Caso 3.2: Combinação de valores dos hiper-parâmetros que obtiveram a maior revocação por tipo de característica . . . . . . . . . . . 44

5.7 Caso 3.2: Resultados quantitativos das imagens binarizadas usando as mêtricas do DIBCO para as imagens 71 imagens de teste, onde 40 são manuscritas e 31 tipografadas. . . . . . . . . . . . . . 45

5.8 Desempenho do método proposto em relação aos métodos do estado da arte. 54 


\section{Sumário}

1 Introdução 1

1.1 Processamento de Imagens de Documentos Antigos . . . . . . . . . . . . 2

1.2 Binarização e Segmentação . . . . . . . . . . . . . . . . . . . . . . . . 3

1.3 Competições DIBCO . . . . . . . . . . . . . . . . . 4

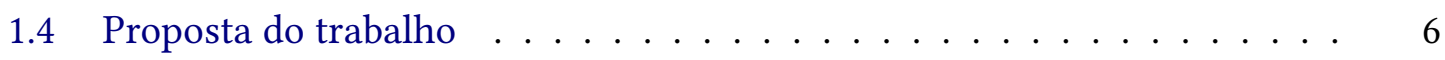

1.5 Organização do Trabalho . . . . . . . . . . . . . . . . 7

2 Estado da Arte 9

2.1 Métodos baseados em heurística . . . . . . . . . . . . . 9

2.1.1 Métodos Globais . . . . . . . . . . . . . . . 9 9

2.1 .2 Métodos Locais . . . . . . . . . . . . . . . . . . . . 10

2.1.3 Métodos Híbridos . . . . . . . . . . . . . . . . . . . . . . 11

2.2 Métodos baseados em aprendizagem de máquina . . . . . . . . . . . . . . 12

2.2.1 Aprendizagem não supervisionada . . . . . . . . . . . . . . 13

2.2.2 Aprendizagem supervisionada . . . . . . . . . . . . . 13

2.2.3 Aprendizagem Profunda . . . . . . . . . . . . . . . . . . . 14

3 Metodología Proposta $\quad 15$

3.1 Workflow da metodología proposta . . . . . . . . . . . . 15

3.2 Estratégia de combinação de características . . . . . . . . . . . . . . . 16

3.3 Conjunto grande de amostras . . . . . . . . . . . . . . . . . . . . . . 19

3.3.1 Gradiente Descendente Estocástico (SGD) . . . . . . . . . . . . 20

4 Conjunto de dados e Métricas de avaliação 23

4.1 Conjunto de dados da competição de binarização . . . . . . . . . . . . . 23

4.1.1 Ground Truth . . . . . . . . . . . . . . . . 25

4.2 Métricas de avaliação das imagens binarizadas . . . . . . . . . . . . 26

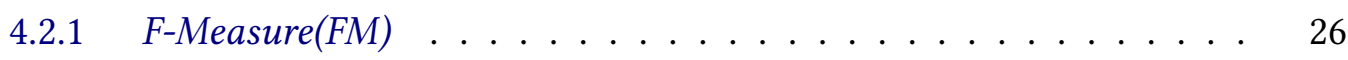

$4.2 .2 \quad$ Pseudo-FMeasure $(p F M) \ldots \ldots \ldots 27$ 
4.2.3 Peak Signal to Noise Ratio(PSNR) . . . . . . . . . . . . . . . . . . 27

4.2.4 Distance-Reciprocal Distortion(DRD) . . . . . . . . . . . 28

4.3 Métrica de avaliação para o resultado do OCR . . . . . . . . . . . . . 28

4.4 Classes desbalanceadas . . . . . . . . . . . . . . . . . . . 30

5 Experimentos e Análise de Resultados 33

5.1 Planejamento dos experimentos . . . . . . . . . . . . . 33

5.1.1 Segundo os tipos de documentos históricos . . . . . . . . . 33

5.1 .2 Segundo os tipos de características . . . . . . . . . . . 34

5.1.3 Padronização das características . . . . . . . . . . . . . 35

5.1.4 Hiper-parâmetros a avaliar . . . . . . . . . . . . 35

5.1.5 Amostragem estratificada (StratifiedKFold) . . . . . . . . . . . 35

5.2 Experimentos e Resultados . . . . . . . . . . . . . . . . . . . . 35

5.2.1 Caso 3.1: Treinar com imagens manuscritas e tipografadas e testar com imagens manuscritas e tipografadas . . . . . . . . . 36

5.2.2 Caso 3.2: Treinar com imagens manuscritas e testar com manuscritas e tipografadas . . . . . . . . . . . . . . 39

5.3 Comparação e análise de Resultados . . . . . . . . . . . . . . . . 46

5.3.1 Desempenho segundo as métricas do DIBCO . . . . . . . . . 46

5.3.2 Desempenho segundo o Tesseract(OCR) . . . . . . . . . . . . 47

5.4 Comparação com os métodos do estado da arte . . . . . . . . . . . . . . . 49

5.4.1 Segundo as métricas DIBCO . . . . . . . . . . . . . . . . . 49

5.4 .2 Segundo o OCR . . . . . . . . . . . . . . . 51

5.5 Discussão de resultados . . . . . . . . . . . . . . . . . . 51

6 Conclusões $\quad 55$

6.1 Limitações e pesquisas futuras . . . . . . . . . . . . . . . . . . 56

A Visualizador de imagens $\quad 57$

A.1 Tela inicial . . . . . . . . . . . . . . . . . . 57

A.2 Visualizáção numa escala maior (zoom) . . . . . . . . . . . . . 58

A.3 Visualização da subtração de imagens (diferenças) . . . . . . . . . . . . . 59

A.4 Visualização de imagens tipografadas e dos textos extraidos . . . . . . . 60

$\begin{array}{lc}\text { Bibliografia } & 63\end{array}$ 


\section{Capítulo 1}

\section{Introdução}

Há uma vasta quantidade de informação nos textos antigos manuscritos e tipografados de alto valor histórico e cultural. Assim, grandes esforços para a digitalização e disponibilização desses documentos têm sido feito nos últimos anos.

A Figura 1.1 apreesenta um fluxo típico das etapas envolvidas na análise de documentos, começa pela digitalização ou obtenção do documento, segue a binarização, continua com a análise das características(seja texto ou gráficos) e finalmento mostra a descrição do documento. Note-se que a binarização de imagens é uma das etapas preliminares de préprocessamento na tarefa de sistemas OCR, esses sistemas OCR, por sua vez, encontram ampla aplicabilidade em tarefas como recuperação de informações (WeInMAN et al., 2014) e compactação de dados (Huttenlocher et al., 1999).

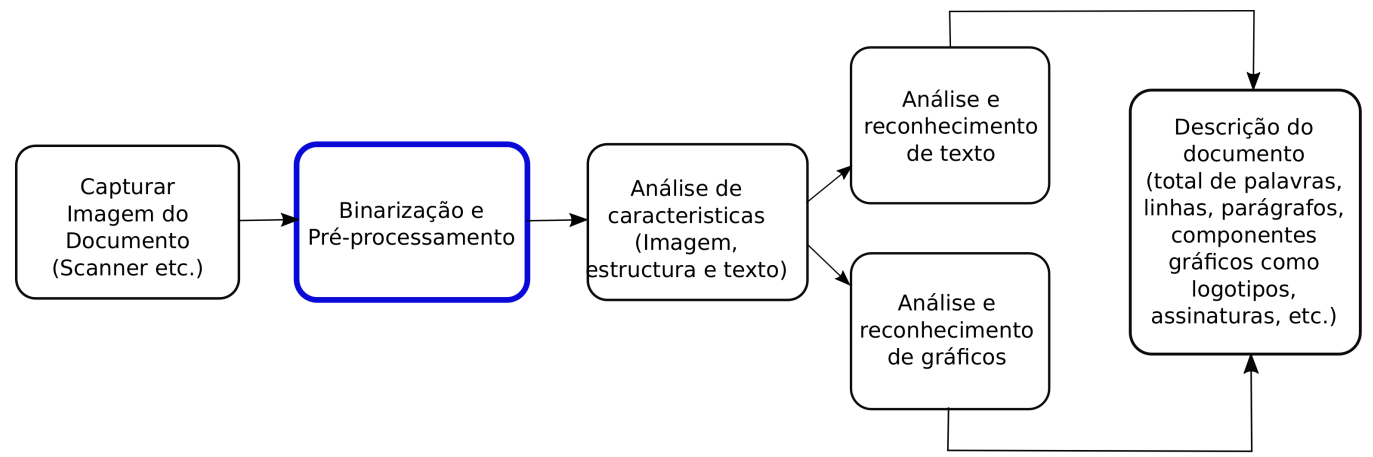

Figura 1.1: Etapas envolvidas no processo de análise de documentos segundo DIXIT e SHIRDHONKAR, 2015.

Os sistemas de Reconhecimento Óptico de Caracteres (OCR) não têm grande sucesso nesses documentos por diversas razões, por exemplo, devido a defeitos por envelhecimento do papel, manchas, iluminação desigual, dobras, escrita do verso transparecendo na frente, pouco contraste entre texto e fundo, entre outros. Uma das etapas importantes para o sucesso de um OCR é a boa segmentação da parte escrita do fundo do documento (binarização) e essa etapa é particularmente sensível a esses defeitos que são próprios de documentos históricos. 


\subsection{Processamento de Imagens de Documentos Anti- gos}

Imagens de documentos antigos tipografados ou manuscritos pertencem a uma classe específica de documentos que podem se diferenciar bastante de outros tipos de documentos como jornais, artigos científicos ou revistas (LiKformAn-Sulem et al., 2007). Isso acontece porque os documentos históricos têm características que dependem da:

- Variação da parte escrita do documento é individual de cada pessoa, isto é:

- Padrão de escrita diferente.

- Pressões de mão variáveis.

- Letras grossas e finas.

- Alinhamento não bem definidos.

- Rasuras e anotações, entre outros.

A Figura 1.2 ilustra este tipo de características.

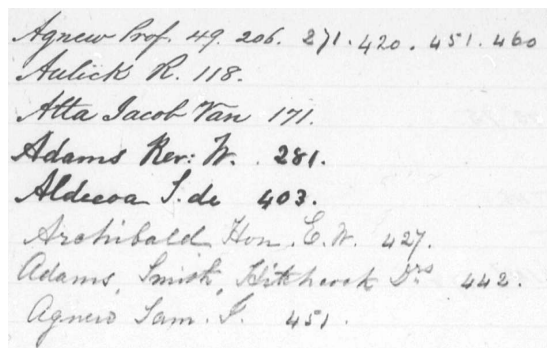

(a)

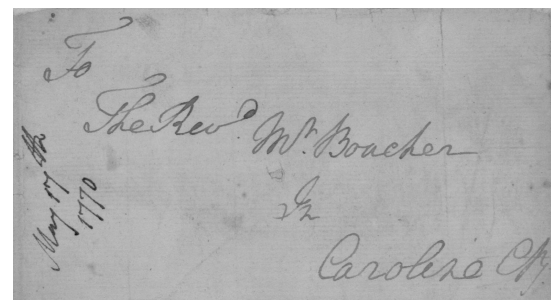

(b)

Figura 1.2: Variação da parte escrita que sobrevém do autor do documento.

- Efeitos da pluma, tinta e papel, por exemplo:

- Filtragem e espalhamento da tinta (faded ink).

- Manchas do verso aparecendo na frente (bleed-through).

- Escrita do verso aparecendo na frente devido à má qualidade do papel (gosthing).

A Figura 1.3 ilustra este tipo de características.
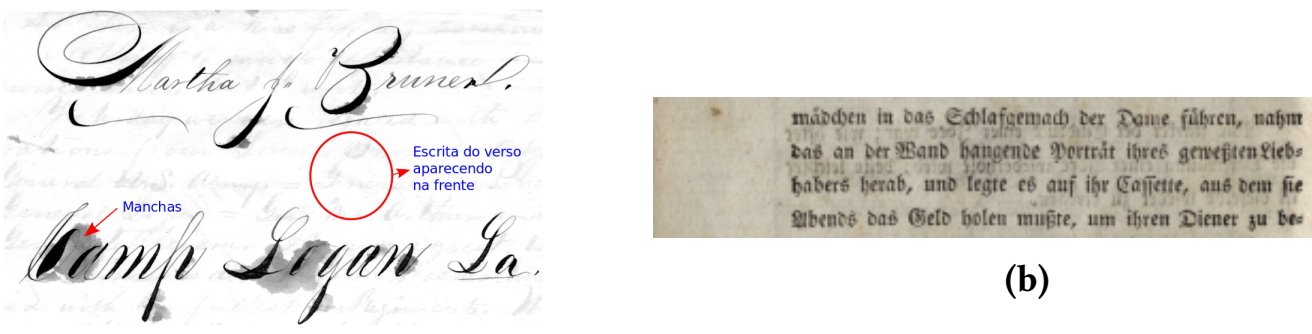

(b)

(a)

Figura 1.3: Efeitos da pluma, da tinta e do papel no documento. 
- Degradações, quer dizer:

- Sombras ou manchas (stains).

- Dobramentos ou rugas.

- Ruído devido à variação de iluminação durante a digitalização do documento.

- Dados perdidos, texto apagado.

- Variação de contraste.

- Efeitos de deformação, entre outros.

A Figura 1.4 ilustra este tipo de características.

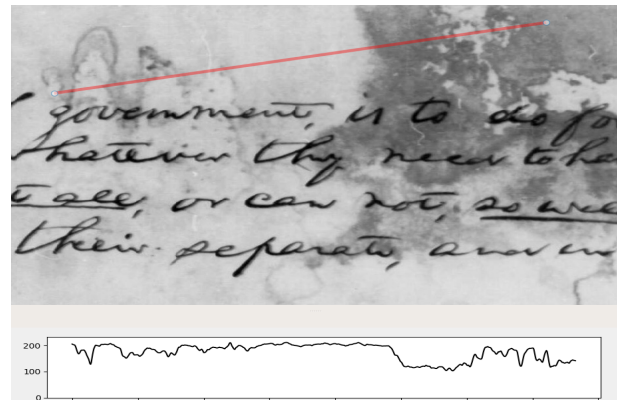

(a)

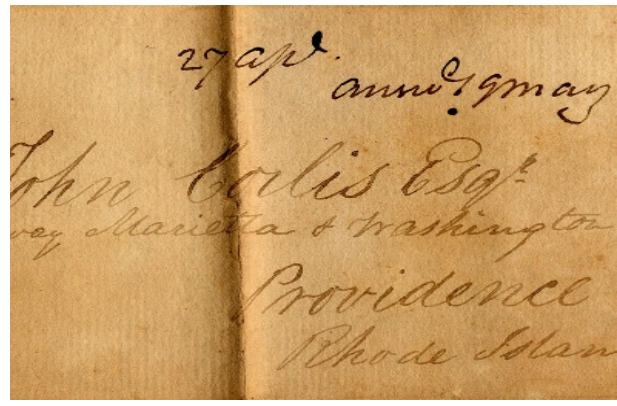

(b)

Figura 1.4: Exemplos de degradações de documentos. a) O histograma mostra a variação das tonalidades de cinza do fundo no segmento da linha vermelha, note-se a variação dos tons de cinza nesse segmento. $b$ ) Dobramentos ou rugas.

Infelizmente, a maioria das imagens de documentos históricos contém as diversas características em conjunto, como apresentada na Figura 1.5.

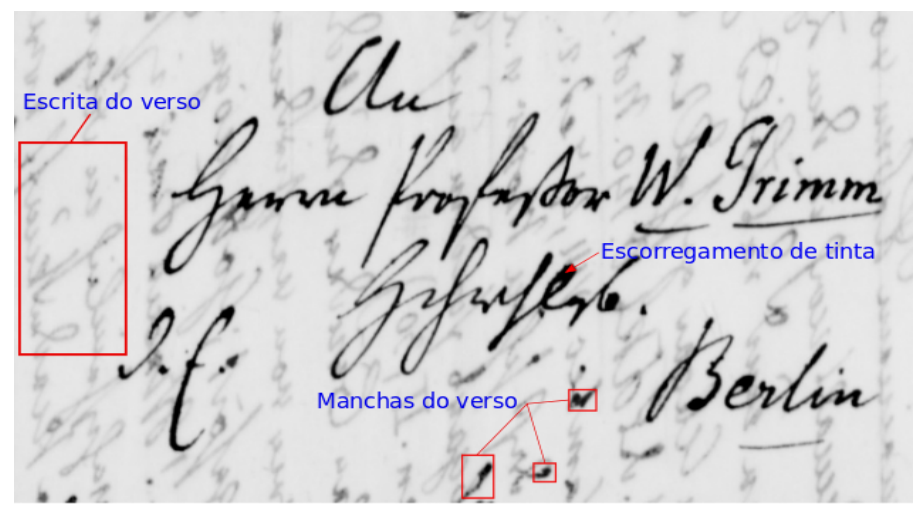

Figura 1.5: Diversas características em conjunto que os documentos antigos que apresentam.

\subsection{Binarização e Segmentação}

A binarização ou limiarização(thresholding) é uma das técnicas mais simples de segmentação e consiste na classificação dos pixeis de uma imagem de acordo com a especificação de um ou mais limiares. 
Por exemplo, se considerarmos como propriedade os níveis de cinza da imagem $f$ : $Z \times Z \rightarrow[0,255]$, uma maneira de extrair os objetos do fundo é por meio da seleção de um limiar $T$ (um valor de nível de cinza) que separe os dois grupos. Então, cada ponto $x \in Z \times Z$ tal que $f(x)>T$ é denominado um ponto do objeto(texto); caso contrário, o ponto é denominado um ponto do fundo. A imagem binarizada $g(x)$ pode ser definida como

$$
g(x)= \begin{cases}0, & \text { se } f(x) \leq T \\ 1, & \text { se } f(x)>T\end{cases}
$$

A representação de uma imagem binaria, é uma representação em branco e preto do objeto (o texto) e não objeto (ou seja, o fundo), ele é o formato preferido para análise de imagem, especialmente análise de imagem de documentos que consiste em objetos textuais (IsMAIL et al., 2018).

As múltiplas degradações apreesentadas na seção 1.1 tornam o processo de binarização uma tarefa desafiadora (OUAFEK e Kholladi, 2018), pois ferramentas de análise de documentos, tais como OCR e DIARS, normalmente requerem imagens binarizadas para poder alcançar resultados satisfatórios. Os bons resultados desta etapa são indispensáveis para melhorar a qualidade do sistema de reconhecimento de texto. Uma binarização imprópria causa manchas, riscos, falhas na segmentação, as fusões, fraturas e outras deformações nas formas dos caracteres e, como consequência, causa deterioração do desempenho do OCR, como podemos observar na Figura 1.6.

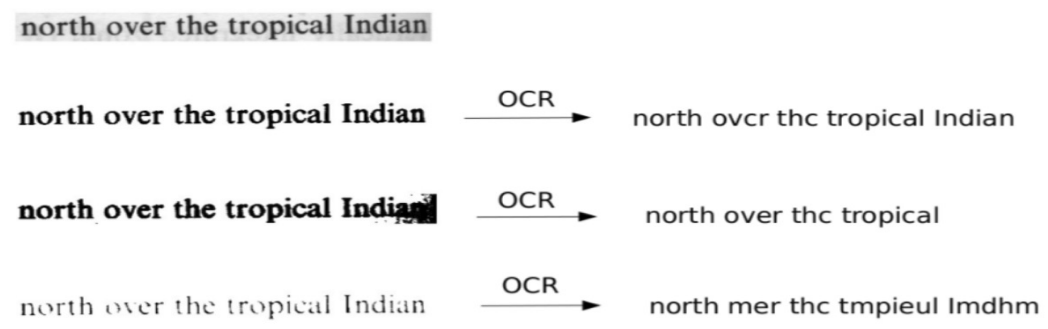

Figura 1.6: Efeitos da binarização no $O C R$

\subsection{Competições DIBCO}

Nos últimos 8 anos foram realizadas competições de binarização de documentos históricos para abordar o problema em questão que levaram ao avanço do estade da arte na área, competições tais como o Document Image Binarization Contest (DIBCO), regulado no contexto da International Conference on Document Analysis and Recognition (ICDAR), e o Handwritten Document Image Binarization Contest (H-DIBCO) regulado no contexto da International Conference on Frontiers in Handwriting Recognition (ICFHR). Podem-se encontrar diversas soluções, pelo fato da natureza do problema de ser subjetiva e ill-posed (Howe, 2011), devido à grande variação que pode ser encontrada nos tipos de imagens de entrada, a tarefa de binarização se torna mais difícil de alcançar, portanto, não existe um método genérico que possa ser usado para lidar com vários tipos de imagens e degradações de documentos históricos, cada método tem sua própria especificidade. 
Por exemplo, métodos bastante consolidados no estado da arte são do OTsu, 1979, do Sauvola e Pietikäinen, 2000, do H. Lu et al., 2004 e do Howe, 2011, por terem conseguido os primeiros lugares ou serem parte do pipeline dos métodos mais complexos que obtiveram os primeiros lugares nas competições do DIBCO. Na Figura 1.7 pode-se observar os resultados desses métodos de binarização a partir de um documento antigo manuscrito (Figura 1.7a) e também de um documento antigo tipografado (Figura 1.7b), cada uma com suas próprias características, a imagem 1.7a apresenta degradações em conjunto (escrita do verso aparecendo na frente, sombra, iluminação desigual) e a imagem 1.7b apresenta padrões de escrita e cores diferentes (letras grossas e finas, assim como cores vermelhas e pretas). Quando aplicamos o método do OTSU, 1979 o resultado da binarização é boa para a imagem $1.7 \mathrm{~b}$ porém ruim para a imagem $1.7 \mathrm{a}$; com o método do SAUVOLA e PietikëInen, 2000 nenhuma binarização ficou boa (Figura 1.7e e Figura 1.7f), mas com o método do Howe, 2013 consegue-se bons resultados (imagens $1.7 \mathrm{~g}$ e $1.7 \mathrm{~h}$ ) para as duas imagens, mas nem sempre é assim. Isso quer dizer que os resultados dos métodos são variáveis e que dependem das próprias características da imagem e as vantagens de cada método, sendo que para algumas imagens consegue-se um bom desempenho e, infelizmente menor desempenho para as outras, além disso a binarização de imagens é tipicamente sensível às configurações dos parâmetros de controle da técnica empregada (VATs et al., 2017).

Dada essa dificuldade do problema da binarização, onde a natureza do método de binarização de imagem empregada em qualquer aplicação deve ser adaptada especificamente à natureza da imagem de entrada, a binarização da imagem permanece um problema em aberto.

Por isso, nós propomos uma técnica de binarização baseado em aprendizagem de máquina que resgata as vantagens dos métodos específicos ou heurísticos do estado da arte, e adicionando descritores de textura para melhorar a performance e resolver o problema em questão. Além disso a técnica opera como um todo em um workflow, onde o resultado da binarização influencia diretamente no desempenho das etapas subsequentes num sistema OCR, tendo em conta a necessidade de ter um algoritmo de binarização de imagens de documentos históricos que preserve ao máximo o conteúdo de texto de tal documento. 
$s$ imagens e da diferença entre delas

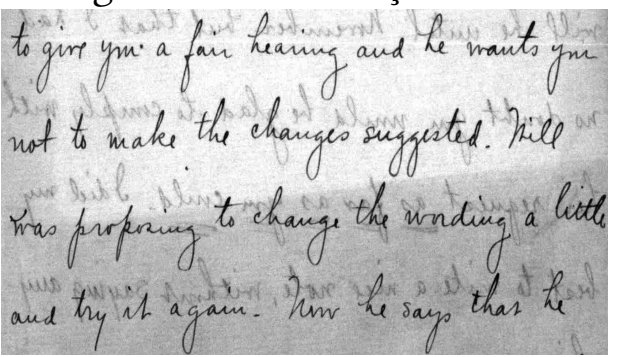

(a) Imagem original manuscrita

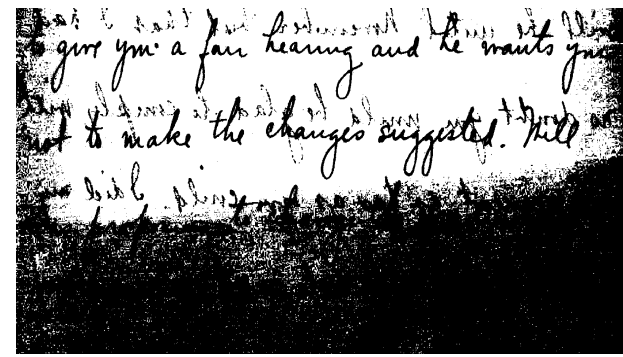

(c) Método do OTSU, 1979

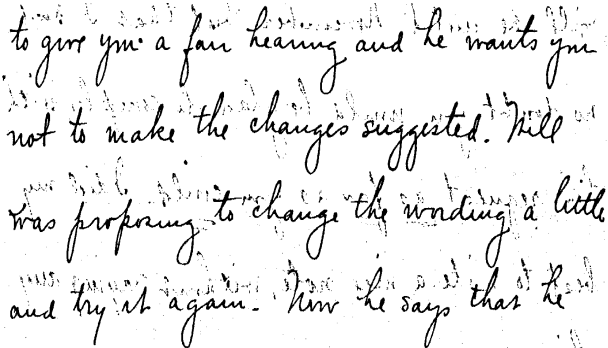

(e) Método do Sauvola e PietikäInen, 2000

$$
\begin{aligned}
& \text { to gine you a fair heaing and he mants ym } \\
& \text { not to make the changes suggested. Bill } \\
& \text { was perpasing to change the wonding a litte } \\
& \text { and try it again. ther he says thas he }
\end{aligned}
$$

(g) Método do Howe, 2013

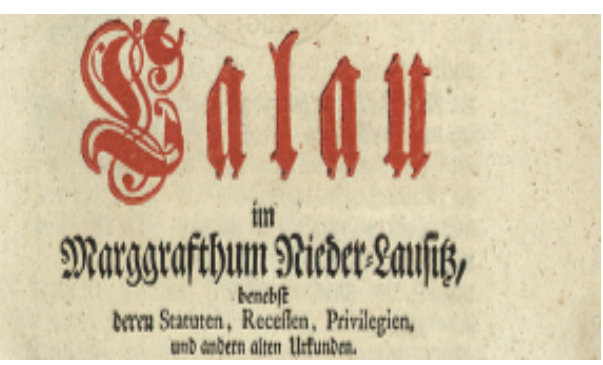

(b) Imagem original tipografada

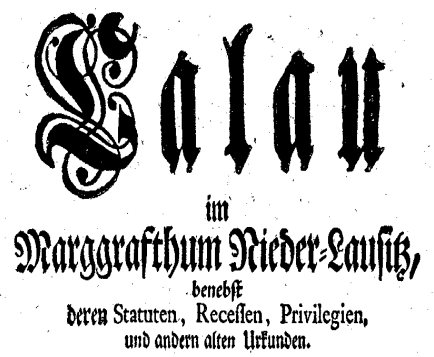

(d) Método do OTSU, 1979

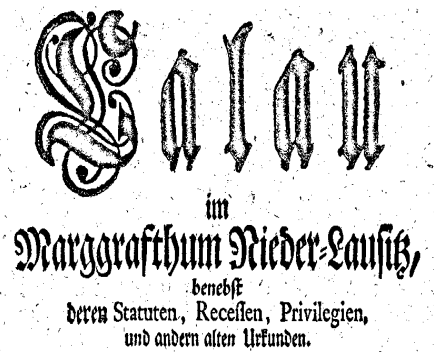

(f) Método do Sauvola e PietikäInen, 2000

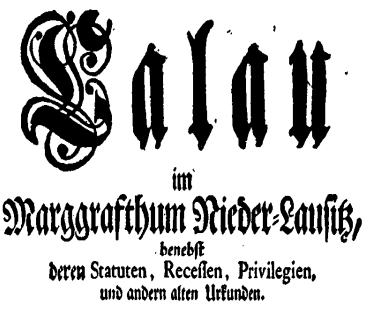

(h) Método do Howe, 2013

Figura 1.7: Resultados da binarização utilizando métodos consolidados no estado da arte para uma imagem manuscrita e para uma imagem tipografada das competições do DIBCO, note-se os resultados variáveis que são obtidos pelos métodos.

\subsection{Proposta do trabalho}

Neste trabalho fizemos um estudo comparativo de métodos de segmentação de documentos antigos e propusemos um método novo baseado em aprendizado de máquina que tem desempenho ligeiramente superior aos métodos do estado da arte.

Além do estudo comparativo: 
1. Implementamos métodos existentes de binarização de documentos do estado da arte.

2. Propomos um método de binarização baseado em aprendizado de máquina que resgata as vantagens dos métodos heurísticos.

3. Elaboramos um fluxo de informações (workflow) onde o método proposto de binarização é integrado operando em um sistema OCR.

4. Criamos um Ground Truth de textos dos documentos antigos tipografados, o que torna possível fazer comparações com o resultados obtidos.

5. Finalmente, avaliamos todo o processo de ponta a ponta no workflow proposto, isto é, os resultados da binarização foram passados por um OCR e o texto extraído foi comparado com os textos GT.

\subsection{Organização do Trabalho}

O restante desta dissertação é organizado como segue:

No Capítulo 2, apresentamos uma revisão do estado da arte que categorizados segundo métodos heurísticos que são os métodos globais, locais e híbridos e segundo métodos baseados em classificação utilizando aprendizagem de maquina que são, métodos utilizando aprendizagem não supervisionada, métodos utilizando aprendizagem supervisionada $\mathrm{e}$ métodos utilizando aprendizagem profunda.

No Capítulo 3, apresentamos a metodologia dessenvolvida, isto é, o workflow proposto que contém o treinamento e predição dos modelos, a obtenção do documento binarizado pelo método proposto, até a avaliação dos resultados de ponta a ponta (end-to-end) num sistema OCR, e a descrição da estrategia de combinação de características.

No Capítulo 4, descrevemos o conjunto de dados utilizado no trabalho, as métricas de avaliação padrão utilizados nas competições DIBCO para a avaliação das imagens binarizadas e a métrica para a avaliação do resultado do OCR. Também métricas para avaliar a performance do modelo.

No Capítulo 5, apresentam-se os experimentos e resultados do método proposto, etapa por etapa, desde o planejamento dos experimentos, a performance do modelo segundo as métricas do DIBCO e segundo o OCR, a comparação com os métodos do estado da arte, e a discussão dos resultados.

No Capítulo 6, concluimos a dissertação resumindo as descobertas relevantes, limitações e discutindo possíveis trabalhos futuros a serem realizados na busca da binarização eficiente de imagens de documentos. 



\section{Capítulo 2}

\section{Estado da Arte}

Há diversos métodos de binarização descritos na literatura e eles são categorizados de várias formas, por exemplo, surveys ou revisões dos métodos de binarização feitos por Chaki et al., 2014, Ajitha e Kannan, 2014, Kaur e Mahajan, 2014, More e Dighe, 2016, e CHAuHAN et al., 2016 propuseram três categorias básicas:

- Métodos globais

- Métodos locais e

- Métodos híbridos.

Além deles, trabalhos recentes (OuAfeK e Kholladi, 2018; Westphal et al., 2018; Vo et al., 2018) propõem métodos baseados em classificação utilizando aprendizagem. Aqui, vamos descrever ambas abordagens:

- Métodos baseados em heurística (global, local e híbrido).

- Métodos baseados em aprendizagem de máquina (supervisionada, não supervisionada e aprendizagem profunda).

\subsection{Métodos baseados em heurística}

Os métodos de binarização heurística podem ser ainda categorizados em três subcategorias: globais, locais e híbridas.

\subsubsection{Métodos Globais}

Conforme implícito no nome, métodos globais consideram um único valor de limiar para uma imagem ser binarizada. Nesses métodos, o limiar é geralmente determinado pela análise do histograma dos níveis de cinza da imagem e buscam um mínimo, ou máximo de uma função sobre alguma métrica do histograma. Por exemplo, pode-se referir aos métodos baseados em análise discriminante como apresentado por OTSU, 1979, ou separação de histograma como o apresentado por KiTtLER et al., 1985. Isto é, algoritmos que avaliam a distribuição dos níveis de cinza da imagem toda e calculam um limiar baseado 
em estatísticas globais da imagem como variância intra-classe ou inter-classe (Rafael C Gonzalez e Richard E Woods, 2002) das regiões do texto e do fundo. A clara vantagem dos métodos globais é ser extremamente rápida. Por outro lado, uma grande desvantagem com um limiar global é que ele dá pouca, ou nenhuma, importância sobre as relações espaciais dos pixeis, o que é ainda pior na presença de ruído. Esse é normalmente o caso das imagens de documentos históricos, por apresentarem uma complexidade maior devido aos diversos defeitos, que são explicados na seção 1.1. Consequentemente, essas imagens não são bem segmentadas por algoritmos desse tipo e apresentam resultados ruins e irregulares.

\subsubsection{Métodos Locais}

No caso dos métodos locais, ao invés de se calcular um único limiar global, valores de limiares diferentes são calculados para cada pixel da imagem, levando-se em conta as características das suas vizinhanças locais (definidas por uma janela centrada em torno do pixel). Os métodos de limiarização local sanam, até certo ponto, as deficiências dos métodos globais ao lidar com as variações de brilho nos documentos. Os métodos de limiarização locais, e,g. o SAuvola e PietikäInen, 2000 e o Niblack, 1985, calculam o limiar a partir das estatísticas locais da imagem em torno do ponto (pixel) que está sendo tratado. Exemplos de estatísticas locais são a média e a variância das intensidades dos pixeis dentro de uma janela ao redor do ponto de interesse.

O algoritmo apresentado por NiBlack, 1985 é um dos primeiros métodos de binarização a seguir essa abordagem. Para uma imagem em níveis de cinza $f$, é estimado o limiar $T_{N i b k}(f(x))$ para cada um dos pixeis da imagem a partir da média $\mu(f(x))$ e do desvio padrão $\sigma(f(x))$ em uma vizinhança do tamanho $W_{N} \times W_{N}$, onde $N$ é o tamanho da janela, utilizando a expressão:

$$
T_{N i b k}(f(x))=\mu(f(x))+k \times \sigma(f(x))
$$

Onde $k$ é uma constante de valor negativo menor que um, o efeito dela é ou de abaixar ou de elevar coletivamente o valor do limiar $T_{N i b k}(f(x))$, decidindo a importância do termo do desvio padrão $\sigma(f(x))$ no limiar $T_{N i b k}(f(x))$.

O algoritmo apresentado por SAuvola e PietikÄInen, 2000 e uma extensão do método de Niblack, 1985 e tenta melhorar a binarização adicionando uma constante $L$ que representa o intervalo dinâmico do desvio padrão. Utilizada a expressão 2.2 .

$$
T_{\text {Sau }}(f(x))=\mu(f(x))+\left[1+k \times\left(\frac{\sigma(f(x))}{L}-1\right)\right]
$$

As desvantagens desses métodos são:

- Ajuste manual de parâmetros.

- Alta sensibilidade à escolha de parâmetros.

- Problema para lidar com imagens que tem iluminação desigual, fundo ruidoso, cores similares de texto e fundo. 


\subsubsection{Métodos Híbridos}

Os métodos híbridos combinam informações globais e locais para rotular um pixel como texto ou como fundo. Tantos os métodos globais, quanto locais, foram estabelecidos há muito tempo para resolver problemas de binarização automaticamente. No entanto, ao abordar as deficiências de cada método, os métodos híbridos foram propostos para atender os casos mais desafiadores. Na literatura, foi apresentada a seguinte recategorização por SEZgin e SANKuR, 2004, introduzindo-se seis classes de métodos de binarização: métodos baseados na forma do histograma, métodos baseados no agrupamento, métodos baseadas na entropia, métodos baseados em atributos do objeto, métodos espaciais e métodos locais.

1. Métodos baseados na forma do histograma analisa propriedades dos histogramas suavizados (ou seja, picos, vales, curvaturas).

2. Métodos baseados no agrupamento agrupam amostras de níveis de cinza em duas partes, objeto e fundo, ou alternativamente. Modela as amostras como uma mistura de dois gaussianos

3. Métodos baseados em entropia utiliza a entropia das regiões do fundo e do objeto, a entropia cruzada entres imagens originais e binarizadas, etc.

4. Métodos baseados em atributos do objeto medem a semelhança entre o nível de cinza e as imagens binarizadas, por exemplo, similaridade de forma fuzzy, coincidência de bordas. etc.

5. Métodos espaciais usam distribuição de probabilidades de ordem superior e/ou correlação entre pixeis.

6. Métodos locais adaptam o valor de limiar em cada pixel de acordo com as características locais da imagem.

A Tabela 2.1, obtida do artigo do Ismail et al., 2018, apresenta as categorias de métodos de binarização na seguinte perspectiva: a categoria dos métodos híbridos é posicionada no bloco mais à esquerda, correspondente à definição de que é uma classe de métodos que combina métodos globais e locais. As categorias apresentadas pelo artigo do SEZGIN e SANKUR, 2004 estão à direita, onde as primeiras quatro categorias podem ser consideradas como métodos globais e as duas últimas como métodos locais. Quaisquer combinações das categorias apresentadas por SEZGIN e SANKUR, 2004 podem também ser consideradas como métodos híbridos.

\begin{tabular}{|l|l|l|}
\hline \multirow{4}{*}{ Híbridos } & \multirow{3}{*}{ Global } & baseado na forma do histograma \\
& & baseado no agrupamento \\
& & baseado na entropia \\
\cline { 3 - 3 } & \multirow{2}{*}{ Local } & baseado nos atributos do objeto \\
\cline { 3 - 3 } & & local \\
\hline
\end{tabular}

Tabela 2.1: Categorias das técnicas de binarização, segundo ISMAIL et al., 2018. 
Uma crítica importante de todos esses métodos é que, ou eles têm muitos parâmetros para serem ajustados, ou eles são codificados em etapas de binarização para atender aos requisitos de um determinado conjunto de documentos.

Existe ainda um outro tipo de abordagem que enquadra-se como um problema de otimização, geralmente modelado com campos aleatórios de Markovs (CAO e GovindARAJU, 2009) que considera a imagem binária de destino como um campo aleatório de Markov binário que minimiza uma função de custo. Por exemplo, o método apresentado por Howe, 2013 propõe uma estimação automática de parâmetros usando uma função de custo com regras heurísticas. Esse método foi apresentado na competição "Handwritten" DIBCO (H-DIBCO) de 2012 e faz parte de diversos métodos da literatura. O artigo de Mishra et al., 2011 define uma função de energia e a qualidade da binarização é determinada por um valor de energia cuja função tem que ser minimizada com a finalidade que encontrar uma binarização ótima utilizando um esquema de corte em grafos iterativo, atinge precisão de $88 \%$ e sensibilidade de $91 \%$.

Há ainda outros algoritmos, como o método proposto em Basilios GATos et al., 2006 composto de várias etapas distintas:

- Um pré-processamento usando um filtro passa-baixa de Wiener (JAIn, 1989).

- Uma estimativa aproximada de regiões do texto usando o método proposto em SAUvola e Pietikäinen, 2000.

- O cálculo da região de fundo interpolando intensidades vizinhas.

- Um limiar combinando a superfície de fundo calculada com a imagem original e, finalmente

- Uma etapa de pós-processamento para melhorar a qualidade das regiões de texto e preservar a conectividade do traço.

O método usa a distância de Levenshtein (Levenshtein, 1966) para avaliar a qualidade do resultado comparando o GT com a imagem resultante binarizada do método, os resultados mostram que o método consegue alcançar um 37\% de melhoria comparado com outros métodos do estado da arte, porém o processo envolve muitos passos.

Outro método bem sucedido é o proposto em S. Lu et al., 2010, que consegue uma imagem de contraste adaptativo baseado no máximo e no mínimo local para a extração do fundo apresentado por BERNSEN, 1986. O mapa de contraste é combinado com o detetor de bordas de Canny (CAnny, 1986) para identificar a borda das letras. Por último o documento é binarizado usando uma limiarização local baseado nos valores das bordas.

Os métodos acima mencionados se encaixam na abordagem heurística, eles foram bem sucedidos nos seus respetivos contexto.

\subsection{Métodos baseados em aprendizagem de má- quina}

Técnicas de aprendizado de máquina são aplicadas nos trabalhos recentes, os categorizamos em três abordagens, são elas: utilizando aprendizagem supervisionada, utilizando 
aprendizagem não supervisionada, e utilizando aprendizagem profunda.

\subsubsection{Aprendizagem não supervisionada}

Em relação aos métodos baseados em aprendizagem não supervisionada, o trabalho apresentado em Su et al., 2012 agrupa os pixeis em três classes: o texto, o fundo e o incerto, sendo que esta última ainda é classificada depois em texto ou fundo de acordo com uma medida de distância entre a duas classes. Em termos de desempenho, o F-Measure(FM) do método é de $81.08 \%$. O método apresentado em MogHADDAM et al., 2013 propõe um framework não supervisionado de "ensemble" de classificadores, ou seja, combinam-se vários métodos de binarização que dependem de modelos do problema, ou de regras heurísticas. Em termos de desempenho, o FM é de $92.76 \%$. Na competição do H-DIBCO 2014 descrito pelo artigo do NTIRogiannis, Basilis Gatos et al., 2014 foram propostos métodos não supervisionados baseados no agrupamento do Fuzzy C-Means e Location Cluster Model (Murray e Grubesic, 2002), cujo maior FM é 93.5\%.

\subsubsection{Aprendizagem supervisionada}

A abordagem baseada em aprendizado supervisionado consiste em observar cada pixel da imagem, extrair características locais e utilizando um algoritmo de aprendizado, produzir uma representação de um mapeamento que decida sobre as duas possíveis categorias (objeto, ou fundo). Os métodos de aprendizagem supervisionada revisados nesta seção são aplicados de diferentes maneiras, por exemplo, no artigo CHOU et al., 2010, tentou-se encontrar um modelo apropriado de binarização para sub-regiões de um documento. A imagem é inicialmente particionada em regiões de $n \times n$ pixeis e usa-se o método de Support Vector Machines (SVM) para treinar e posteriormente classificar um ponto em texto, ou fundo, coleta o seu próprio conjunto de dados com documentos impressos de jornais e revistas, obteve um FM de 96.88\%. O método apresentado em Wu et al., 2016 aprende uma função de decisão que utiliza um treinamento em duas etapas: primeiro o Gaussian Naive Bayes (Murphy et al., 2006) e depois o método ExtraTrees (Geurts et al., 2006). O FM obtido para os datasets DIBCO de 2012, 2013 e 2014 são, respectivamente, $92.01 \%, 91.40 \%$ e $92,69 \%$.

Quando usam-se Redes Neurais, o tipo mais comum é o Perceptron Multi-Camadas (MLP) (Chi e Wong, 2001; Hidalgo et al., 2005; Chamchong e Fung, 2010; VArghahan et al., 2011; Kefali et al., 2014; Alginahi, 2004). A ideia é também classificar cada pixel em texto e fundo a partir características estatísticas e de textura obtidas a partir de uma janela ao redor do pixel a ser classificado. No trabalho de AlginAHI, 2004 são calculadas 8 características estatísticas; pela falta de data de treinamento o usuario tem que preparar os dados selecionando um pixel e rotulando se é texto ou fundo. Em OuAfeK e KHOlladi, 2018, apresenta-se um método de binarização iniciado por uma fase de processamento para melhorar o contraste da imagem e eliminar ruídos; depois, para a estimativa de texto e fundo, é aplicada a interpolation impainting (BERTALMIo et al., 2000), que é usada como característica para treinar e testar a rede neural. As principais vantagens dos métodos baseados em aprendizado supervisionado é a ausência de heurísticas na escolha 
de parâmetros e, em geral, a não necessidade de pré ou pós-processamento. Os dados de treinamento devem, no entanto, ser selecionados cuidadosamente.

\subsubsection{Aprendizagem Profunda}

Recentemente, os arcabouços de Aprendizagem Profunda (deep learning) (GoodfELLow et al., 2016), principalmente as Redes Neurais Convolucionais (CNN) (GoodfELLow et al., 2016) têm sido aplicadas ao problema de binarização de imagens de documentos por causa da quantidade de dados de treinamento presente nos problemas de imagens. Diferentes tipos de estruturas de redes profundas foram utilizadas para o problema de binarização de documentos. O trabalho de PAstor-Pellicer et al., 2015 propõe uma arquitetura CNN para a tarefa de binarização, conseguindo um FM de 87.74. Embora o resultado não seja competitivo com o estado da arte, a abordagem também é robusta para aplicar em documentos que não descrevem necessariamente informações de texto, como feito pelo trabalho de Calvo-Zaragoza, Vigliensoni et al., 2017 que aplica a rede em documentos musicais. O trabalho de AfzAl et al., 2015 formula a binarização de imagens de documentos como uma Rede Neural Recorrente (RNN) do tipo "Long Short-Term Memory" (LSTM) (GoodfELlow et al., 2016), o LSTM 2D, que é empregado para processar uma sequência $2 \mathrm{D}$ de pixeis para a classificação de cada pixel em fundo ou texto. Os autores reportam um FM de 94.53\%. Também, em Calvo-Zaragoza e GALlego, 2017 propõe-se uma arquitetura do tipo Selectional Auto-Encoder dedicada a apreender uma transformação end-to-end para binarizar uma imagem. Esse modelo consegue um FM de 89.99. Em Vo et al., 2018, propõe-se uma arquitetura baseado numa Rede Profunda Supervisionada (DSN) Hierárquica. Essa rede tem uma arquitetura hierárquica que incorpora camadas laterais para melhorar a convergência no treinamento. Em termos de resultado, o FM conseguido foi de $93,3 \%$, 94, 4\%, 96, 66\%, 90.1\% para os dataset DIBCO 2011, DIBCO 2013, H-DIBCO 2014 e o H-DIBCO 2016, respectivamente. Ainda que os resultados sejam bons, há problemas com ruídos de fundo dominantes e de traços finos ou fracos. O trabalho WestPHAL et al., 2018 apresenta um algoritmo de binarização baseado em RNN, utilizando células Grid LSTM para manipular entradas multidimensionais e incorporar informações de contexto em cada passo da binarização. No dataset H-DIBCO 2016, o resultado do FM foi de $88.79 \pm 4.80$ que é melhor que o método obtido pelo ganhador da competição H-DIBCO 2016 (Pratikakis, ZAGORIs et al., 2016), porém pior que o método do apresentado em Vo et al., 2018.

Embora, os métodos de aprendizado de máquina apresentem vantagens como: pipeline mais simples, não precisam de etapas de pré-processamento ou pós-processamento, e uma vez serem treinados a binarização é rápida, também apresentam desvantagens como: requerem conjuntos de testes padronizados e de dados ground truth para a aprendizagem. 


\section{Capítulo 3}

\section{Metodología Proposta}

Neste capítulo apresentamos uma proposta de binarização de imagens de documentos tipografados e manuscritos baseada em aprendizado de máquina supervisionado. Basicamente, usamos uma estrategia de combinação de características extraídas da imagem e dos resultados de técnicas bem estabelecidas na literatura (métodos heurísticos e descritores de textura). Além das métricas usuais de avaliação na competição DIBCO, usamos o Reconhecimento Óptico de Caracteres (OCR) para extrair o texto da imagem binarizada e avaliar quanto o método de classificação influencia a qualidade do reconhecimento do texto extraido. Isto é aprensentado na forma de encademento de processos ou workflow.

\subsection{Workflow da metodología proposta}

A Figura 3.1 apresenta o encadeamento de processos(workflow) da metodología proposta.

Como o nosso método de binarização proposta e baseado em aprendizajem de máquina, temos as duas etapas usuais para obter o modelo (DUDA et al., 2012): o treinamento e a predição. Na etapa do treinamento, faz-se a escolha do modelo e procede-se a validação, onde eventualmente se ajusta o modelo para o problema em questão. Na predição, ou teste, avalia-se a binarização resultante do modelo.

A entrada para o modelo, tanto no treinamento/validação, quanto na predição, é formada de imagens dos documentos em escala de cinzas. A partir delas extraem-se as características mediante uma estratégia descrita na Fig. 3.2. O classificador utilizado no workflow é um SVM Linear otimizado com o Gradiente Descendente Estocástico (determinado na seção 3.3.1). Na etapa de predição, faz-se a aplicação do modelo apreendido, que resulta na binarização da imagem e avalia-se o resultado usando as métricas da competição DIBCO e usando o reconhecimento de caracteres opticos (OCR) dos documentos tipografados com o Tesseract. No caso das imagens manuscritas, é feita apenas a avaliação quantitativa, quer dizer usando as métricas do DIBCO, pois não foi possível criar o padrão ouro do texto e a competição não fornece o texto transcrito das imagens. 
Detalhamos em seguida a extração das características ou features para treinar o modelo.

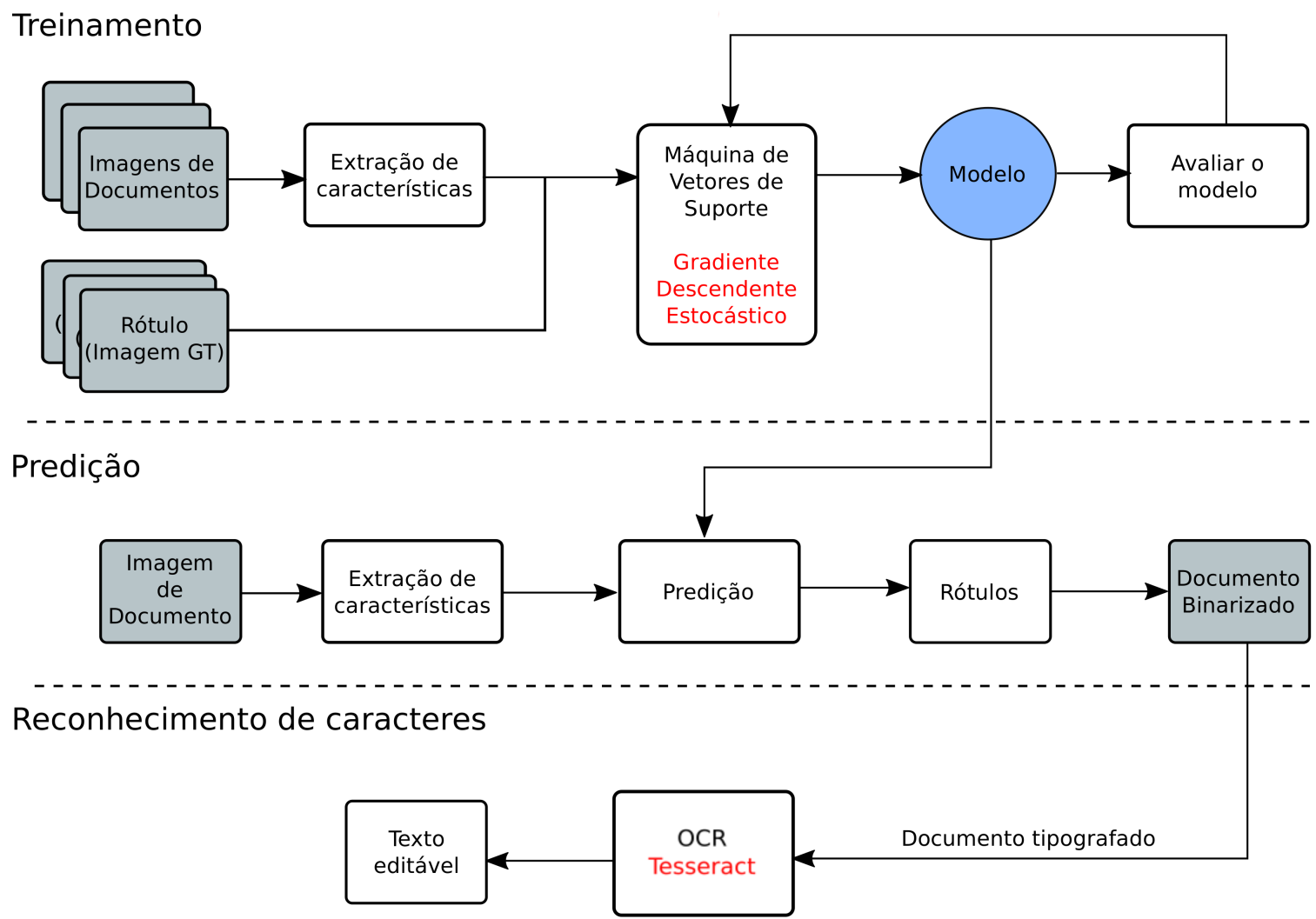

Figura 3.1: Fluxo de informações (workflow) da metodología proposta.

\subsection{Estratégia de combinação de características}

A Fig. 3.2 descreve o processo da extração das características a partir da imagem de documento em níveis de cinza. Além da imagem original, foram utilizadas o resultado de técnicas heurísticas bem estabelecidas no estado da arte e descritores de textura. Os métodos heurísticos foram selecionados por serem ganhadores ou serem parte de um método mais complexo com bom desempenho nas competições do DIBCO.

- Métodos heurísticos: Eles são:

- Otsu, 1979.

- Niblack, 1985.

- Sauvola e Pietikäinen, 2000.

- Su et al., 2013.

- Howe, 2011.

- Descritores de textura: Utilizamos o "Relative Darkness Index" (RDI) proposto pelo Wu et al., 2016, que é uma variação do "Local Ternary Pattern" (LTP) (TAN e 
TRIGGS, 2010). Os descritores descreven características intrinsecas de textura para o texto num documento.

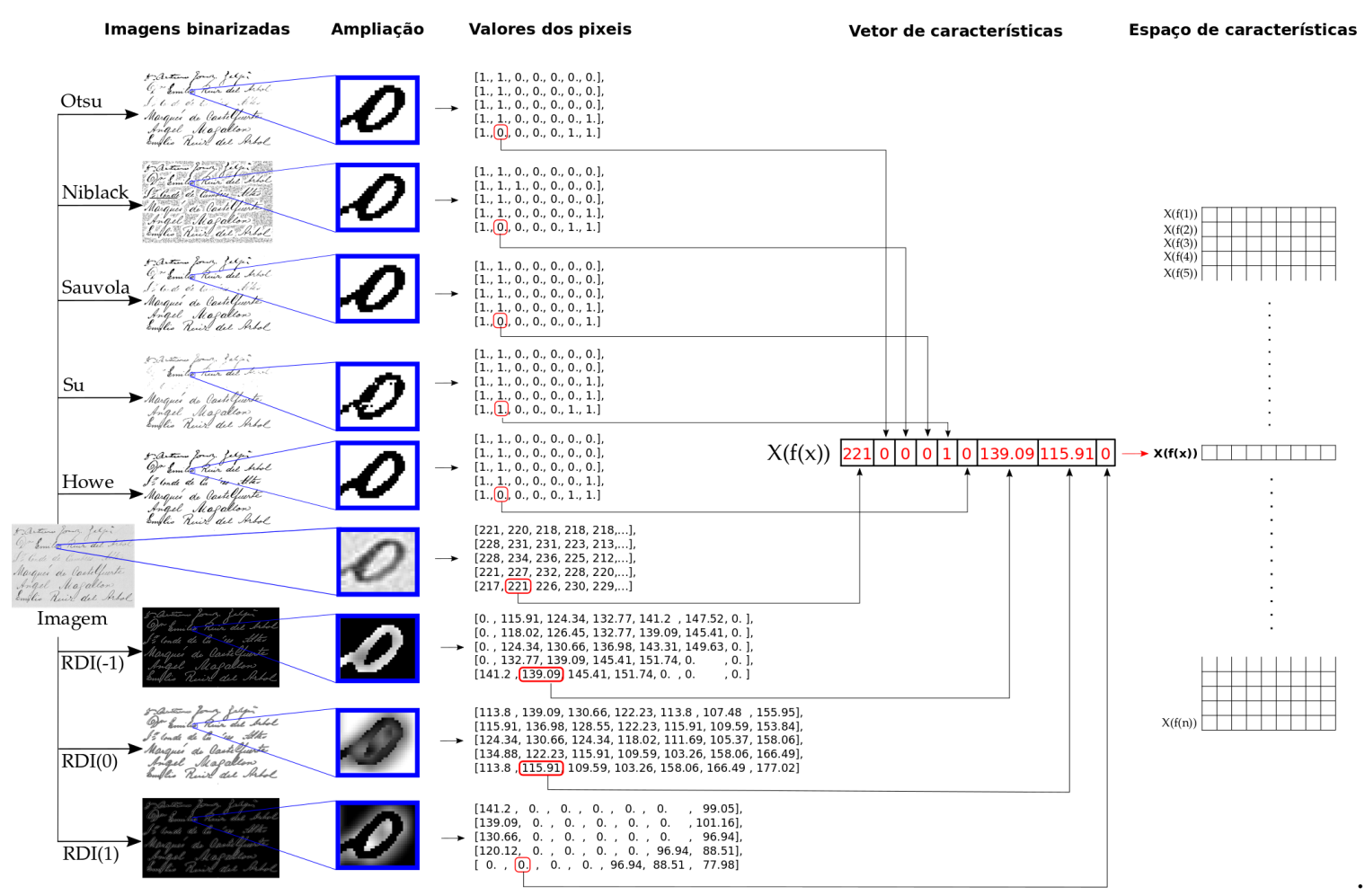

Figura 3.2: Estratégia de combinação das características.

1. Otsu - método para estimativa de um limiar global proposto por Otsu (Oтsu, 1979). O resultado deste método é um valor limiar denotado por $T_{O t s u}$. A segmentação é feita comparando-se o valor de $f(x)$ em cada ponto do domínio da imagem com $T_{O t s u}$ da seguinte maneira:

$$
X^{O t s u}(f(x))= \begin{cases}1, & \text { se } f(x)>T_{O t s u}(f(x)) \\ 0, & \text { caso contrário }\end{cases}
$$

Os valores são 0 e 1 correspondem, respectivamente, ao texto e ao fundo.

2. Niblack - método para estimativa de um limiar local proposto por Niblack (NIBLACK, 1985). A segmentação é feita comparando-se o valor de $f(x)$ em cada ponto do domínio da imagem com $T_{N i b k}$ da seguinte maneira:

$$
X^{N i b k}(f(x))= \begin{cases}1, & \text { se } f(x)>T_{N i b k}(f(x)) \\ 0, & \text { caso contrário }\end{cases}
$$

Onde $T_{N i b k}(f(x))$ é obtida pela equação 2.1 com $W$ de tamanho $35 \times 35$. O valor $k$ é definido heuristicamente como sendo de 0.8 .

3. Sauvola - método para estimativa de um limiar local proposto por Sauvola (SAUvola e PietikÄInen, 2000). A segmentação é feita comparando-se o valor de $f$ em cada 
ponto do domínio da imagem com $T_{\text {Sau }}$ da seguinte maneira:

$$
X^{\operatorname{Sau}}(f(x))= \begin{cases}1, & \text { se } f(x)>T_{\text {Sau }}(f(x)) \\ 0, & \text { caso contrário }\end{cases}
$$

Onde $T_{\text {Sau }}(f(x))$ é obtida pela equação 2.2 com $W$ de tamanho $35 \times 35, L$ com o valor 128 e $k$ com 0.2 .

4. Su - método baseado no gradiente morfológico (diferença entre a dilatação e a erosão morfológica) para gerar um mapa de contrastes proposto por Su (Su et al., 2013). Este método teve muito sucesso na competição DIBCO 2009 (primeiro lugar) e sua força está no cálculo do mapa definido por:

$$
X^{S u}(f(x))=\frac{\delta_{B}(f(x))-\varepsilon_{B}(f(x))}{\delta_{B}(f(x))+\varepsilon_{B}(f(x))+\epsilon_{s u}}
$$

Onde $\delta_{B}(f(x))$ e $\varepsilon_{B}(f(x))$ são, respectivamente a dilatação e a erosão (Rafael C. Gonzalez e Richard E. Woods, 2006) de $f$ pelo elemento estruturante $B$ e $\epsilon_{s u}$ é uma constante de valor 0.12 .

5. Howe - método proposto por Howe (Howe, 2011), que também teve muito sucesso (primeiro lugar) no H-DIBCO 2012. Nele, define-se uma segmentação objetivo como uma rotulagem dos pixeis que minimiza uma função de energia global. Em seguida, formula-se o termo fidelidade-de-dados (data-fidelity) dessa energia a partir do Laplaciano da imagem para distinguir o texto do fundo. Finalmente, incorporam-se as descontinuidades das bordas usando o algoritmo de CANNy, 1986. No trabalho de Howe (Howe, 2013), examina-se o comportamento do método (Howe, 2011) sob uma variedade de configurações diferentes usando o corte mínimo em grafo. No trabalho foi usado o primeiro método do Howe (Howe, 2011). Denotaremos o resultado por $X^{H o}(f(x))$.

Então os resultados dos métodos acima mencionados são imagens binarias, onde o 1 é um pixel pertencente ao fundo e o 0 é um pixel pertencente ao texto.

A continuação seguem os descritores de textura.

6. Relative Darkness Index (RDI) - As três próximas segmentações utilizam padrões ternários locais (Local Ternary Patterns - LTP).

O LTP consiste na comparação da intensidade do pixel que está sendo avaliado, digamos $x$, com cada pixel na sua vizinhança, $\mathcal{N}_{r}(x)$, definida por um raio de tamanho $r$. O valor da imagem em cada ponto $q, q \in \mathcal{N}_{r}(x)$, é comparado com o valor da imagem em $x$ e, baseado em uma tolerância $t$, gera o valor da imagem resultante. Formalmente, se $x$ é o ponto sendo analisado, $f(x)$ é comparado com o valor de $f$ no ponto $q$, quer dizer, $f(q)$ :

$$
\operatorname{LTP}(q)= \begin{cases}+1, & \text { se } f(q) \geq f(x)+t \\ -1, & \text { se } f(q) \leq f(x)-t \\ 0, & \text { se }|f(q)-f(x)|<t\end{cases}
$$


Onde $t \neq 0$ é um valor de tolerância, predefinido como sendo igual a 10 .

O conjunto de valores de LTP para cada ponto $x$ da imagem tem cardinalidade $\left|\mathcal{N}_{r}(x)\right|$ (tamanho da vizinhança) e, faz-se a contagem da frequência de cada valor nesse conjunto. Esse histograma revela propriedades intrínsecas da imagem, denominado como Relative Darkness Index, para cada valor do $\operatorname{LTP}(\{-1,0,1\})$, e resulta numas imagens que vamos chamar de $X^{R D I(1)}, X^{R D I(0)}$ e $X^{R D I(-1)}$.

$$
\begin{aligned}
X^{R D I(1)}(f(x)) & =\frac{1}{\left|\mathcal{N}_{r}(x)\right|} \sum_{q \in \mathcal{N}_{r}(x)}\left\lfloor\frac{\operatorname{LTP}(q)+1}{2}\right\rfloor \\
X^{R D I(0)}(f(x)) & =\frac{1}{\left|\mathcal{N}_{r}(x)\right|} \sum_{q \in \mathcal{N}_{r}(x)}|| L T P(q)|-1| \\
X^{R D I(-1)}(f(x)) & =\frac{1}{\left|\mathcal{N}_{r}(x)\right|} \sum_{q \in \mathcal{N}_{r}(x)}\left\lfloor\frac{|L T P(q)-1|}{2}\right\rfloor
\end{aligned}
$$

A Fig. 3.2 apresenta um exemplo de cada uma destas imagens. O RDI(-1) é a imagem obtida quando se faz a contagem simples do valor -1 , pode-se observar que os pixeis pertencentes ao texto tem alta resposta para esse valor. $R D I(0)$ é a imagem obtida quando se faz a contagem simples do valor 0 , onde regiões homogêneas do fundo ficam expostas, e o RDI(1) é a imagem quando se faz a contagem com o valor 1 , os pixeis próximos às bordas conseguem se destacar.

A segunda coluna da Fig. 3.2 (coluna dos resultados das técnicas) mostra o resultado para os cinco métodos heurísticos (acima da imagem original) que são imagens binarizadas e para as três variações do RDI que são imagens em níveis em cinza (abaixo da imagem original). Para cada imagem, ampliou-se o mesmo pedaço (coluna Ampliação) e, na coluna à direita, observam-se os valores de intensidade da referida ampliação. A partir desses valores forma-se um vetor de características $\mathbf{X}(f(x))$ combinando todos os resultados das técnicas acima com a imagem original para cada ponto da imagem, isto é:

$$
\begin{aligned}
\mathrm{X}(f(x))= & {[f(x),} \\
& X^{\text {Otsu }}(f(x)), X^{N i b k}(f(x)), X^{S a u}(f(x)), X^{S u}(f(x)), X^{H o}(f(x)), \\
& \left.X^{R D I(-1)}(f(x)), X^{R D I(0)}(f(x)), X^{R D I(1)}(f(x))\right]
\end{aligned}
$$

Na coluna Vetor de características da Figura 3.2, pode-se observar a combinação de características. Finalmente, o espaço de características é formado pelo conjunto de amostras do tipo $\mathbf{X}(f(x))$ de nove dimensões.

\subsection{Conjunto grande de amostras}

Fazendo uma média aritmética simples dos tamanhos das imagens do nosso conjunto de dados, imagens manuscritas quanto tipografadas (Tabela 4.1), obtemos que a altura e 
largura média das imagens é de $719 \times 1551$ pixeis, então a quantidade de pixeis do tamanho médio é de 1115169, isto é, mais de um milhão de pixeis.

Agora, nós estamos propondo una binarização utilizando classificação, especificamente classificação baseado no pixel (pixel-based classification), onde a partir de um vetor característica o classificador binário prediz se um pixel é texto ou é fundo.

Considerando o tamanho médio de uma imagem do nosso conjunto de dados, $719 \times 1551$, o tamanho do espaço de características é de mais de um milhão de pontos para uma imagem só. Agora, caso treinarmos o modelo usando a terceira parte das imagens do conjunto de dados, isto é 35 imagens, tendo em conta que cada imagem tem mais de 1 milhão de pixeis, o tamanho do conjunto de treinamento seria de $35 \times 1115169$ que resulta aproximadamente 40 milhões de amostras.

Treinar com tão quantidade de amostras se torna inviável para qualquer classificador de aprendizado de máquina, outra opção é tomar uma amostra aleatória, porém quais amostras são representativas? e a distribuição original dos dados ainda seria preservada?. A continuação descrevemos a estratégia usada.

\subsubsection{Gradiente Descendente Estocástico (SGD)}

O Botтou, 2010, propõe utilizar o Gradiente Descendente Estocástico(SGD) para treinar com conjuntos de dados grandes, no nosso trabalho é utilizado para acelerar o treinamento, ele usa amostras aleatórias dos dados(batch) ao invés de analisar todas as amostras ou instâncias existentes como faz o Gradiente Descendente. Na prática o mais comum é utilizar os chamados mini-batches(amostra aleatória dos dados) com um tamanho fixo $B$. Após executar diversas iterações(sendo que cada interação irá adaptar os parâmetros usando as instâncias no mini-batch atual), espera-se obter uma aproximação do método do Gradiente Descendente que utiliza todas as instâncias para treinar. Além disso, o SGD assegura uma convergência mais rápida e a trajetória estocástica permite escapar de um mínimo local.

O classificador utilizado é um classificador linear, especificamente a Máquina de Vetores de Suporte con kernel Linear (SVM Linear), porque métodos de classificação lineares possuem um baixo custo computacional, e geralmente demandam pouco tempo de processamento devido a sua simplicidade de implementação, baixo custo computacional na etapa de treinamento, tende a produzir um classificador com maior capacidade de generalização, pode ser útil em problemas com grande quantidade de amostras devido ao baixo custo computacional, mas principalmente devido a que nossos dados são aproximadamente linearmente separáveis, segundo o teste feito utilizando o LDA, Linear Discriminant Analysis como mostra a Figura 3.3,onde os vetores de características do nosso espaço de características foram projetados em um plano, o eixo " $\mathrm{X}$ " dos gráficos é o mesmo plano para os dois gráficos, cada lado do plano separa as duas classes, o primeiro gráfico é o group False que representa o Fundo, e segundo gráfico é o group True que é o Texto. No primeiro gráfico os pixeis que na verdade são fundo ficam no lado esquerdo do eixo "X", os Verdadeiros Negativos, e no lado direito aparecem aqueles pontos que na verdade são texto mas estão do lado do fundo, os Falsos Negativos, mesmo assim eles são poucos. No segundo 
gráfico temos pixeis projetados como fundo, no lado esquerdo os Falsos Positivos e no lado direito os Verdadeiros Positivos, pode-se notar que a quantidade de Falsos Postivos e Falsos Negativos é pouca em comparação com os Verdadeiros Positivos e Verdadeiros Negativos, pelo que podemos concluir que os dados são separaveis linearmente e um classificador linear é o adequado para o problema em questão.
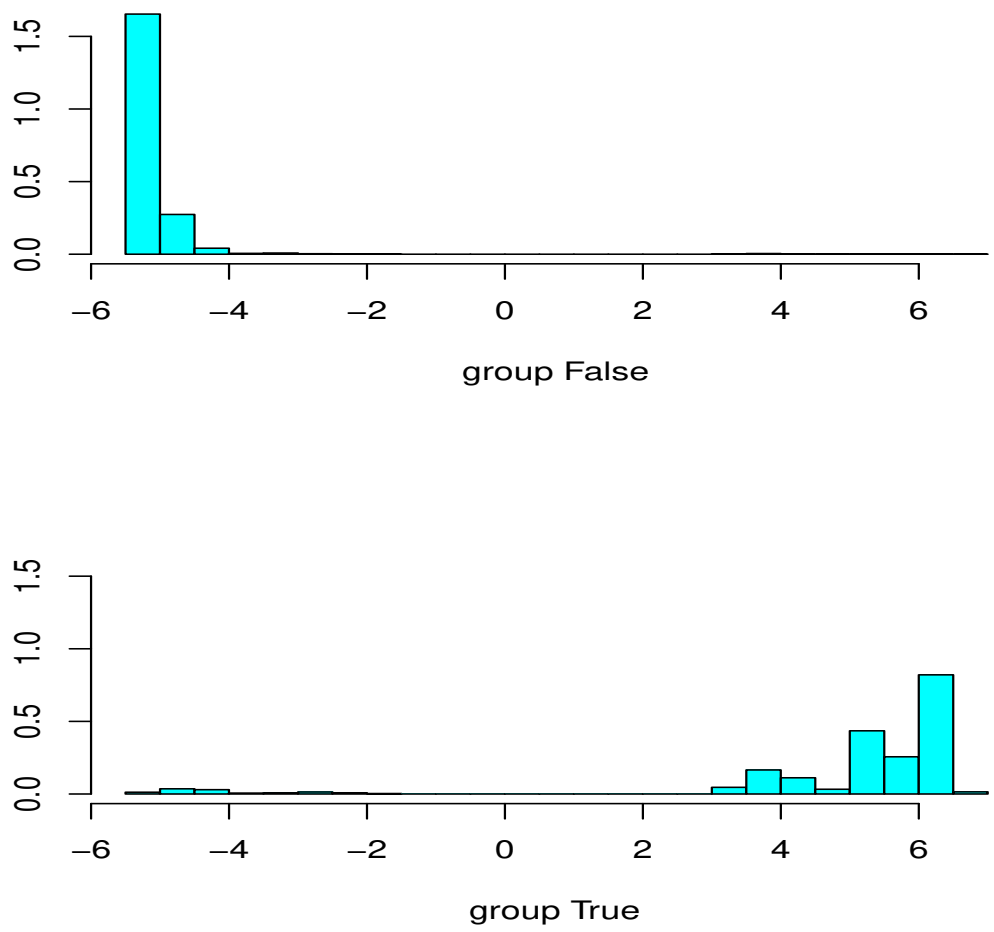

Figura 3.3: Dados do nosso espaço de características projetados em um plano usando o LDA Os dados do nosso espaço de vetores são projetados em um plano usando o LDA, o eixo "X" dos gráficos é o mesmo plano para os dois gráficos, cada lado do plano separa as duas classes, o primeiro gráfico é o group False que representa o Fundo, e segundo gráfico é o group True que é o Texto. No primeiro gráfico os pixeis que na verdade são fundo ficam no lado esquerdo do eixo "X", os Verdadeiros Negativos, e no lado direito aparecem aqueles pontos que na verdade são texto mas estão do lado do fundo, os Falsos Negativos, mesmo assim eles são poucos. No segundo gráfico temos pixeis projetados como fundo, no lado esquerdo os Falsos Positivos e no lado direito os Verdadeiros Positivos, pode-se notar a quantidade de Falsos Postivos e Falsos Neagativos é pouca em comparação com os Verdederos Positivos e Verdadeiros Negativos, pelo que podemos concluir que os dados são separaveis linearmente e um classificador linear é o adequado para o problema em questão. 



\section{Capítulo 4}

\section{Conjunto de dados e Métricas de avali- ação}

Em conjunto com o Document Image Binarization Contest (DIBCO), regulado no contexto da International Conference on Document Analysis and Recognition (ICDAR), e o Handwritten Document Image Binarization Contest (H-DIBCO) regulado no contexto da International Conference on Frontiers in Handwriting Recognition (ICFHR), os organizadores do concurso publicam o respectivo conjunto de dados de avaliação após cada competição e as métricas para medir a qualidade da binarização. Os métodos apresentados e as métricas de avaliação para cada competição são descritos pelo seguintes trabalhos de: Pratikakis, Zagoris et al., 2017; Pratikakis, Zagoris et al., 2016; Ntirogiannis, Basilis Gatos et al., 2014; Pratikakis, Basilis Gatos et al., 2013; Pratikakis, Basilis Gatos et al., 2012; Pratikakis, Basilis Gatos et al., 2011; Pratikakis, Basilis Gatos et al., 2010; Basilis GAtos et al., 2009 que são disponibilizados para cada competição. As métricas de avaliação para as imagens binarizadas quanto para o matching de texto também são descritas, assim como, a medida utilizada para a performance do classificador pois temos classes desbalanceadas.

\subsection{Conjunto de dados da competição de binariza- ção}

Os conjuntos de dados da competição são considerados dados benchmark para a binarização de documentos, eles são disponibilizados e neste trabalho foram usados todos eles, tanto do DIBCO e quanto do H-DIBCO. A principal diferença entre os conjuntos de dados DIBCO e H-DIBCO é que os conjuntos de dados H-DIBCO consistem apenas em documentos manuscritos, enquanto os conjuntos de dados DIBCO consistem em documentos manuscritos e tipografados. Os dataset disponibilizados e utilizados no 
trabalho são: DIBCO 2009¹ , H-DIBCO $2010^{2}$, DIBCO 2011 ${ }^{3}$, H-DIBCO $2012^{4}$, DIBCO $2013^{5}$, H-DIBCO $2014^{6}$, H-DIBCO $2016^{7}$ e o DIBCO $2017^{8}$.

Foram combinados os oito conjuntos de dados para formam um único conjunto de dados. O conjunto de dados completo consiste de 106 imagens de documentos históricos manuscritos, ou tipografados, para as quais há as correspondentes imagens com segmentação verificada (Ground Truth - GT), que podem ser usadas para avaliação de métodos de segmentação. Os documentos históricos são originários das coleções das seguintes bibliotecas: The Goettingen State and University Library (UGOE), The Bavarian State Library, the British Library, The Library of Congress, o projeto IMPACT, o projeto READ, s.d., entre outros, e a seleção das imagens foi feita de modo a ter degradações representativas como descrito por PRATIKAKIs, Basilis Gatos et al., 2011, e apresentados na seção 1.1.

A Fig. 4.1 apresenta um documento de cada tipo, a imagem 4.1a é manuscrita e a imagem $4.1 \mathrm{~b}$ é tipografada, e a suas correspondentes segmentações verificadas.

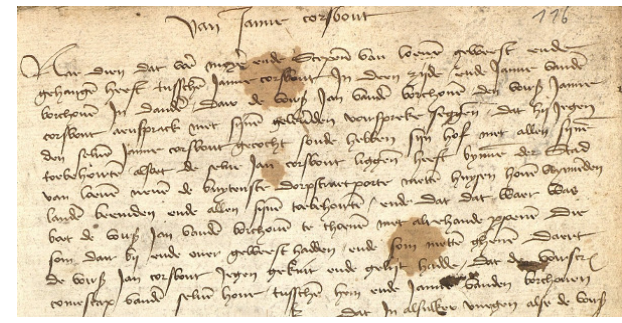

(a) Documento manuscrito

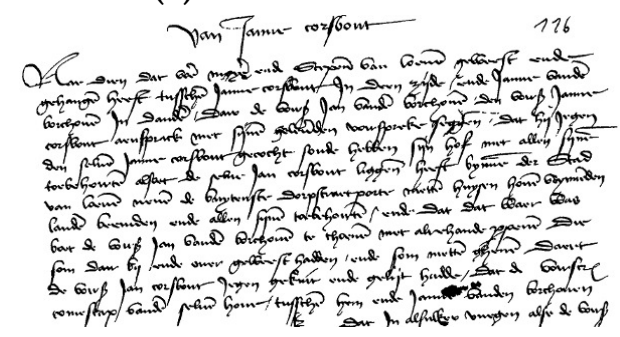

(c) GT da documento manuscrito

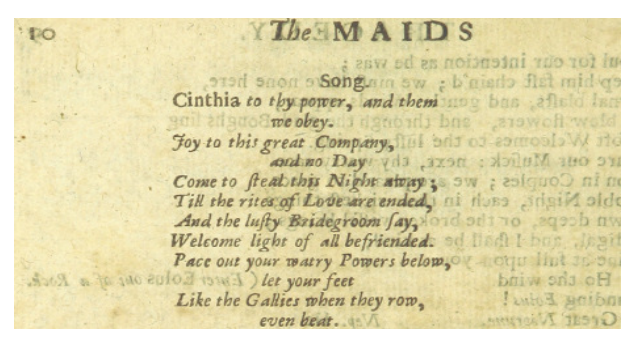

(b) Documento tipografado

10 The M A I D S

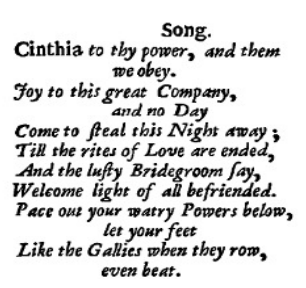

(d) GT do documento tipografado

Figura 4.1: Tipos de documentos históricos e as suas correspondentes segmentações verificadas(GT).

Temos mais exemplos de imagens de documentos antigos manuscritos na Figura 4.2 e mais exemplos de imagens de documentos antigos tipografados na Figura 4.3, ambos tipos de documentos são da serie DIBCO 2013, note-se a diversidade de características e degradações dos documentos.

A Tab. 4.1 apresenta a quantidade de imagens manuscritas e tipografadas dos conjuntos

\footnotetext{
${ }^{1}$ http://users.iit.demokritos.gr/ bgat/DIBCO2009/

${ }^{2}$ http://users.iit.demokritos.gr/ bgat/H-DIBCO2010/

${ }^{3} \mathrm{http}: / /$ utopia.duth.gr/ ipratika/DIBCO2011/

${ }^{4} \mathrm{http}: / /$ utopia.duth.gr/ ipratika/HDIBCO2012/

${ }^{5}$ http://utopia.duth.gr/ ipratika/DIBCO2013/

${ }^{6}$ http://users.iit.demokritos.gr/ kntir/HDIBCO2014/

${ }^{7}$ http://vc.ee.duth.gr/h-dibco2016/

${ }^{8}$ https://vc.ee.duth.gr/dibco2017/
} 

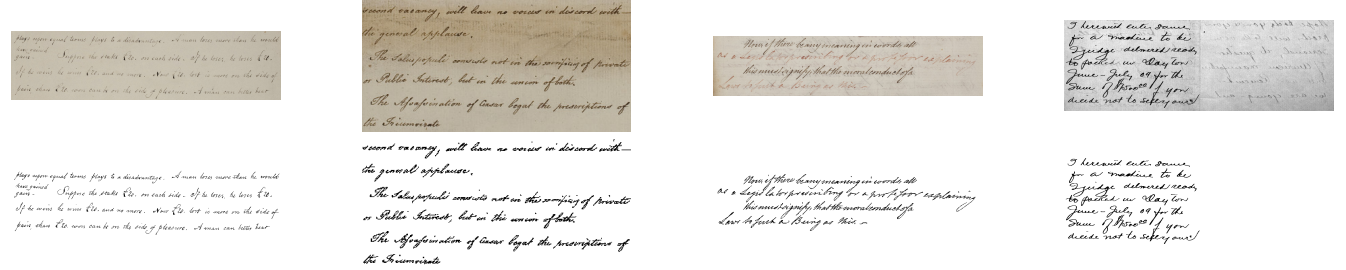

Figura 4.2: Documentos manuscritos do DIBCO 2013 e os seus correspondentes GT
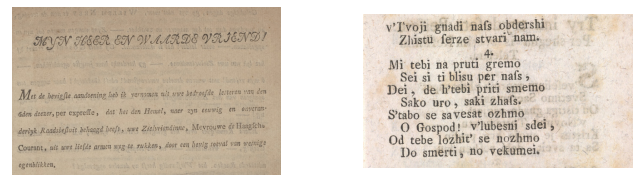

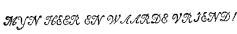

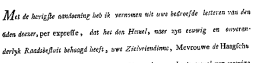

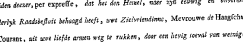
correr, stat

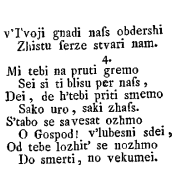

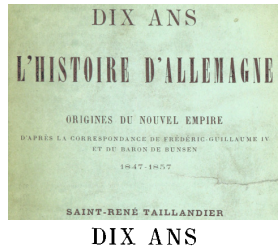

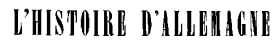

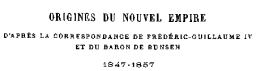

SAIMT.RERE TALLTANDISB

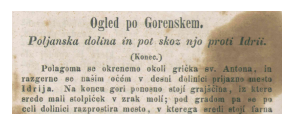

Ogled po Gorenskem.
dolina in pot skos njo proti ldrii.

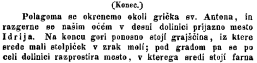

Figura 4.3: Documentos tipografados do DIBCO 2013 e os seus correspondentes GT

de dados de diversos anos, das 106 imagens do conjunto de dados, 75 são manuscritas e 31 são tipografadas.

\begin{tabular}{|l|c|c|c|}
\hline Competição & Manuscritas & Tipografadas & Total \\
\hline DIBCO 2009 & 5 & 5 & 10 \\
\hline H-DIBCO 2010 & 10 & 0 & 10 \\
\hline DIBCO 2011 & 8 & 8 & 16 \\
\hline H-DIBCO 2012 & 14 & 0 & 14 \\
\hline DIBCO 2013 & 8 & 8 & 16 \\
\hline H-DIBCO 2014 & 10 & 0 & 10 \\
\hline H-DIBCO 2016 & 10 & 0 & 10 \\
\hline DIBCO 2017 & 10 & 10 & 20 \\
\hline \multicolumn{1}{|c|}{ Total } & $\mathbf{7 5}$ & $\mathbf{3 1}$ & $\mathbf{1 0 6}$ \\
\hline
\end{tabular}

Tabela 4.1: Quantidade e tipo de documentos históricos nas competições DIBCO

\subsubsection{Ground Truth}

Por ser uma competição, o DIBCO disponibiliza um conjunto de dados Padrão Ouro (Ground Truth, GT). Para cada imagem, o conjunto contém o resultado da binarização ideal. Os valores dos pixeis da imagem GT servem como rótulos (labels) para os processos de aprendizagem supervisionada. Os valores das imagens binarizadas são:

- 1 : para o texto, e

- -1 : para o fundo. 
Para cada ponto do espaço de características ou vetor de característica é atribuído um rótulo.

\subsection{Métricas de avaliação das imagens binarizadas}

Compreendem um conjunto de métricas que são adequadas para fins de avaliação no contexto de análise e reconhecimento de imagens de documentos, usados na competição do DIBCO, vamos utilizar o conjunto de métricas da última competição da serie DIBCO, que é do Pratikakis, Zagoris et al., 2017. Geralmente essas métricas fazem uso do Padrão Ouro ou Segmentação Verificada $(G T)$. O GT não pode ser obtido por um processo completamente automatizado, pois se tal processo existisse, então ele mesmo seria o método de binarização perfeito. Por outro lado, a criação manual de GT é bastante demorada, suscetível a falhas humanas e pouco reprodutível. Portanto, um processo semiautomático foi desenvolvido para as competições $D I B C O$, em que a intervenção humana ocorre de forma bastante controlada. Este processo devido a NTIRogiAnNis, Basilios Gatos et al., 2008 baseia-se na construção de um GT esqueleto, onde a imagem original é binarizada e esqueletonizada, e o usuário tem que manualmente consertar o esqueleto para apagar os segmentos pertencentes a falsos positivos da binarização, assim como desenhar todos os segmentos para formar o esqueleto completo para cada letra. Finalmente, é feita a dilatação do esqueleto, condicionada pelas bordas obtidas através do método do CANNY, 1986, cujo resultado é o $G T$.

Temos os seguintes termos:

- True Positive (TP): é um pixel classificado como de texto e cujo equivalente no GT era também um pixel de texto.

- True Negative (TN): é um pixel classificado como de fundo e cujo equivalente no GT era um pixel de fundo.

- False Positive (FP): é um pixel classificado como de texto e cujo equivalente no GT era um pixel de fundo.

- False Negative (FN): é um pixel classificado como de fundo e cujo equivalente no GT era um pixel de texto.

Estas siglas nas fórmulas denotam o número de pixeis em cada categoria. Note que elas formam uma partição do conjunto de pixeis da imagem, portanto a soma do números de pixeis de cada categoria é igual ao número de pixeis da imagem inteira.

A seguir, apresentamos as métricas de avaliação.

\subsubsection{F-Measure(FM)}

Esta métrica é computada através da média harmônica de duas medidas bastante comuns:

$$
\text { Precisão }=\frac{T P}{T P+F P}
$$




$$
\text { Revocação }=\frac{T P}{T P+F N}
$$

Então, o F-Measure é:

$$
\text { F-Measure }(\mathrm{FM})=\frac{2 \times \text { Precisão } \times \text { Revocação }}{\text { Precisão }+ \text { Revocação }}
$$

Ela representa uma porcentagem, i.e., está no intervalo real de 0 a 1, e quanto maior for seu valor, mais próximo do GT é a imagem binarizada.

\subsubsection{Pseudo-FMeasure(pFM)}

É uma medida semelhante à F-Measure mas, ao invés de utilizar a Revocação, utiliza o chamado Pseudo Recall, que nada mais é do que a Revocação considerando o esqueleto da imagem GT (no inglês, skeletonized ground truth). Esta imagem, definida em NTIROGIANNIS, Basilios GATos et al., 2008, é o esqueleto da imagem binarizada e posterior correção manual.

Esta métrica introduzida em Pratikakis, Basilis Gatos et al., 2010 diferencia-se das demais por necessitar de duas imagens padrão para avaliar o resultado de uma binarização: o GT e seu esqueleto. Como esta métrica não foi utilizada no DIBCO 2009 e 2011, não é possível utilizá-la em seus conjuntos de dados a não ser que o esqueleto seja obtido do GT, o que produz resultados bem diferentes de um esqueleto corrigido manualmente. $\mathrm{O}$ cálculo é semelhante ao F-Measure em todos os aspectos: calcula-se a Precisão com o GT, o Revocação com o esqueleto de GT, que é o Pseudo Recall, e o resultado é a média harmônica das duas como na F-Measure, possuindo também mesmo significado.

\subsubsection{Peak Signal to Noise Ratio(PSNR)}

Esta medida foi proposta por STATHIs et al., 2008 e é calculada como a razão entre sinal de "pico" (GT) e o "ruído" (resultado da segmentação), para isso utiliza o MSE, ou erro quadrático médio, da seguinte forma:

$$
P S N R=10 \times \log \left(\frac{C^{2}}{M S E}\right)
$$

o MSE é dado por:

$$
M S E=\frac{\sum_{x \in E}(f(x)-g(x))^{2}}{|E|}
$$

onde $f$ é a imagem segmentada ou binarizada, $g$ é o GT, $|E|$ é a dimensão da imagem(quantidade de pixeis) e $C$ é a diferença média dos níveis de cinzas entre o texto e o fundo.

O PSNR mede a diferença da imagem ponto a ponto, não levando em conta a relações 
mútuas entre pixeis e, de forma semelhante ao F-Measure, quanto maior o valor do PSNR, mais parecidas são as imagens. Note que, caso as imagens sejam idênticas, seu valor não é definido.

\subsubsection{Distance-Reciprocal Distortion(DRD)}

Esta métrica foi proposta por H. Lu et al., 2004 e mede a distorção presente em uma imagem binaria que se correlaciona bem com uma avaliação humana. Para isso, utiliza como peso o inverso da distância dos pixeis errados (FP ou FN) em torno de um erro, pois a percepção de distorção aumenta quanto mais perto um erro for do outro. Estes pesos são representados em uma matriz quadrada de dimensão ímpar $m$. A matriz denotada por $W_{m}$ é definida da seguinte forma, com $1 \leq i, j \leq m$ e $i_{c}=j_{c}=\frac{(m+1)}{2}$ os índices da posição central da matriz.

$$
W_{m}(i, j)= \begin{cases}0, & \text { se } i=i_{c} \text { e } j=j_{c} \\ \frac{1}{\sqrt{\left(i-i_{c}\right)^{2}+\left(j-j_{c}\right)^{2}}}, & \text { caso contrário }\end{cases}
$$

O DRD é definida como:

$$
D R D=\frac{\sum_{k=1}^{|S|} D R D_{k}}{N U B N}
$$

onde $S$ o conjunto dos pixeis errados( $F P$ ou $F N)$, o $D R D_{k}$ é a distorção do k-ésimo pixel em $S$, calculada somando as diferenças entre o GT e a imagem binarizada $B_{k}$ de cada pixel na janela $W_{k}$ de tamanho $m$ por $m$ centrada neste pixel, multiplicando-se pelo peso correspondente matriz $W_{m}$. A matriz $W_{m}(i, j)$ é normalizada dividindo-se cada um dos seus elementos pela soma de todos os seus elementos, a matriz normalizada é denotada por $W_{N m}(i, j)$. O valor valor de $m$ é 5 .

$$
D R D_{k}=\sum_{i=-2}^{2} \sum_{j=-2}^{2}\left|G T_{k}(i, j)-B_{k}(x, y)\right| \times W_{N m}(i, j)
$$

O NUBN é o número de blocos $8 \times 8$ não-uniformes da imagem.

Ao contrário das métricas anteriores, quanto menor for o valor de $D R D$, melhor será a qualidade da binarização.

\subsection{Métrica de avaliação para o resultado do OCR}

Após binarizar uma imagen, continuamos com a extração do texto da imagem binarizada de acordo com o workflow proposto (Fig. 3.1), com a finalidade de que a imagem binarizada possa ser avaliada em termos dos resultados num sistema de OCR. 
O programa de OCR utilizado é o Tesseract ${ }^{9}$, versão 4.0, que é um programa open source baseado no LSTM (Long Short Term Memory (GoodfELlow et al., 2016)).

Para comparar o resultado do OCR, precisamos do texto Ground Thruth (GT), ou seja, a transcrição humana do texto da imagem do documento. Neste trabalho o GT foi composto a partir da transcrição manual das imagens. Para cada imagem tipografada do conjunto de dados, 31 imagens segundo a Tabela 4.1, foram extraídos manualmente seus textos correspondentes. Note que os textos não estão escritos apenas em inglês, mas em outros idiomas como o:

- Alemão (escrito em Fraktur ${ }^{10}$ ).

- Latim.

- Holandês.

- Francês.

- Esloveno.

- Croata.

- Inglês.

Alguns OCRs como o Tesseract necessitam que o usuário forneça o idioma do texto para fazer a correta extração do texto a partir da imagem. Assim, para cada imagem, foi informado o idioma no qual o texto foi escrito. Pelo fato que as imagens manuscritas são quase incompreensíveis, fizemos o GT dos textos apenas das imagens tipografadas. Finalmente, fazemos uma comparação deles para avaliar o matching usando a distância entre duas cadeias de caracteres, como definido por NAVARro, 2001. A função de Levenshtein (Levenshtein, 1966) foi escolhida para este trabalho. Ela é uma métrica de distância entre duas cadeias que permite três operações: a inserção, a exclusão e a substituição de caracteres, cada uma tendo seus custos unitários. A distância pode ser vista como o mínimo número de inserções, exclusões e substituções que são necessários para tornar duas cadeias iguais. O valor devolvido pela distância Levenshtein é utilizado para calcular o matching de duas cadeias da seguinte maneira: é a soma dos comprimentos de ambas cadeias menos a distância de Levenshtein tudo dividido pela soma dos comprimentos de ambas cadeias.

$$
\text { matching }=\frac{n-d_{L}}{n}
$$

onde $n$ é a soma dos comprimentos de ambas cadeias e $d_{L}$ é a distância Levenshtein. Utilizamos o algoritmo de Levenshtein implementado na biblioteca fuzzywuzzy do Python.

A Fig. 4.4 descreve o processo.

\footnotetext{
${ }^{9}$ https://github.com/tesseract-ocr/tesseract

${ }^{10}$ Fraktur é uma caligrafia do alfabeto latino, semelhante ao Gótico
} 


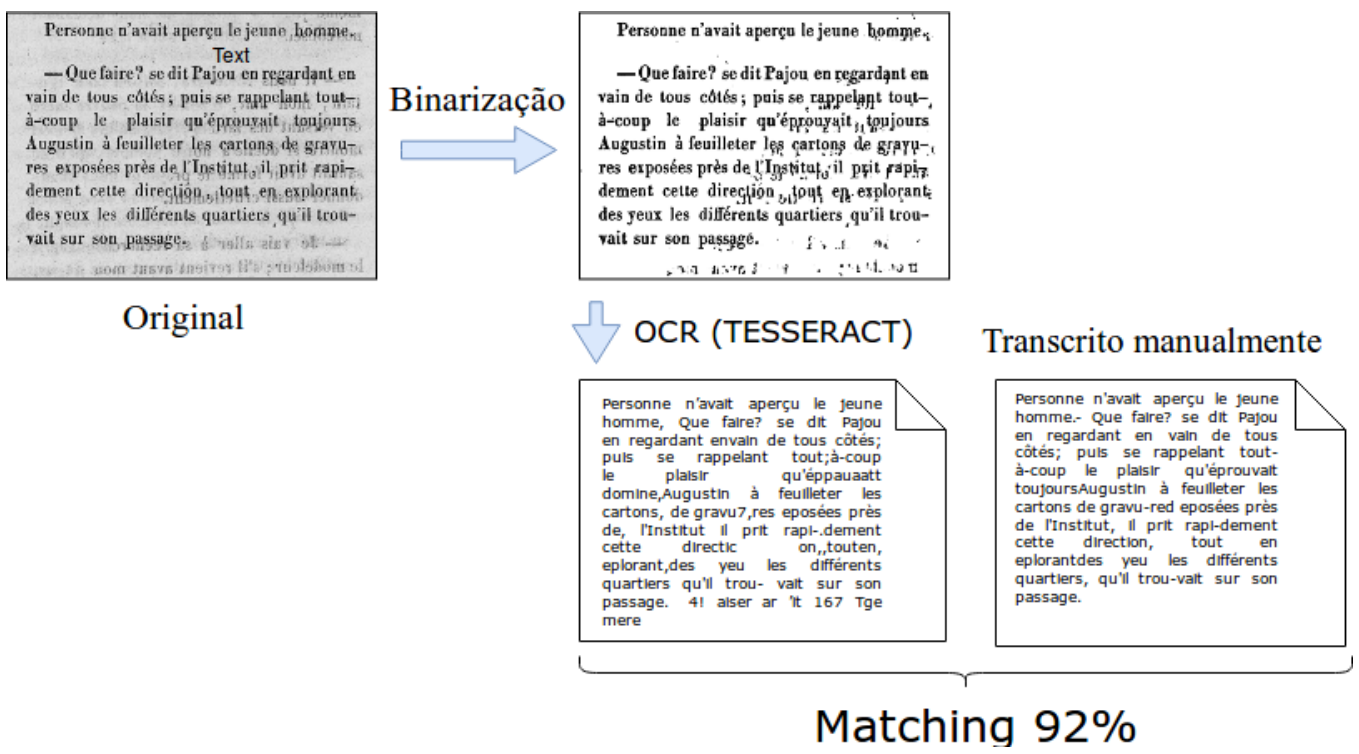

Figura 4.4: Métrica de avaliação para o resultado do OCR.

\subsection{Classes desbalanceadas}

Imagens de documentos geralmente consistem em mais pixeis de fundo do que de texto. Isso pode-ser observado, por exemplo, na Fig. 4.1a (documento manuscrito) e na Fig. 4.1b (documento tipografado). O problema de classes desbalanceadas é tratado com cuidado por Guo (Guo et al., 2008) e aplica-se bem ao nosso trabalho pois, caso contrário, corre-se o risco que um modelo sempre rotule um pixel como sendo de fundo e a acurácia desse modelo seria pelo menos $90 \%$, o que não nos interessa pois perderíamos todos os pixeis de texto.

Assim, há dois problemas relacionados ao desbalanceamento de classes. O primeiro problema está relacionado com o cross-validation para ter nos folds amostras representativas de cada classe que será melhor tratado no próximo capítulo pois ele implica numa estratégia diferenciada para a forma como são usados os exemplos no treinamento (amostragem estratificada). O segundo problema relaciona-se a fragilidade da acurácia como medida de sucesso de um classificador. Por isso, as métricas como a precisão (precision) e a revocação (recall) são mais adequadas para o problema em questão (GÉron, 2017). Descrevemos elas a seguir:

Precisão: Relação entre os pixeis que foram corretamente classificados como texto e o total que foi classificado como texto, é representada pela Eq. 4.1.

Revocação: Relação entre os pixeis que foram corretamente classificados como texto e o que é realmente texto, é representada pela Eq. 4.2, ela quer dizer:

$$
\text { Revocação }=\frac{\# \text { corretamente classificados como texto }}{\text { \#texto real }}
$$

Neste trabalho, priorizamos alcançar a preservação máxima de informações de texto (devido a sua importância), isso é, obter todos os pixeis que pertencem ao texto da imagem, 
mesmo que pixeis do fundo sejam classificados como texto (FP, falsos positivos). Evita-se que o texto seja reconhecido como fundo (FN, falsos negativos) pois estaríamos perdendo pixeis e dificultando o reconhecimento do texto. Assim, a Revocação é a métrica mais adequada para avaliar o desempenho do modelo pois quanto maior a revocação, maior o número de pixeis reconhecidos como texto. 



\section{Capítulo 5}

\section{Experimentos e Análise de Resultados}

Neste capítulo apreesentamos um conjunto de experimentos para determinar o classificador adequado para o problema de segmentação de imagens de documentos antigos. O resultado, ou imagem binarizada, é avaliado quantitativamente, isto é, por métricas estabelecidas pela competição DIBCO e, além disso, para as imagens tipografadas também são avaliadas qualitativamente, isto é, usando OCR, especificamente o Tesseract.

\subsection{Planejamento dos experimentos}

Os experimentos foram planejados para avaliar a performance do classificador quando o conjunto de treinamento utiliza apenas imagens manuscritas, apenas imagens tipografadas, ou um conjunto de treinamento misturado, segundo os tipos de características obtidas da estratégia de combinação de características apresentada na Seção 3.2.

\subsubsection{Segundo os tipos de documentos históricos}

Como os tipos de documentos do conjunto de dados que trabalhamos são documentos manuscritos, ou tipografados, algumas questões foram levantadas durante a pesquisa, quais sejam: (1) qual o efeito de treinar o classificador com imagens manuscritas e testar com imagens tipografadas? (2) E se ele é treinado com ambos tipos de imagens? Para responder tais perguntas, apresentamos a Tabela $5.1 \mathrm{com}$ as diversas possibilidades de combinações de uso do conjunto de dados. A Coluna 1 apresenta os casos que serão avaliados, a Coluna 2 apresenta o nome do caso, a Coluna 3 apresenta o subconjunto de treinamento e a Coluna 4, o conjunto de testes.

Descrevemos a seguir cada um dos casos e os problemas relacionados ao executálos.

- Caso 1: treinar e testar apenas com imagens tipografados tem o problema da pouca quantidade de imagens tipografadas. 


\begin{tabular}{|c|l|l|l|}
\hline Casos a avaliar & \multicolumn{1}{|c|}{ Descrição } & \multicolumn{1}{c|}{ Treinamento } & \multicolumn{1}{c|}{ Teste } \\
\hline Caso 1 & Apenas imagens tipografadas & tipografadas & tipografadas \\
\hline Caso 2 & Apenas imagens manuscritas & manuscritas & manuscritas \\
\hline \multirow{2}{*}{ Caso 3 } & \multirow{2}{*}{ Ambos tipos de imagens } & Caso 3.1: manuscritas e tipogradas & \multirow{2}{*}{ manuscritas e tipografadas } \\
\cline { 3 - 3 } & & Caso 3.2: manuscritas & Caso 3.3: tipografadas \\
& &
\end{tabular}

Tabela 5.1: Casos avaliados segundo as combinações de tipos de documentos históricos para o treinamento e para teste do modelo.

- Caso 2: treinar e testar apenas com manuscritos melhora um pouco o problema pois há duas vezes mais exemplos, mas ainda há um outro problema que é o resultado do OCR ser ruim para imagens manuscritas.

- Caso 3: treinar com uma mistura de imagens manuscritas e tipografadas. O Caso 3.1, treina-se e testa-se tanto com imagens tipografadas, quanto manuscritas. O Caso 3.2, treina-se com imagens manuscritas, mas testa-se tanto manuscritas quanto tipografadas. O Caso 3.3, treinar com imagens tipografadas e testar com imagens imagens tipografadas e manuscritas, tem o mesmo problema do Caso 1, poucas imagens de treinamento.

Por tanto, focamos no Caso 3.1 e no Caso 3.2.

\subsubsection{Segundo os tipos de características}

Uma outra questão que se pode colocar é:

Será que a classificação de texto é boa utilizando apenas características de textura, ou heurísticas e intensidade? Relembrando as características apresentadas no Capítulo 3.

Características de textura:

$$
\mathrm{X}(f)(x)=\left[X^{R D I(-1)}(f)(x), X^{R D I(0)}(f)(x), X^{R D I(1)}(f)(x)\right]
$$

Características heurísticas e a intensidade:

$$
\begin{aligned}
\mathrm{X}(f)(x)= & {[f(x),} \\
& \left.X^{\mathrm{Otsu}}(f)(x), X^{N i b k}(f)(x), X^{S a u}(f)(x), X^{S u}(f)(x), X^{H o}(f)(x)\right]
\end{aligned}
$$

Ambos tipos de características: isto é, intensidade, textura, e heurísticas. Mostrada na Eq. 3.2. 


\subsubsection{Padronização das características}

Cada conjunto de características é padronizada através de uma transformação de centralização; neste trabalho usamos o StandardScaler ()$^{1}$ do pacote preprocessing do Scikit-Learn. A função centraliza os dados de acordo com a média e o desvio padrão dos dados.

\subsubsection{Hiper-parâmetros a avaliar}

Como o método proposto é baseado em aprendizado, uma pergunta relacionada ao processo de aprendizado é: qual combinação de hiper-parâmetros resulta melhor na revocação?. Para responder a esta pergunta, fizemos uma busca em grade nos valores dos hiper-parâmetros expostos na Tabela 5.2 para o classificador SVM Linear com Gradiente Descendente Estocástica.

\begin{tabular}{|l|l|}
\hline Hiper-parâmetros & Valores \\
\hline 'alpha:' & $0.01,0.001,0.0001,0.00001,0.000001$ \\
\hline 'penalty:' & '12', 'elasticnet' \\
\hline 'class_weight:' & 'None', 'balanced' \\
\hline
\end{tabular}

Tabela 5.2: Grade de hiper-parâmetros a avaliar

\subsubsection{Amostragem estratificada (StratifiedKFold)}

A avaliação dos modelos, variando-se os hiper-parâmetros, é feita com conjunto de validação através da técnica de cross-validation. No entanto, pelo fato de termos classes desbalanceadas, caso escolhamos os exemplos para cada fold aleatoriamente, pode acontecer que tomemos amostras somente do fundo (pois é a classe majoritária, $90 \%$ do conjunto). Assim, é mais adequado obter folds que tenham amostras representativas para cada classe do conjunto, pois é importante ter um número suficiente de amostras do nosso conjunto para cada classe em cada fold. Para isso, utiliza-se a amostragem estratificada que toma amostras respeitando-se as proporções das classes. O StratifiedKfold do sklearn divide o conjunto em $K$ folds estratificados, onde $K=10$ nestes experimentos.

\subsection{Experimentos e Resultados}

Nesta seção apresentamos os resultados dos experimentos de acordo com o que foi exposto no planejamento.

\footnotetext{
${ }^{1}$ http://scikit-learn.org/stable/modules/generated/sklearn.preprocessing.StandardScaler.html
} 


\subsubsection{Caso 3.1: Treinar com imagens manuscritas e tipografadas e testar com imagens manuscritas e tipografadas}

O experimento consiste em treinar e testar tanto com imagens tipografadas quanto manuscritas. De acordo a quantidade de imagens descrita na Tabela 4.1, temos 75 imagens manuscritas e 31 imagens tipografadas, no total 106 imagens:

- No treinamento utilizou-se um terço imagens 35 imagens assim escolhidas:

- 25 imagens manuscritas (33\% das manuscritas)

- 10 imagens tipografadas (33\% das tipografadas)

- No teste vamos utilizas as imagens restantes, isto é, 71 imagens.

As imagens foram escolhidos aleatoriamente do conjunto de dados, e para cada imagem fez-se a extração de características segundo o procedimento apresentado na Figura 3.2. Foram observados mais de 40 milhões de amostras (vetores de características), das quais $92,4 \%$ é fundo e apenas $7,6 \%$ é texto, isso mostra a grande desproporção entre as duas classes. Agora, vamos a responder à pergunta feita na Seção 5.1.2, qual seja:

\section{Será que a classificação de texto e fundo é boa utilizando apenas?}

- Características de textura, Eq. 5.1

- Características heurísticas e a intensidade, Eq. 5.2

- Ambos tipo de características, Eq. 3.2

A Tabela 5.3 apresenta os valores dos parâmetros de 'alpha', 'penalty' e 'class_weight' com os quais se obteve a maior revocação (após a média de 10 iterações).

\begin{tabular}{|c|c|c|c|}
\hline & \multicolumn{3}{|c|}{ Combinação de valores que obtiveram a maior revocação por tipo de característica } \\
\hline Hiper-parâmetros & Características de textura & Características heurísticas e de intensidade & Ambos tipos de características \\
\hline 'alpha' & 0.00001 & 0,01 & 0,001 \\
\hline 'penalty' & 'elasticnet' & $' 12$ ' & '12' \\
\hline 'class_weight' & 'balanced' & 'balanced' & 'balanced' \\
\hline \hline Maior revocação & $\mathbf{0 , 9 0 9}$ & $\mathbf{0 , 9 5 8}$ & $\mathbf{0 , 9 6 3}$ \\
\hline
\end{tabular}

Tabela 5.3: Caso 3.1: Combinação de valores dos hiper-parâmetros que obtiveram a maior revocação por tipo de característica

Após ter os hiper-parâmetros ajustados para cada modelo, se faz a etapa de predição onde é obtida a binarização da imagem.

\section{Resultados Quantitativos}

Baseado nas métricas do DIBCO descritas na Seção 4.2, os resultados são mostrados na Tabela 5.4, na qual temos 71 linhas, uma para cada imagem (50 manuscritas e 21 tipografadas). Para cada imagem foi calculado o $F M$, o $p F M$, o PSNR e o DRD. Os valores em negrito são os maiores valores para cada imagem. Também pode-se notar que para as imagens, DIBCO2011HW1, DIBCO2012H01, entre outras, os valores da métrica DRD são iguais para os três modelos, e para a imagem DIBCO2013HW05 o valor do FM e DRD são altos, isso acontece porque geralmente os valores do $D R D$ são pequenos (menores a 
um), e ao serem arrendodados para uma melhor visualização (imprimimos apenas os dois primeiros dígitos após o ponto) isso faz que as diferenças sutis não sejam percebidos.

Note-se que fazendo um média dos valores das métricas das 71 imagens para cada modelo, obteve-se os maiores scores das métricas do DIBCO para o conjunto de características Heurísticos e intensidade.

Podemos observar que na Tab. 5.4 tem-se valores das métricas baixos nas quatro métricas nos três modelos, é o caso da imagem DIBCO2011PR2 e da imagem DIBCO201713, ambas tipografadas. Isto acontece porque os modelos do Caso 3.1 foram treinados em su maioria com imagens manuscritas, e os modelos não lidam bem com imagens tipografadas que tem ruido bem forte do fundo(texto do verso aparecendo da frente).

A Figura 5.1 mostra os resultados da Tabela 5.4 na forma de gráficos boxplot para cada métrica e para cada modelo treinado com os tipos de conjunto de características. Cada gráfico apresenta uma métrica do DIBCO e o gráfico da Figura 5.1a mostra os valores do F-Measure onde pode-se observar que as caraterísticas de heurísticas e intensidade conseguem um F-Measure(FM) maior. O gráfico da Figura 5.1b mostra os valores do $p F M$, o gráfico da Figura 5.1c os valores do PSNR e o gráfico da Figura 5.1d os valores do DRD. Para cada um das métricas os melhores valores conseguiram-se com as características heurísticas e intensidade.

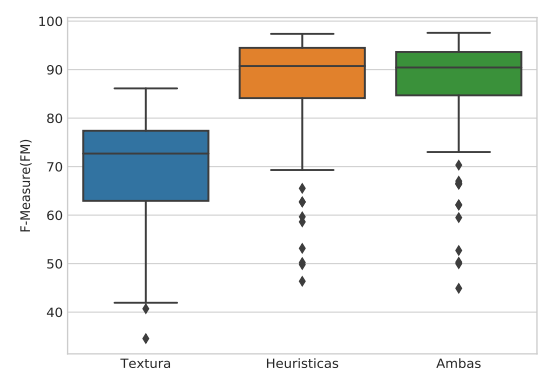

(a) F-Measure $(\%)(\uparrow)$

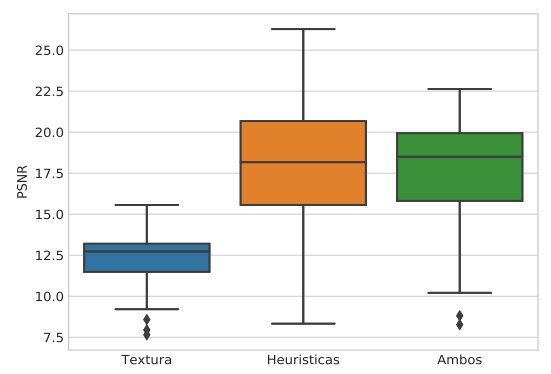

(c) Peak Signal to Noise Ratio ( $\uparrow)$

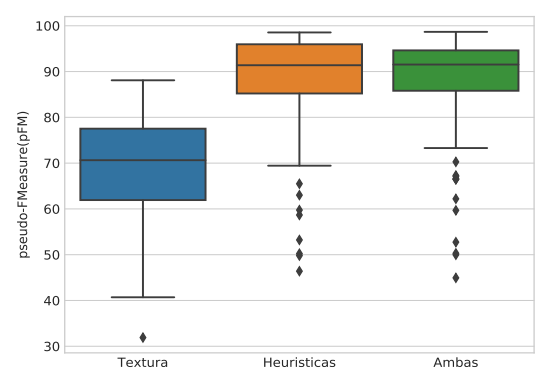

(b) Pseudo-FMeasure (\%)( $\uparrow)$

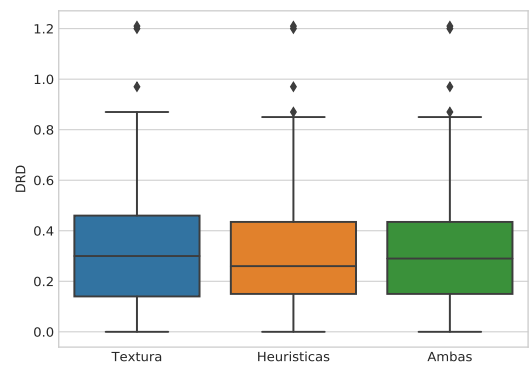

(d) Distance Reciprocal Distortion Metric ( $\downarrow)$

Figura 5.1: Caso 3.1: Resultados das métricas do DIBCO por conjunto de características 


\section{Resultados Qualitativos}

Nesta seção apresentamos os resultados da avaliação do OCR, como descrito no Cap. 4. Recordando, usando a distância Levenshtein, fizemos a comparação dos resultados do OCR das imagens originais binarizadas (DIBCO) com os resultados do OCR das imagens do método proposto. Como o Tesseract devolve uma cadeia de caracteres com problemas quando o texto não é reconhecido, por exemplo: “>\%«-«- ”, entre outros. Assim, antes de fazer a comparação, eliminamos esses caracteres aceitando apenas os caracteres que são válidos segundo o algoritmo a seguir.

Seja $c$ um caractere pertencente à sequência sendo analisada, aceitamos $c$ caso umas das condições seja satisfeita:

- c esteja contido em “" ",, ,:;/?!()’\&-[] “", ’””. Pois consideramos esses caracteres como válidos num texto.

- c.isalpha() ${ }^{2}$, isto é, verifica-se se $c$ tem o conteúdo apenas alfabético. Caracteres alfabéticos são aqueles definidos no conjunto de caracteres Unicode.

- c.isdigit( $)^{3}$; verifica-se se que o caracter é um dígito.

Vale lembrar também que temos textos em diferentes idiomas e cada um tem caracteres especiais que são dificilmente reconhecidos pelo ORC. São eles: Alemão fraktur: Ä, ä, Ö, ö, Ü, ü, ß, r

Latin: ã, ẽ, õ, ũ, æ, Æ, á, é, í, ó

Holandês: [, $\mathbb{E}$

esloveno: È, É, é, è, č, í, š, ž, ž

Os textos também contêm símbolos de pontuação, dos quais foram considerados: $"$. , : ; / ? ! ( )'\& - \$"“"

A Tabela 5.5 descreve o processo da avaliação pelo OCR; na primeira coluna apresentamos uma imagem tipografada do DIBCO2017 e suas respectivas segmentações de acordo com os métodos testados: caracteristicas de textura, caracteristicas heuristicas e de intensidade e a última com todas as caracteristicas (textura, intensidade e heurísticas). A segunda coluna apresenta o GT (igual para todas as linhas dessa coluna). A terceira coluna apresenta o resultado do OCR. A quarta coluna apresenta o resultado do casamento entre as colunas 2 e 3 . Nota-se que o resultado a partir do método com todas as características é o melhor, apresentado valor de casamento de $92 \%$, contra $91 \%$ do método usando apenas textura, ou $89 \%$ da imagem sem tratamento algum, ou $80 \%$ do método misturando característias heurísticas e de intensidade.

A Figura 5.2 apresenta os resultados para todas as 25 imagens tipografadas do conjunto de testes. Note que se extrairmos o texto diretamente da imagem original, a mediana dos resultados obtidos é $80 \%$, enquanto que a partir da imagem binarizada utilizando todas as caracteristicas é de quase $90 \%$.

\footnotetext{
${ }^{2}$ https://docs.python.org/3/library/stdtypes.html

${ }^{3}$ https://docs.python.org/3/library/stdtypes.html
} 


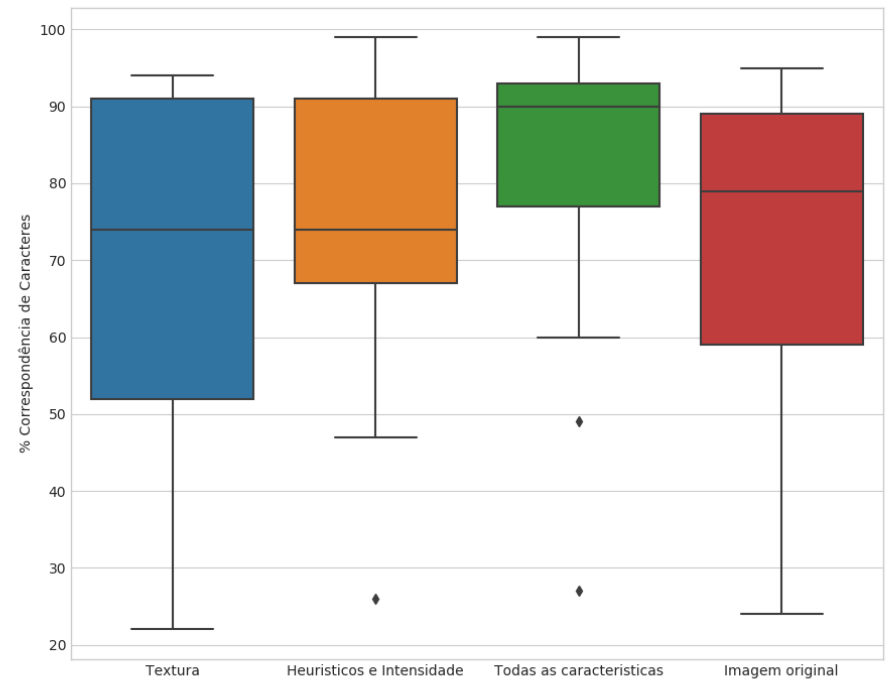

Figura 5.2: Caso 3.1: Porcentagem de casamento obtida a partir da comparação de caracteres dos textos extraídos pelo Tesseract das imagens binarias obtidas utilizando caracteristicas de textura, caracteristicas heuristicas e intensidade, e utilizando todas as caracteristicas e também da imagem original. Note que a maior porcentagem de texto extraido(90\%) obteve-se com imagens binarias utilizando todas as caracteristicas.

\subsubsection{Caso 3.2: Treinar com imagens manuscritas e testar com manuscritas e tipografadas}

Agora o experimento consiste em treinar com imagens manuscritas e testar tanto com imagens tipografadas quanto manuscritas. De acordo a quantidade de imagens descrita na Tabela 4.1, temos 75 imagens manuscritas e 31 imagens tipografadas, no total 106 imagens:

- No treinamento utilizou-se um terço das imagens 35 imagens assim escolhidas:

- 35 imagens manuscritas(33\% do conjunto de dados)

- No teste vamos utilizar as imagens restantes, isto é, 71 imagens (manuscritas quanto tipografadas).

Aplicamos o mesmo processo do Caso 3.1 e determinamos primeiro os hiper-parâmetros para os modelos. A Tabela 5.6 apresenta os valores dos parâmetros de 'alpha', 'penalty' $e$ 'class_weight' com os quais se obteve a maior revocação (após a média de 10 iterações).

Como anteriormente, após ter os hiper-parâmetros ajustados para cada modelo, faz-se a predição onde são obtidas as binarizações das imagens. Neste caso temos 40 imagens manuscritas e 31 tipografadas para teste. 


\section{Resultados Quantitativos}

A Tabela 5.7 apresenta os resultados quantitativos para as 71 imagens de teste.

Pode-se observar que os valores das métricas DIBCO da imagem DIBCO2011PR2 na Tab. 5.7 que são do Caso 3.2 conseguiram aumentar respeito ao valores das métricas DIBCO da mesma imagem no Caso 3.1. Isto acontence porque aqui se utilizaram major quantidade de imagens tipografadas para o treinamento dos modelos que no Caso 3.1

Note-se que geralmente os valores das métricas obtidas no Caso 3.1 (Tab. 5.4) são maiores para imagens manuscritas pois se utilizou maior quantidade de imagens manuscritas para o treinamento e no Caso 3.2 os resultados mellhoram para as imagens tipografadas (Tab. 5.7) pois o treinamento e feito com mais imagens tipografadas.

A Figura 5.3 apresenta, na forma de gráficos boxplot, os resultados da Tabela 5.7. Note que com o conjunto de caracteristicas Heuristicos e intensidade se conseguem maiores valores FM, pFM, PSNR, e o menor valor de DRD, que é o desejado.

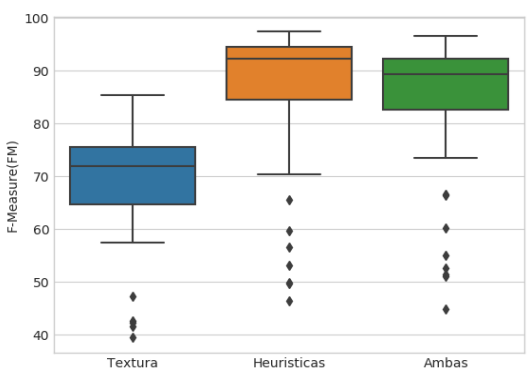

(a) F-Measure $(\%)(\uparrow)$

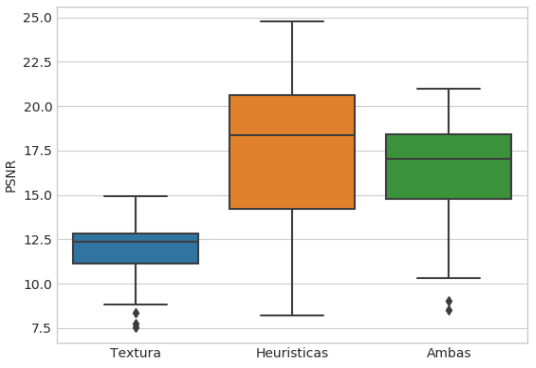

(c) Peak Signal to Noise Ratio $(\uparrow)$

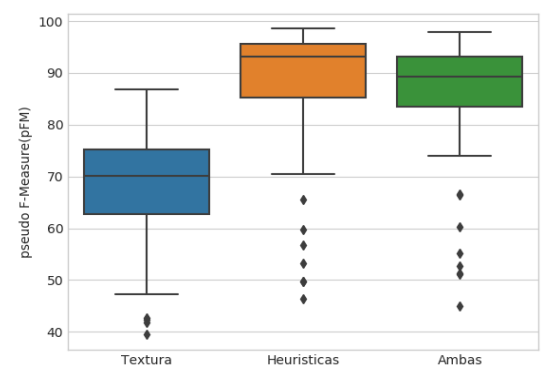

(b) Pseudo-FMeasure (\%)( $\uparrow)$

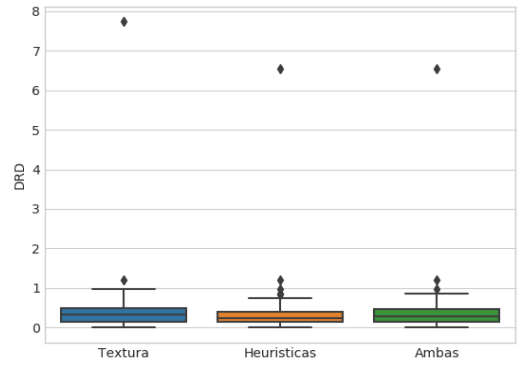

(d) Distance Reciprocal Distortion Metric ( $\downarrow$ )

Figura 5.3: Caso 3.2: Resultados das métricas do DIBCO por conjunto de características.

\section{Resultados Qualitativos}

Fazendo o casamento do texto extraido pelo Tesseract só das imagens tipografadas da mesma forma que no caso anterior, obtiveram-se os resultados apresentados na Figura 5.4, cuja interpretação é semelhante à anterior. Note mais uma vez que a maior porcentagem 
de texto extraido (90\%) obteve-se com imagens binarias utilizando todas as caracteristicas.

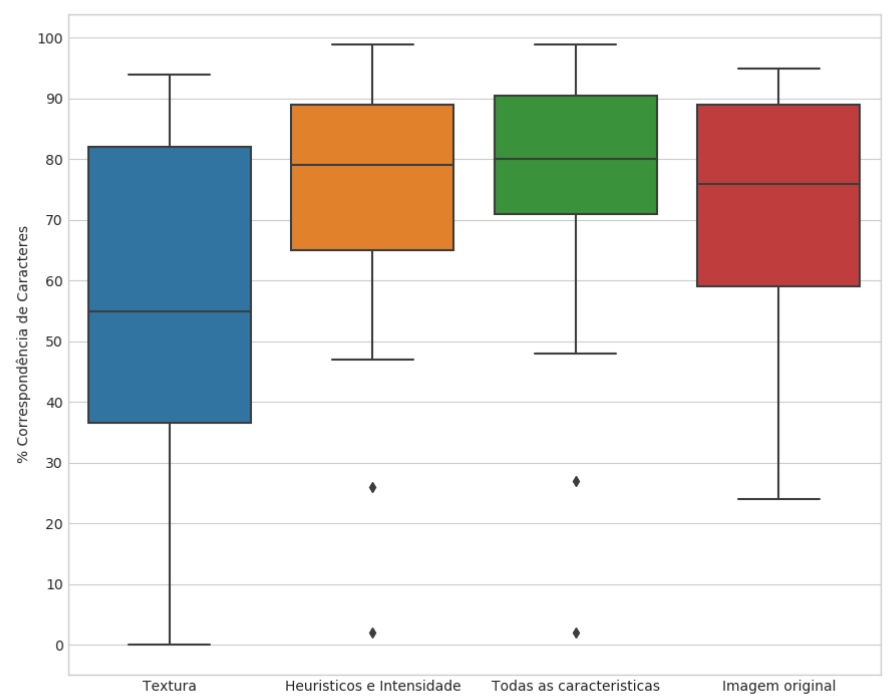

Figura 5.4: Caso 3.2: Porcentagem de casamentos obtidos a partir da comparação de caracteres dos textos extraídos pelo Tesseract das imagens binarias obtidas utilizando caracteristicas de textura, caracteristicas heuristicas e intensidade, e utilizando todas as caracteristicas e também da imagem original. Note-se que a maior porcentagem de texto extraido(90\%) se obteve com imagens binarias utilizadas todas as caracteristicas. 


\begin{tabular}{|c|c|c|c|c|c|c|c|c|c|c|c|c|c|}
\hline \multirow{2}{*}{ Imagens } & \multirow{2}{*}{ Tipo de imagem } & \multicolumn{4}{|c|}{ Textura } & \multicolumn{4}{|c|}{ Heurísticos e intensidade } & \multicolumn{4}{|c|}{ Todas as características } \\
\hline & & FM & pFM & PSNR & DRD & FM & pFM & PSNR & DRD & FM & pFM & PSNR & DRD \\
\hline DIBCO2009H02 & manuscrita & 60.84 & 60.83 & 15.56 & 1.20 & 62.72 & 63.01 & 15.97 & 1.20 & 62.14 & 62.20 & 15.82 & 1.20 \\
\hline DIBCO2009H03 & manuscrita & 78.07 & 78.37 & 12.73 & 0.75 & 90.57 & 91.08 & 17.02 & 0.59 & 93.73 & 94.27 & 18.96 & 0.55 \\
\hline DIBCO2009H05 & manuscrita & 63.21 & 63.01 & 13.67 & 0.77 & 90.49 & 90.90 & 21.19 & 0.59 & 87.83 & 87.83 & 19.94 & 0.65 \\
\hline DIBCO2010H01 & manuscrita & 79.74 & 79.56 & 12.85 & 0.43 & 95.38 & 97.03 & 20.06 & 0.60 & 93.49 & 94.84 & 18.45 & 0.36 \\
\hline DIBCO2010H02 & manuscrita & 65.93 & 65.77 & 13.42 & 0.36 & 95.23 & 95.96 & 23.64 & 0.36 & 87.11 & 87.18 & 18.87 & 0.36 \\
\hline DIBCO2010H03 & manuscrita & 73.47 & 75.20 & 13.21 & 0.56 & 94.12 & 97.01 & 20.83 & 0.83 & 93.06 & 94.51 & 19.93 & 0.83 \\
\hline DIBCO2010H04 & manuscrita & 76.23 & 76.79 & 13.17 & 0.28 & 93.18 & 93.79 & 19.41 & 0.28 & 91.69 & 92.09 & 18.45 & 0.28 \\
\hline DIBCO2010H07 & manuscrita & 74.16 & 74.41 & 13.21 & 0.30 & 92.50 & 93.19 & 19.55 & 0.30 & 90.81 & 91.53 & 18.60 & 0.30 \\
\hline DIBCO2010H09 & manuscrita & 65.92 & 66.76 & 13.40 & 0.57 & 93.36 & 96.21 & 22.12 & 0.12 & 86.04 & 87.01 & 18.36 & 0.30 \\
\hline DIBCO2011HW1 & manuscrita & 41.93 & 42.20 & 7.65 & 0.28 & 50.23 & 50.23 & 8.33 & 0.28 & 49.98 & 49.98 & 8.27 & 0.28 \\
\hline DIBCO2011HW2 & manuscrita & 43.85 & 43.85 & 11.72 & 0.38 & 70.56 & 70.60 & 16.67 & 0.41 & 66.58 & 66.60 & 15.81 & 0.41 \\
\hline DIBCO2011HW3 & manuscrita & 50.72 & 50.83 & 11.15 & 0.22 & 69.30 & 69.45 & 14.51 & 0.15 & 66.36 & 66.48 & 13.86 & 0.15 \\
\hline DIBCO2011HW4 & manuscrita & 55.83 & 55.96 & 11.30 & 0.61 & 58.61 & 58.67 & 11.56 & 0.37 & 67.01 & 67.09 & 13.16 & 0.37 \\
\hline DIBCO2011HW7 & manuscrita & 40.70 & 40.70 & 12.05 & 0.58 & 46.36 & 46.40 & 12.88 & 0.35 & 44.91 & 44.94 & 12.56 & 0.35 \\
\hline DIBCO2011HW8 & manuscrita & 44.19 & 44.18 & 11.71 & 0.00 & 69.95 & 69.94 & 16.50 & 0.85 & 66.48 & 66.48 & 15.72 & 0.85 \\
\hline DIBCO2012H01 & manuscrita & 58.00 & 59.50 & 12.32 & 0.16 & 95.60 & 95.59 & 22.88 & 0.16 & 93.40 & 93.18 & 21.00 & 0.16 \\
\hline DIBCO2012H02 & manuscrita & 60.61 & 59.57 & 11.31 & 0.36 & 85.83 & 87.57 & 16.56 & 0.36 & 84.46 & 85.72 & 16.04 & 0.36 \\
\hline DIBCO2012H04 & manuscrita & 65.35 & 64.12 & 13.22 & 0.74 & 91.77 & 91.14 & 20.84 & 0.45 & 89.63 & 88.85 & 19.70 & 0.45 \\
\hline DIBCO2012H06 & manuscrita & 71.24 & 70.90 & 12.89 & 0.37 & 77.43 & 77.69 & 14.21 & 0.22 & 92.16 & 92.21 & 19.61 & 0.37 \\
\hline DIBCO2012H08 & manuscrita & 72.92 & 73.01 & 12.83 & 0.40 & 87.34 & 87.52 & 16.90 & 0.34 & 94.13 & 94.39 & 20.57 & 0.42 \\
\hline DIBCO2012H09 & manuscrita & 79.25 & 79.00 & 12.49 & 0.00 & 96.70 & 97.37 & 21.21 & 0.00 & 96.07 & 96.55 & 20.42 & 0.00 \\
\hline DIBCO2012H12 & manuscrita & 67.92 & 67.93 & 12.73 & 0.34 & 95.97 & 96.60 & 23.29 & 0.00 & 92.87 & 93.00 & 20.62 & 0.32 \\
\hline DIBCO2012H14 & manuscrita & 64.50 & 64.46 & 12.99 & 0.26 & 93.82 & 94.57 & 22.26 & 0.17 & 90.73 & 90.97 & 20.31 & 0.17 \\
\hline DIBCO2013HW01 & manuscrita & 61.85 & 61.41 & 13.49 & 0.14 & 93.49 & 93.31 & 23.09 & 0.14 & 89.71 & 88.88 & 20.83 & 0.14 \\
\hline DIBCO2013HW02 & manuscrita & 73.36 & 73.95 & 13.30 & 0.00 & 94.35 & 95.65 & 21.12 & 0.60 & 92.10 & 92.92 & 19.51 & 0.60 \\
\hline DIBCO2013HW04 & manuscrita & 68.26 & 66.46 & 13.81 & 0.25 & 84.56 & 84.78 & 17.62 & 0.16 & 83.43 & 83.51 & 17.24 & 0.16 \\
\hline DIBCO2013HW05 & manuscrita & 62.33 & 62.29 & 14.34 & 0.43 & 53.15 & 53.22 & 12.64 & 0.26 & 52.71 & 52.74 & 12.55 & 0.26 \\
\hline DIBCO2013HW06 & manuscrita & 70.71 & 70.64 & 12.72 & 0.08 & 93.99 & 94.46 & 20.73 & 0.03 & 92.06 & 92.20 & 19.40 & 0.03 \\
\hline DIBCO2013HW07 & manuscrita & 34.55 & 31.90 & 14.83 & 0.00 & 62.72 & 69.44 & 18.99 & 0.46 & 62.07 & 67.29 & 18.74 & 0.46 \\
\hline DIBCO2013HW08 & manuscrita & 70.58 & 70.09 & 13.08 & 0.23 & 90.74 & 91.38 & 19.17 & 0.15 & 88.57 & 88.84 & 18.12 & 0.15 \\
\hline DIBCO2014H04 & manuscrita & 85.61 & 85.37 & 13.19 & 0.58 & 97.37 & 98.54 & 21.03 & 0.58 & 97.20 & 98.34 & 20.75 & 0.58 \\
\hline DIBCO2014H06 & manuscrita & 77.75 & 72.10 & 11.29 & 0.72 & 95.17 & 95.45 & 18.31 & 0.85 & 94.19 & 94.39 & 17.45 & 0.85 \\
\hline DIBCO2014H07 & manuscrita & 77.00 & 78.36 & 13.10 & 0.26 & 94.48 & 95.60 & 19.99 & 0.21 & 95.01 & 95.98 & 20.48 & 0.26 \\
\hline DIBCO2014H08 & manuscrita & 61.25 & 61.26 & 14.17 & 0.66 & 96.18 & 97.18 & 26.28 & 0.66 & 91.69 & 91.94 & 22.63 & 0.66 \\
\hline DIBCO2014H09 & manuscrita & 80.74 & 82.34 & 13.51 & 0.14 & 95.03 & 95.95 & 19.98 & 0.24 & 95.59 & 96.53 & 20.52 & 0.24 \\
\hline DIBCO201610 & manuscrita & 73.99 & 77.83 & 10.56 & 0.87 & 82.76 & 83.90 & 12.37 & 0.87 & 82.65 & 83.39 & 12.29 & 0.87 \\
\hline DIBCO20161 & manuscrita & 70.28 & 61.57 & 13.06 & 0.00 & 90.68 & 90.80 & 18.59 & 0.51 & 89.55 & 89.49 & 18.02 & 0.51 \\
\hline DIBCO20164 & manuscrita & 78.20 & 77.82 & 15.11 & 0.47 & 92.17 & 96.02 & 20.62 & 0.00 & 92.25 & 95.74 & 20.63 & 0.00 \\
\hline DIBCO20165 & manuscrita & 71.55 & 71.06 & 12.77 & 0.15 & 90.34 & 90.43 & 18.36 & 0.21 & 94.62 & 96.10 & 21.26 & 0.12 \\
\hline DIBCO20166 & manuscrita & 75.61 & 74.65 & 14.04 & 0.36 & 87.96 & 89.98 & 17.85 & 0.36 & 87.61 & 89.14 & 17.65 & 0.36 \\
\hline DIBCO20167 & manuscrita & 81.64 & 83.55 & 13.77 & 0.32 & 93.16 & 96.73 & 18.67 & 0.42 & 92.93 & 96.12 & 18.50 & 0.00 \\
\hline DIBCO20169 & manuscrita & 78.22 & 77.78 & 12.22 & 0.31 & 89.31 & 88.25 & 15.53 & 0.30 & 89.71 & 88.52 & 15.74 & 0.30 \\
\hline DIBCO201710 & manuscrita & 83.01 & 85.39 & 12.73 & 0.08 & 94.88 & 94.92 & 18.13 & 0.05 & 97.58 & 97.57 & 21.52 & 0.05 \\
\hline DIBCO20172 & manuscrita & 78.63 & 78.02 & 12.80 & 0.08 & 90.53 & 92.96 & 17.14 & 0.06 & 89.52 & 91.59 & 16.63 & 0.06 \\
\hline DIBCO20173 & manuscrita & 74.57 & 74.83 & 13.00 & 0.07 & 95.35 & 96.35 & 21.40 & 0.12 & 92.20 & 93.20 & 18.97 & 0.07 \\
\hline DIBCO20174 & manuscrita & 66.17 & 66.17 & 12.30 & 0.09 & 88.26 & 88.81 & 18.17 & 0.09 & 84.17 & 84.67 & 16.63 & 0.09 \\
\hline DIBCO20175 & manuscrita & 63.62 & 63.28 & 13.73 & 0.24 & 88.78 & 89.47 & 20.36 & 0.24 & 85.42 & 85.89 & 19.00 & 0.24 \\
\hline DIBCO20176 & manuscrita & 81.80 & 79.83 & 11.02 & 1.21 & 94.04 & 96.78 & 15.80 & 1.21 & 94.34 & 96.80 & 16.01 & 1.21 \\
\hline DIBCO20177 & manuscrita & 79.29 & 76.51 & 10.59 & 0.50 & 93.49 & 95.41 & 15.60 & 0.60 & 93.61 & 95.35 & 15.67 & 0.60 \\
\hline DIBCO20179 & manuscrita & 77.18 & 77.27 & 12.34 & 0.12 & 90.60 & 90.95 & 16.78 & 0.12 & 90.58 & 90.80 & 16.77 & 0.12 \\
\hline DIBCO2009P02 & tipografado & 75.62 & 73.96 & 10.03 & 0.30 & 96.92 & 97.39 & 18.85 & 0.00 & 96.86 & 97.16 & 18.75 & 0.00 \\
\hline DIBCO2009P05 & tipografado & 72.69 & 78.53 & 10.55 & 0.34 & 84.96 & 86.20 & 13.05 & 0.34 & 84.94 & 86.69 & 13.17 & 0.34 \\
\hline DIBCO2011PR1 & tipografado & 61.34 & 62.72 & 9.50 & 0.45 & 75.21 & 75.08 & 11.51 & 0.39 & 77.55 & 77.42 & 12.09 & 0.45 \\
\hline DIBCO2011PR2 & tipografado & 42.92 & 43.07 & 7.95 & 0.26 & 49.80 & 49.80 & 8.71 & 0.15 & 50.30 & 50.30 & 8.81 & 0.15 \\
\hline DIBCO2011PR3 & tipografado & 86.13 & 88.09 & 12.69 & 0.00 & 95.20 & 96.82 & 17.47 & 0.29 & 96.69 & 98.38 & 19.15 & 0.29 \\
\hline DIBCO2011PR4 & tipografado & 78.40 & 74.67 & 12.60 & 0.28 & 94.49 & 97.71 & 19.10 & 0.17 & 95.89 & 98.67 & 20.40 & 0.00 \\
\hline DIBCO2011PR5 & tipografado & 59.59 & 59.77 & 10.10 & 0.14 & 65.52 & 65.49 & 10.85 & 0.17 & 70.31 & 70.27 & 11.85 & 0.17 \\
\hline DIBCO2011PR8 & tipografado & 77.60 & 83.37 & 12.06 & 0.70 & 92.23 & 93.72 & 16.78 & 0.70 & 92.15 & 93.58 & 16.74 & 0.70 \\
\hline DIBCO2013PR01 & tipografado & 66.69 & 66.93 & 13.02 & 0.34 & 94.08 & 95.31 & 22.12 & 0.34 & 89.81 & 90.30 & 19.48 & 0.21 \\
\hline DIBCO2013PR02 & tipografado & 77.02 & 76.95 & 12.78 & 0.29 & 95.11 & 95.58 & 20.42 & 0.18 & 95.22 & 95.64 & 20.52 & 0.29 \\
\hline DIBCO2013PR03 & tipografado & 67.40 & 64.48 & 12.23 & 0.48 & 97.26 & 97.62 & 23.97 & 0.33 & 94.05 & 94.20 & 20.42 & 0.33 \\
\hline DIBCO2013PR04 & tipografado & 76.28 & 67.81 & 11.67 & 0.12 & 96.28 & 96.95 & 20.27 & 0.12 & 95.54 & 96.09 & 19.44 & 0.12 \\
\hline DIBCO2013PR05 & tipografado & 78.38 & 64.18 & 10.82 & 0.14 & 89.17 & 89.59 & 13.55 & 0.00 & 89.09 & 89.47 & 13.51 & 0.17 \\
\hline DIBCO2013PR06 & tipografado & 62.67 & 61.31 & 9.21 & 0.13 & 72.80 & 73.09 & 10.78 & 0.13 & 73.01 & 73.29 & 10.82 & 0.13 \\
\hline DIBCO2013PR08 & tipografado & 74.32 & 75.94 & 12.59 & 0.28 & 76.00 & 76.62 & 12.76 & 0.24 & 93.67 & 94.74 & 19.47 & 0.28 \\
\hline DIBCO201711 & tipografado & 72.75 & 56.21 & 10.87 & 0.18 & 93.83 & 93.81 & 17.47 & 0.20 & 96.58 & 96.56 & 20.16 & 0.10 \\
\hline DIBCO201713 & tipografado & 48.41 & 48.46 & 8.58 & 0.97 & 59.66 & 59.75 & 10.21 & 0.97 & 59.49 & 59.68 & 10.21 & 0.97 \\
\hline DIBCO201715 & tipografado & 75.95 & 79.86 & 10.78 & 0.36 & 86.09 & 86.08 & 13.13 & 0.22 & 88.47 & 88.34 & 14.07 & 0.36 \\
\hline DIBCO201717 & tipografado & 67.09 & 67.46 & 13.14 & 0.13 & 97.17 & 96.43 & 25.35 & 0.11 & 90.44 & 89.93 & 19.73 & 0.15 \\
\hline DIBCO201719 & tipografado & 73.41 & 73.37 & 12.82 & 0.00 & 85.88 & 88.70 & 16.47 & 0.00 & 89.48 & 91.67 & 17.84 & 0.00 \\
\hline DIBCO201720 & tipografado & 78.97 & 81.54 & 12.48 & 0.36 & 83.69 & 85.64 & 13.70 & 0.22 & 90.36 & 92.99 & 16.36 & 0.36 \\
\hline Mé & & 68.82 & 68.27 & 12.32 & 0.35 & 85.8 & 86.7 & 17.74 & 0.33 & 85.66 & 86.35 & 17.49 & 0.34 \\
\hline
\end{tabular}

Tabela 5.4: Caso 3.1: Resultados quantitativos das imagens binarizadas usando as mêtricas do DIBCO para as imagens 71 imagens de teste. 


\begin{tabular}{|c|c|c|c|}
\hline Imagens & $\begin{array}{lll}\begin{array}{l}\text { Texto } \\
\text { manualmente }\end{array} & \text { extraido } \\
\end{array}$ & Texto obtido pelo OCR & Matching \\
\hline 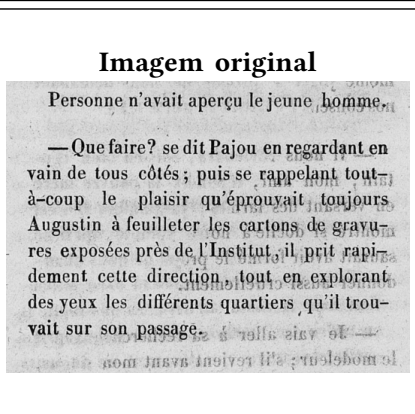 & $\begin{array}{l}\text { Personne n'avait aperçu le jeune } \\
\text { homme-- Que faire? se dit Pajou } \\
\text { en regardant en vain de tous cô- } \\
\text { tés; puis se rappelant tout-à-coup } \\
\text { le plaisir qu'éprouvait toujoursAu- } \\
\text { gustin à feuilleter les cartons de } \\
\text { gravu-red eposées près de l'Institut, } \\
\text { il prit rapi-dement cette direction, } \\
\text { tout en eplorantdes yeu les diffé- } \\
\text { rents quartiers, qu'il trou-vait sur } \\
\text { son passage. }\end{array}$ & $\begin{array}{l}\text { Personne n'avait aperçu le jeune } \\
\text { homme, Que faire? se dit Pajou } \\
\text { en regardant envain de tous } \\
\text { côtés; puis se rappelant tout;à- } \\
\text { coup le plaisir qu'éppauaatt } \\
\text { domine,Augustin à feuilleter les } \\
\text { cartons, de gravu7,res eposées } \\
\text { près de, l'Institut il prit rapi- } \\
\text {.dement cette directic on,,touten, } \\
\text { eplorant,des yeu les différents } \\
\text { quartiers qu'il trou- vait sur son } \\
\text { passage. } 4 \text { ! aiser ar'it } 167 \text { Tge mere }\end{array}$ & $89 \%$ \\
\hline 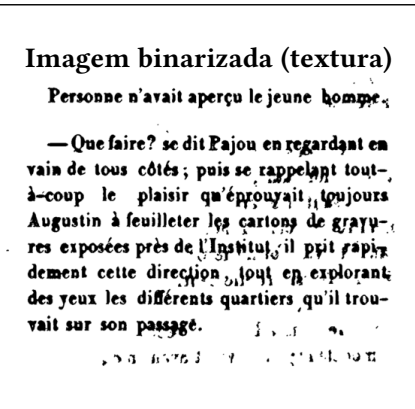 & $\begin{array}{l}\text { Personne n'avait aperçu le jeune } \\
\text { homme.- Que faire? se dit Pajou } \\
\text { en regardant en vain de tous cô- } \\
\text { tés; puis se rappelant tout-à-coup } \\
\text { le plaisir qu'éprouvait toujoursAu- } \\
\text { gustin à feuilleter les cartons de } \\
\text { gravu-red eposées près de l'Institut, } \\
\text { il prit rapi-dement cette direction, } \\
\text { tout en eplorantdes yeu les diffé- } \\
\text { rents quartiers, qu'il trou-vait sur } \\
\text { son passage. }\end{array}$ & $\begin{array}{l}\text { Personne n'avait aperçu le jeune } \\
\text { homme Que faire? se dit Pajou } \\
\text { en regardant envain de tous cô- } \\
\text { tés ; puis se rappelant tout-,à-coup } \\
\text { le plaisir qu'éprouyait, pujoursAu- } \\
\text { gustin à feuilleter les cartons de } \\
\text { grayy-,res eposées près de l'Institut } \\
\text { il pit gapigdement cette direckion } \\
\text { 1199t en eplorantdes yeu les diffé- } \\
\text { rents quartiers qu'il trou-vait sur } \\
\text { son passagé. EL } 54 \text { HG HUTR à O7 } \\
\text { s'aHtLuN }\end{array}$ & $91 \%$ \\
\hline 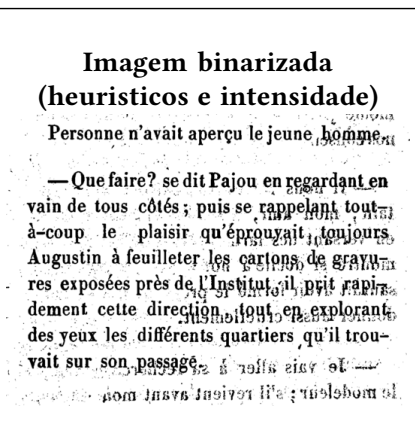 & $\begin{array}{l}\text { Personne n'avait aperçu le jeune } \\
\text { homme.- Que faire? se dit Pajou } \\
\text { en regardant en vain de tous cô- } \\
\text { tés; puis se rappelant tout-à-coup } \\
\text { le plaisir qu'éprouvait toujoursAu- } \\
\text { gustin à feuilleter les cartons de } \\
\text { gravu-red eposées près de l'Institut, } \\
\text { il prit rapi-dement cette direction, } \\
\text { tout en eplorantdes yeu les diffé- } \\
\text { rents quartiers, qu'il trou-vait sur } \\
\text { son passage. }\end{array}$ & $\begin{array}{l}\text { Personne r n "avait aperçu le jeune } \\
\text { orme ;Que faire? : se dit Pajou } \\
\text { en regardant. envain de tous cô- } \\
\text { tés ; ; puis se rappelant toutz Tià- } \\
\text { coup. Je plaisir. qu éprouyait ton } \\
0 \text { njours,Augustin à feuilleter les } \\
\text { sostenn, de } 85 \text { avuTsTes eposées } \\
\text { près de l'Institat oiL;prit Faplge- } \\
\text { dement celte direct, foub,en eplo- } \\
\text { rant des yeu les différents Juarti- } \\
\text { ers, qu'il trou- ait Sur Son-Passagé } \\
\text { moffä sicg a1-por inars-Sasiqes He } \\
\text { suislohorn ci }\end{array}$ & $80 \%$ \\
\hline 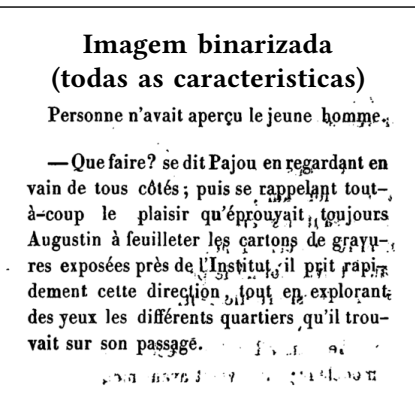 & $\begin{array}{l}\text { Personne n'avait aperçu le jeune } \\
\text { homme-- Que faire? se dit Pajou } \\
\text { en regardant en vain de tous cô- } \\
\text { tés; puis se rappelant tout-à-coup } \\
\text { le plaisir qu'éprouvait toujoursAu- } \\
\text { gustin à feuilleter les cartons de } \\
\text { gravu-red eposées près de l'Institut, } \\
\text { il prit rapi-dement cette direction, } \\
\text { tout en eplorantdes yeu les diffé- } \\
\text { rents quartiers, qu'il trou-vait sur } \\
\text { son passage. }\end{array}$ & $\begin{array}{l}\text { Personne n'avait aperçu le jeune } \\
\text { homme, Que faire? se dit Pajou } \\
\text { en regardant envain de tous cô- } \\
\text { tés ; puis se rappelant tout-,à- } \\
\text { coup le plaisir qu 'éprouyait;, tou- } \\
\text { joursAugustin à feuilleter les car- } \\
\text { tons de grayu-,res eposées près de } \\
\text { L'Institut, il pyit rapizdement cette } \\
\text { direction, out en. eplorant;des yeu } \\
\text { les différents quartiers qu'il trou- } \\
\text { vait sur son passagé. : } 45 \text { aPHA RSR } \\
\text { S } 90 \mathrm{Sa} \mathrm{Hu}\end{array}$ & $92 \%$ \\
\hline
\end{tabular}

Tabela 5.5: Porcentagem de matching(casamento) entre dois textos utilizando distância Levenshtein, onde a partir do texto obtido pelo Tesseract da imagem na primeira coluna e o texto GT feito manualmente se faz a comparação, o resultado é a similaridade entre os textos. Pode-se notar que o texto extraido pelo Tesseract da imagem binarizada com todas as características tem o maior casamento com o texto GT, $92 \%$. 


\begin{tabular}{|c|c|c|c|}
\hline & \multicolumn{3}{|c|}{ Combinação de valores que obtiveram a maior revocação por tipo de característica } \\
\hline Hiper-parâmetros & Características de Textura & Características heurísticas e de intensidade & Ambos tipos de características \\
\hline 'alpha' & 0.001 & $1 \mathrm{e}-06$ & 0.001 \\
\hline 'penalty' & 'elasticnet' & 'l2' & 'l2' \\
\hline 'class_weight' & 'balanced' & 'balanced' & 'balanced' \\
\hline \hline Maior score(revocação) & $\mathbf{0 . 9 1 7}$ & $\mathbf{0 . 9 5 1}$ & $\mathbf{0 . 9 6 2}$ \\
\hline
\end{tabular}

Tabela 5.6: Caso 3.2: Combinação de valores dos hiper-parâmetros que obtiveram a maior revocação por tipo de característica 


\begin{tabular}{|c|c|c|c|c|c|c|c|c|c|c|c|c|c|}
\hline \multirow{2}{*}{ Imagens } & \multirow{2}{*}{ Tipo de imagem } & \multicolumn{4}{|c|}{ Textura } & \multicolumn{4}{|c|}{ Heurísticos e intensidade } & \multicolumn{4}{|c|}{ Todas as características } \\
\hline & & FM & pFM & PSNR & DRD & FM & pFM & PSNR & DRD & FM & pFM & PSNR & DRD \\
\hline DIBCO2009H03 & manuscritas & 75.81 & 76.00 & 12.16 & 0.91 & 90.57 & 91.08 & 17.02 & 0.59 & 88.86 & 89.08 & 16.19 & 0.59 \\
\hline DIBCO2009H04 & manuscritas & 70.18 & 70.13 & 12.13 & 0.70 & 84.60 & 84.90 & 15.79 & 0.70 & 83.33 & 83.43 & 15.35 & 0.70 \\
\hline DIBCO2009H05 & manuscritas & 61.89 & 61.70 & 13.41 & 0.77 & 90.16 & 90.54 & 21.02 & 0.59 & 87.71 & 87.68 & 19.88 & 0.65 \\
\hline DIBCO2010H01 & manuscritas & 77.74 & 77.48 & 12.31 & 0.36 & 95.21 & 96.78 & 19.88 & 0.36 & 92.47 & 93.13 & 17.70 & 0.36 \\
\hline DIBCO2010H02 & manuscritas & 65.44 & 65.30 & 13.32 & 0.36 & 94.89 & 95.57 & 23.31 & 0.36 & 85.31 & 85.31 & 18.20 & 0.36 \\
\hline DIBCO2010H03 & manuscritas & 72.81 & 74.36 & 13.04 & 0.56 & 94.12 & 97.01 & 20.83 & 0.83 & 91.75 & 92.62 & 19.06 & 0.83 \\
\hline DIBCO2010H04 & manuscritas & 74.93 & 75.34 & 12.83 & 0.28 & 93.18 & 93.79 & 19.41 & 0.28 & 90.45 & 90.57 & 17.75 & 0.28 \\
\hline DIBCO2010H06 & manuscritas & 73.11 & 75.05 & 13.76 & 0.76 & 91.13 & 95.22 & 19.60 & 0.55 & 90.55 & 91.77 & 19.00 & 0.55 \\
\hline DIBCO2010H07 & manuscritas & 72.97 & 73.16 & 12.93 & 0.30 & 92.50 & 93.19 & 19.55 & 0.30 & 85.91 & 86.22 & 16.45 & 0.30 \\
\hline DIBCO2010H08 & manuscritas & 72.28 & 74.15 & 12.60 & 0.32 & 93.47 & 94.75 & 19.85 & 0.25 & 85.81 & 86.24 & 16.00 & 0.32 \\
\hline DIBCO2010H09 & manuscritas & 65.18 & 65.88 & 13.23 & 0.57 & 92.66 & 95.43 & 21.64 & 0.12 & 80.88 & 81.38 & 16.67 & 0.57 \\
\hline DIBCO2010H10 & manuscritas & 63.66 & 60.57 & 12.49 & 0.47 & 88.30 & 84.35 & 18.84 & 0.29 & 80.78 & 77.26 & 16.18 & 0.47 \\
\hline DIBCO2011HW1 & manuscritas & 41.57 & 41.81 & 7.52 & 0.28 & 49.73 & 49.73 & 8.23 & 0.28 & 51.13 & 51.15 & 8.50 & 0.28 \\
\hline DIBCO2011HW2 & manuscritas & 42.61 & 42.61 & 11.50 & 0.38 & 70.40 & 70.44 & 16.63 & 0.41 & 66.34 & 66.35 & 15.75 & 0.41 \\
\hline DIBCO2011HW7 & manuscritas & 39.44 & 39.44 & 11.81 & 0.58 & 46.36 & 46.40 & 12.88 & 0.35 & 44.85 & 44.88 & 12.54 & 0.35 \\
\hline DIBCO2012H01 & manuscritas & 57.46 & 58.94 & 12.22 & 0.16 & 95.59 & 95.58 & 22.87 & 0.16 & 93.38 & 93.16 & 20.98 & 0.16 \\
\hline DIBCO2012H06 & manuscritas & 70.00 & 69.66 & 12.62 & 0.37 & 77.43 & 77.69 & 14.21 & 0.22 & 75.92 & 76.04 & 13.82 & 0.22 \\
\hline DIBCO2012H07 & manuscritas & 67.28 & 68.03 & 12.48 & 0.54 & 90.51 & 92.64 & 18.96 & 0.75 & 86.79 & 87.95 & 17.25 & 0.75 \\
\hline DIBCO2012H08 & manuscritas & 71.26 & 71.32 & 12.47 & 0.47 & 87.34 & 87.52 & 16.90 & 0.34 & 86.03 & 86.10 & 16.40 & 0.34 \\
\hline DIBCO2012H11 & manuscritas & 73.28 & 72.54 & 12.24 & 0.28 & 94.92 & 95.65 & 20.62 & 0.28 & 91.36 & 91.34 & 18.06 & 0.10 \\
\hline DIBCO2012H12 & manuscritas & 66.07 & 66.07 & 12.37 & 0.34 & 95.82 & 96.45 & 23.13 & 0.00 & 92.44 & 92.43 & 20.34 & 0.32 \\
\hline DIBC02013HW01 & manuscritas & 61.20 & 60.78 & 13.36 & 0.14 & 93.40 & 93.21 & 23.02 & 0.14 & 89.57 & 88.72 & 20.76 & 0.14 \\
\hline DIBCO2013HW02 & manuscritas & 71.88 & 72.33 & 12.95 & 0.00 & 94.35 & 95.65 & 21.12 & 0.60 & 91.19 & 91.73 & 18.96 & 0.60 \\
\hline DIBCO2013HW03 & manuscritas & 68.67 & 68.59 & 12.47 & 0.27 & 93.58 & 94.48 & 20.78 & 0.19 & 90.47 & 90.44 & 18.83 & 0.19 \\
\hline DIBCO2013HW04 & manuscritas & 67.50 & 65.94 & 13.63 & 0.26 & 84.56 & 84.77 & 17.62 & 0.16 & 83.40 & 83.48 & 17.23 & 0.16 \\
\hline DIBCO2013HW05 & manuscritas & 60.99 & 60.95 & 14.09 & 0.43 & 53.13 & 53.20 & 12.64 & 0.26 & 52.69 & 52.72 & 12.55 & 0.26 \\
\hline DIBCO2013HW06 & manuscritas & 69.34 & 69.27 & 12.43 & 0.08 & 93.99 & 94.46 & 20.73 & 0.03 & 91.79 & 91.88 & 19.24 & 0.03 \\
\hline DIBCO2014H04 & manuscritas & 84.49 & 84.19 & 12.77 & 0.58 & 97.37 & 98.54 & 21.03 & 0.58 & 96.35 & 97.41 & 19.54 & 0.58 \\
\hline DIBCO2014H06 & manuscritas & 76.25 & 70.76 & 10.92 & 0.72 & 94.78 & 95.02 & 17.95 & 0.85 & 93.63 & 93.58 & 17.01 & 0.85 \\
\hline DIBCO2014H09 & manuscritas & 79.19 & 80.24 & 13.03 & 0.14 & 95.03 & 95.95 & 19.98 & 0.24 & 92.74 & 93.24 & 18.18 & 0.24 \\
\hline DIBCO20164 & manuscritas & 77.61 & 77.25 & 14.95 & 0.47 & 92.17 & 96.02 & 20.62 & 0.00 & 92.27 & 95.74 & 20.65 & 0.00 \\
\hline DIBCO20165 & manuscritas & 70.26 & 69.78 & 12.50 & 0.15 & 90.34 & 90.43 & 18.36 & 0.21 & 89.29 & 89.35 & 17.85 & 0.21 \\
\hline DIBCO20167 & manuscritas & 80.78 & 82.28 & 13.48 & 0.32 & 93.16 & 96.73 & 18.67 & 0.42 & 92.77 & 94.49 & 18.25 & 0.42 \\
\hline DIBCO20168 & manuscritas & 64.10 & 61.24 & 8.83 & 0.31 & 74.03 & 74.63 & 10.14 & 0.31 & 76.42 & 77.22 & 10.74 & 0.31 \\
\hline DIBCO201710 & manuscritas & 82.38 & 84.32 & 12.48 & 0.08 & 94.88 & 94.92 & 18.13 & 0.05 & 95.16 & 95.80 & 18.44 & 0.05 \\
\hline DIBCO20171 & manuscritas & 75.29 & 75.25 & 12.43 & 0.05 & 92.39 & 91.88 & 18.30 & 0.05 & 88.28 & 87.83 & 16.20 & 0.05 \\
\hline DIBCO20173 & manuscritas & 72.99 & 73.18 & 12.63 & 0.07 & 94.46 & 95.66 & 20.59 & 0.07 & 91.29 & 92.03 & 18.42 & 0.07 \\
\hline DIBCO20176 & manuscritas & 82.21 & 79.95 & 11.04 & 1.21 & 93.98 & 96.61 & 15.74 & 1.21 & 93.42 & 96.79 & 15.39 & 1.21 \\
\hline DIBCO20178 & manuscritas & 74.86 & 74.62 & 12.82 & 0.51 & 90.57 & 95.51 & 18.37 & 0.00 & 90.48 & 93.15 & 18.12 & 0.00 \\
\hline DIBCO20179 & manuscritas & 76.35 & 76.30 & 12.10 & 0.12 & 90.60 & 90.95 & 16.78 & 0.12 & 89.32 & 89.21 & 16.10 & 0.12 \\
\hline DIBCO2009P01 & tipografadas & 75.30 & 77.54 & 11.37 & 0.34 & 92.31 & 92.90 & 17.06 & 0.64 & 91.77 & 92.28 & 16.73 & 0.64 \\
\hline DIBCO2009P02 & tipografadas & 75.01 & 73.19 & 9.83 & 0.37 & 96.80 & 97.18 & 18.67 & 0.53 & 96.61 & 97.21 & 18.42 & 0.53 \\
\hline DIBCO2009P03 & tipografadas & 63.88 & 65.29 & 9.07 & 0.71 & 97.06 & 97.42 & 19.88 & 0.47 & 95.81 & 96.29 & 18.34 & 0.47 \\
\hline DIBCO2009P04 & tipografadas & 73.28 & 73.71 & 11.52 & 0.50 & 92.34 & 92.92 & 17.68 & 0.30 & 90.65 & 91.07 & 16.72 & 0.30 \\
\hline DIBCO2009P05 & tipografadas & 72.46 & 78.04 & 10.47 & 0.34 & 84.96 & 86.20 & 13.05 & 0.34 & 85.49 & 87.94 & 13.40 & 0.34 \\
\hline DIBCO2011PR1 & tipografadas & 60.10 & 61.44 & 9.25 & 0.45 & 75.21 & 75.08 & 11.51 & 0.39 & 76.51 & 76.44 & 11.75 & 0.45 \\
\hline DIBCO2011PR2 & tipografadas & 42.25 & 42.37 & 7.77 & 0.26 & 49.80 & 49.80 & 8.71 & 0.15 & 51.34 & 51.36 & 9.03 & 0.15 \\
\hline DIBCO2011PR3 & afadas & 85.40 & 86.91 & 12.37 & 0.00 & 95.20 & 96.82 & 17.47 & 0.29 & 94.93 & 97.88 & 17.34 & 0.29 \\
\hline DIBCO2011PR4 & tipografadas & 76.77 & 73.44 & 12.15 & 0.29 & 94.49 & 97.71 & 19.10 & 0.17 & 94.91 & 96.46 & 19.31 & 0.17 \\
\hline DIBCO2011PR5 & tipografadas & 58.71 & 58.80 & 9.88 & 0.14 & 65.52 & 65.49 & 10.85 & 0.17 & 66.61 & 66.58 & 11.06 & 0.17 \\
\hline DIBCO2011PR6 & tipografadas & 58.89 & 56.00 & 12.49 & 0.60 & 56.57 & 56.72 & 11.30 & 0.36 & 55.08 & 55.14 & 11.01 & 0.36 \\
\hline DIBCO2011PR7 & tipografadas & 59.66 & 59.65 & 14.77 & 7.73 & 87.90 & 88.62 & 21.76 & 6.55 & 84.25 & 84.48 & 20.37 & 6.55 \\
\hline DIBCO2011PR8 & tipografadas & 77.13 & 82.19 & 11.86 & 0.70 & 92.23 & 93.72 & 16.78 & 0.70 & 92.20 & 93.67 & 16.74 & 0.70 \\
\hline DIBCO2013PR01 & tipografadas & 65.90 & 66.09 & 12.85 & 0.34 & 94.07 & 95.27 & 22.10 & 0.21 & 89.10 & 89.47 & 19.14 & 0.21 \\
\hline DIBCO2013PR02 & tipografadas & 75.69 & 75.64 & 12.45 & 0.29 & 95.11 & 95.58 & 20.42 & 0.18 & 91.84 & 92.05 & 18.02 & 0.18 \\
\hline DIBCO2013PR03 & tipografadas & 66.49 & 63.66 & 12.04 & 0.48 & 97.26 & 97.62 & 23.97 & 0.33 & 93.72 & 93.88 & 20.16 & 0.33 \\
\hline DIBCO2013PR04 & tipografadas & 74.62 & 66.48 & 11.27 & 0.12 & 96.28 & 96.95 & 20.27 & 0.12 & 93.61 & 93.91 & 17.75 & 0.12 \\
\hline DIBCO2013PR05 & tipografadas & 77.09 & 63.23 & 10.48 & 0.15 & 89.08 & 89.48 & 13.51 & 0.00 & 94.91 & 96.37 & 17.19 & 0.17 \\
\hline DIBCO2013PR06 & tipografadas & 61.21 & 59.76 & 8.91 & 0.13 & 72.80 & 73.09 & 10.78 & 0.13 & 73.49 & 73.96 & 10.95 & 0.13 \\
\hline DIBCO2013PR07 & tipografadas & 81.89 & 85.56 & 10.90 & 0.00 & 96.66 & 97.53 & 18.45 & 0.00 & 95.03 & 97.84 & 16.82 & 0.00 \\
\hline DIBCO2013PR08 & tipografadas & 73.39 & 74.75 & 12.35 & 0.28 & 76.00 & 76.62 & 12.76 & 0.24 & 77.21 & 77.73 & 13.03 & 0.24 \\
\hline DIBCO201711 & tipografadas & 72.00 & 56.62 & 10.63 & 0.19 & 93.83 & 93.81 & $\mathbf{1 7 . 4 7}$ & 0.20 & 91.78 & 91.78 & 16.13 & 0.11 \\
\hline DIBCO201712 & tipografadas & 65.91 & 67.21 & 10.47 & 0.23 & 81.49 & 81.51 & 13.79 & 0.14 & 80.25 & 80.27 & 13.44 & 0.14 \\
\hline DIBCO201713 & tipografadas & 47.23 & 47.19 & 8.34 & 0.97 & 59.66 & 59.75 & 10.21 & 0.97 & 60.19 & 60.28 & 10.31 & 0.97 \\
\hline DIBCO201714 & tipografadas & 61.38 & 62.30 & 10.43 & 0.41 & 77.64 & 77.65 & 13.61 & 0.21 & 75.47 & 75.48 & 13.08 & 0.21 \\
\hline DIBCO201715 & tipografadas & 75.83 & 78.97 & 10.65 & 0.36 & 86.09 & 86.08 & 13.13 & 0.22 & 88.68 & 89.00 & 14.21 & 0.36 \\
\hline DIBCO201716 & tipografadas & 67.43 & 67.27 & 12.83 & 0.21 & 94.27 & 94.30 & 21.79 & 0.13 & 89.66 & 89.67 & 19.01 & 0.13 \\
\hline DIBCO201717 & tipografadas & 65.34 & 65.58 & 12.78 & 0.15 & 96.78 & 96.18 & 24.76 & 0.15 & 89.68 & 89.19 & 19.36 & 0.15 \\
\hline DIBCO201718 & tipografadas & 71.99 & 73.54 & 11.49 & 0.00 & 82.42 & 85.47 & 14.18 & 0.00 & 81.88 & 84.24 & 13.95 & 0.00 \\
\hline DIBCO201719 & tipografadas & 72.25 & 72.17 & 12.55 & 0.00 & 85.88 & 88.70 & 16.47 & 0.00 & 84.74 & 86.13 & 15.92 & 0.00 \\
\hline DIBCO201720 & tipografadas & 77.98 & 80.18 & 12.19 & 0.36 & 83.69 & 85.64 & 13.70 & 0.22 & 84.69 & 86.78 & 14.04 & 0.22 \\
\hline Méc & & 69,07 & 68,75 & 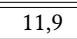 & 0,46 & 86,69 & 87,54 & $\overline{17,56}$ & 0,39 & 84,85 & 85,40 & $\overline{16,44}$ & 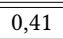 \\
\hline
\end{tabular}

Tabela 5.7: Caso 3.2: Resultados quantitativos das imagens binarizadas usando as mêtricas do DIBCO para as imagens 71 imagens de teste, onde 40 são manuscritas e 31 tipografadas. 


\subsection{Comparação e análise de Resultados}

Nesta seção vamos fazer a comparação dos resultados dos seis classificadores analisados até agora (5.2.1 e 5.2.2) segundo a performance das métricas do DIBCO e segundo a performance com o OCR, mas num mesmo conjunto de testes, um conjunto menor, para não usar nenhuma imagem usada no treinamento. Foi usado um conjunto de 49 imagens (28 manuscritas e 21 tipografadas) para o conjunto de testes. Utilizamos gráficos do tipo boxplot para apresentar os resultados das métricas do DIBCO com valores extraidos da Tabela 5.4 para o Caso 3.1 e da Tabela 5.7 para o Caso 3.2 para as 49 imagens que não foram usadas para treinamento em nenhum dos casos. $\mathrm{O}$ mesmo foi feito para os resultados de casamento de texto dos resultados do OCR.

\subsubsection{Desempenho segundo as métricas do DIBCO}

Primeiramente vamos apresentar a comparação segundo as métricas do DIBCO.

A Figura 5.5 apresenta a comparação dos classificadores do Caso 3.1 e do Caso 3.2 utilizando a métrica F-Measure (FM). Note que para ambos casos testados, os classificadores que foram treinados com o conjunto de características "heuristicos e intensidade" conseguiram os melhores resultados.
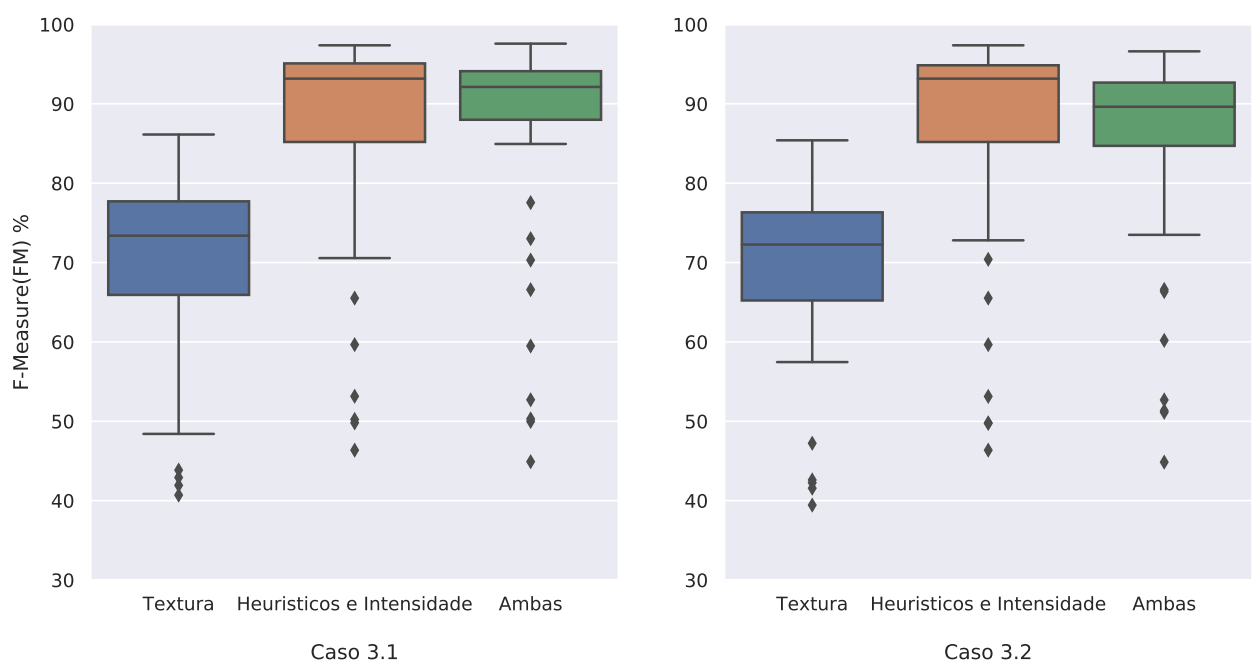

Figura 5.5: Desempenho dos classificadores segundo F-Measure (\%)( $\uparrow)$

As Figuras 5.6 e 5.7 apresentam comparações dos classificadores segundo as métricas Pseudo-FMeasure (pFM) e Peak Signal to Noise Ratio (PSNR), respectivamente. Uma vez mais, os melhores resultados foram para o conjunto de características "heuristicos e intensidade".

A Figura 5.8 apresenta a comparação do desempenho dos classificadores segundo a métrica Distance Reciprocal Distortion (DRD). Em ambos casos obtiveram-se medidas DRD 

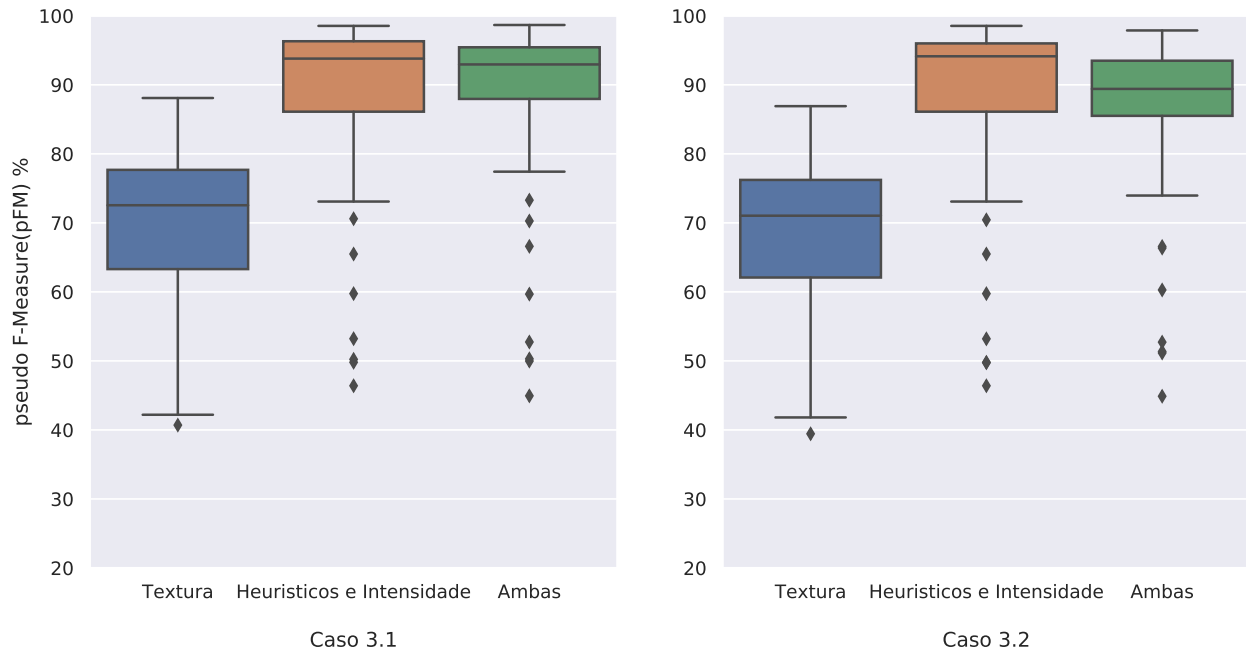

Figura 5.6: Desempenho dos classificadores segundo Pseudo-FMeasure (\%)( $\uparrow)$
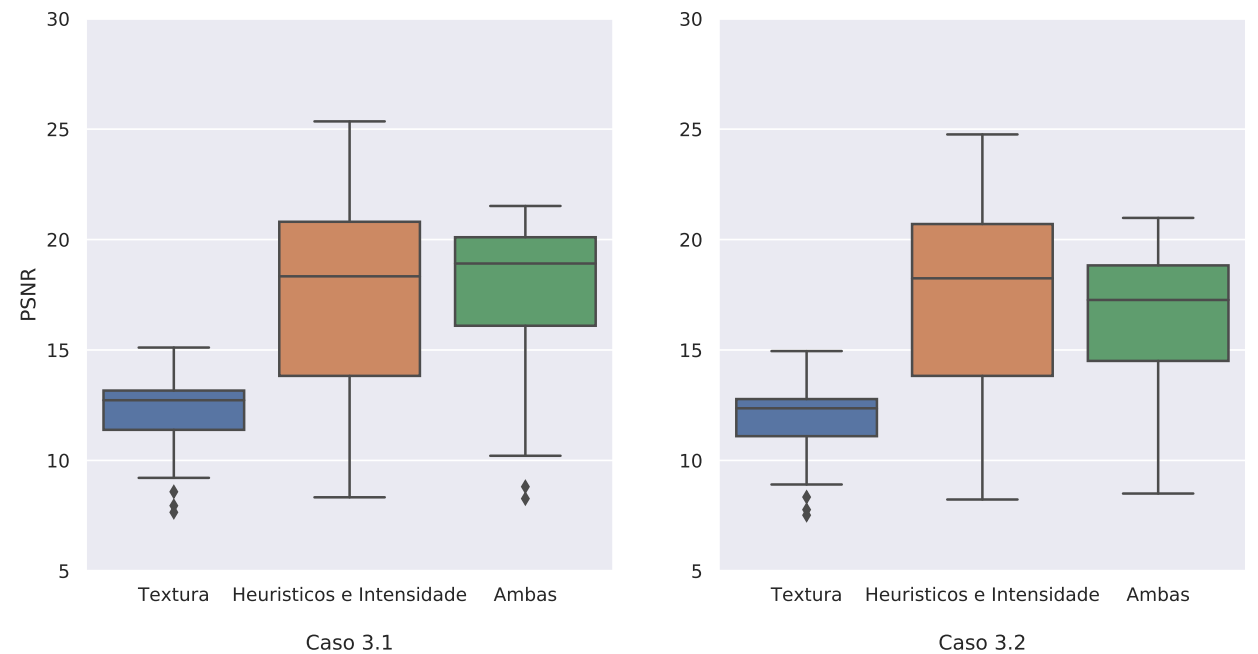

Figura 5.7: Desempenho dos classificadores segundo Peak Signal to Noise Ratio( $\uparrow)$

parecidas, porém no Caso 3.1 a mediana do conjunto de características "heuristicos e intensidade" é menor.

\subsubsection{Desempenho segundo o Tesseract(OCR)}

A comparação das porcentagens de casamento dos textos extraídos pelo OCR com os textos do GT foram feitas apenas para as imagens tipografadas no conjunto das imagens que não foram usadas no treinamento, ou seja, em 21 imagens tipografadas. A comparação com o OCR das imagens originais também foi feita. Os resultados são apresentados em gráficos do tipo boxplot na Figura 5.9.

Note que no Caso 3.1, para o classificador com o conjunto de características "ambas" 

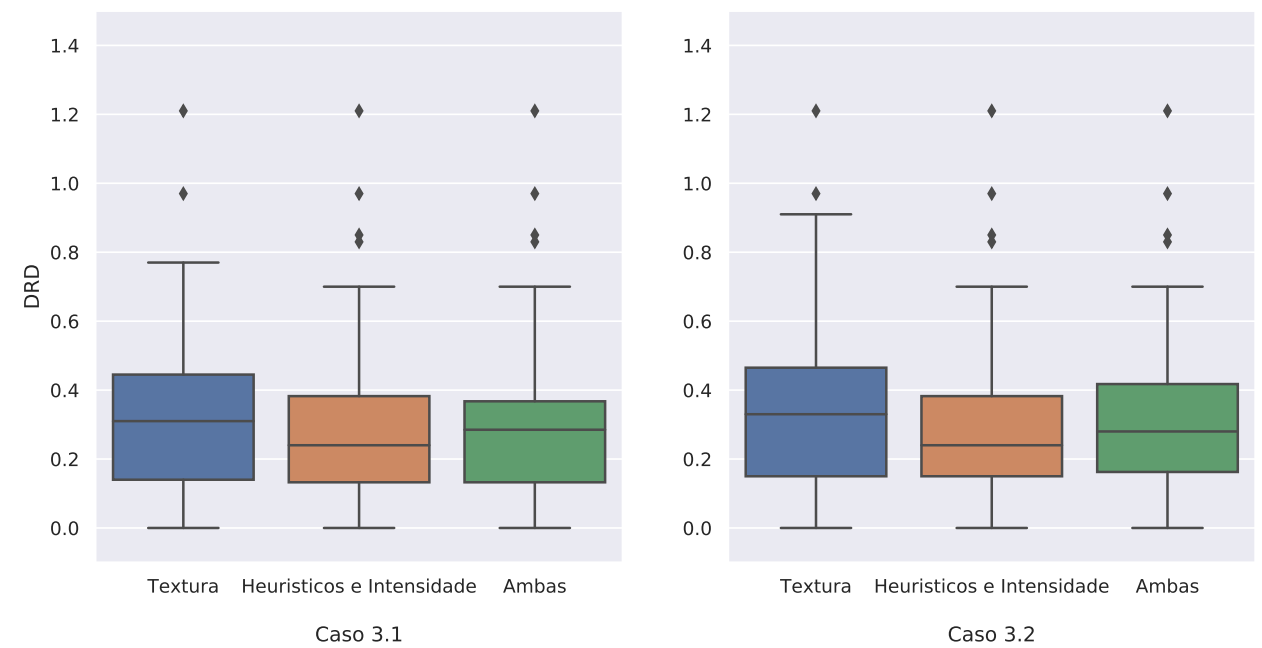

Figura 5.8: Desempenho dos classificadores segundo Distance Reciprocal Distortion Metric $(\downarrow)$

obteve-se o melhor resultado (mediana acima do $90 \%$ e pequena variância dos resultados). Pode-se concluir que o reconhecimento de texto a partir da imagem binaria é melhor do que a imagem original ou em níveis de cinza.
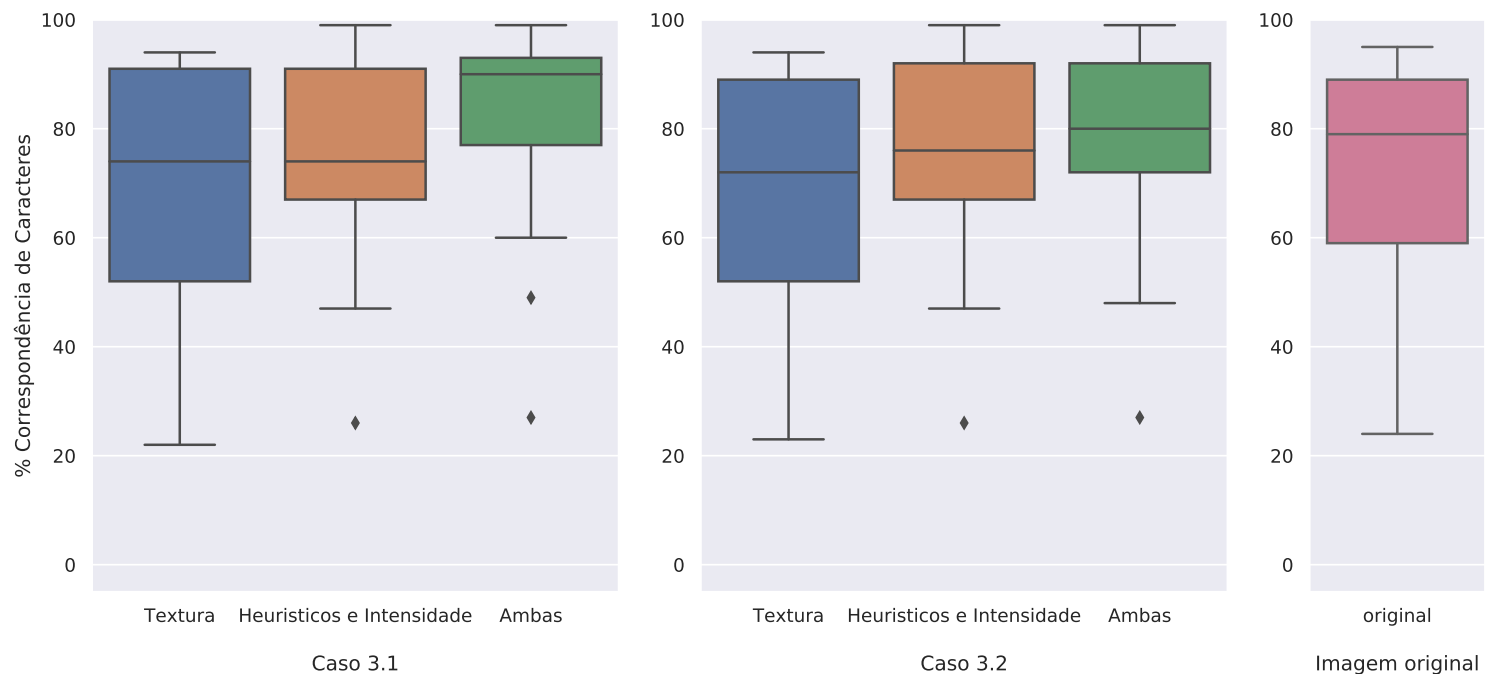

Figura 5.9: Comparação das porcentagens de casamento dos textos extraídos pelo Tesseract das imagens binarias tipografadas obtidos por cada classificador para os Casos 3.1 e 3.2, e também a comparação do texto extraido diretamente da imagem original

Portanto, o desempenho dos classificadores pode ser resumido da seguinte maneira:

- Segundo as métricas do DIBCO, o classificador treinado com o conjunto de características "heuristicos e intensidade", tanto no Caso 3.1 quanto no Caso 3.2 conseguem o melhor desempenho. 
- Segundo o OCR, o classificador treinado com o conjunto de características "ambas" no Caso 3.1, consegue o melhor casamento de texto.

\subsection{Comparação com os métodos do estado da arte}

Nesta seção apresentamos a comparação do método proposto com os métodos do estado da arte, quais sejam:

- Otsu (Otsu, 1979)

- Niblack (Niblack, 1985)

- Sauvola (Sauvola e Pietikäinen, 2000)

- Su (Su et al., 2013)

- Howe (Howe, 2013)

Comparamos usando as métricas DIBCO e, também, usamos o OCR.

\subsubsection{Segundo as métricas DIBCO}

O classificador escolhido para esta comparação foi treinado com o conjunto de características "heuristicos e intensidade", do Caso 3.1, pelo seu melhor desempenho. A Figura 5.10 apresenta o F-Measure para os métodos do estado da arte e também para o método proposto. Os métodos que conseguem os maiores valores são de Howe e o proposto.

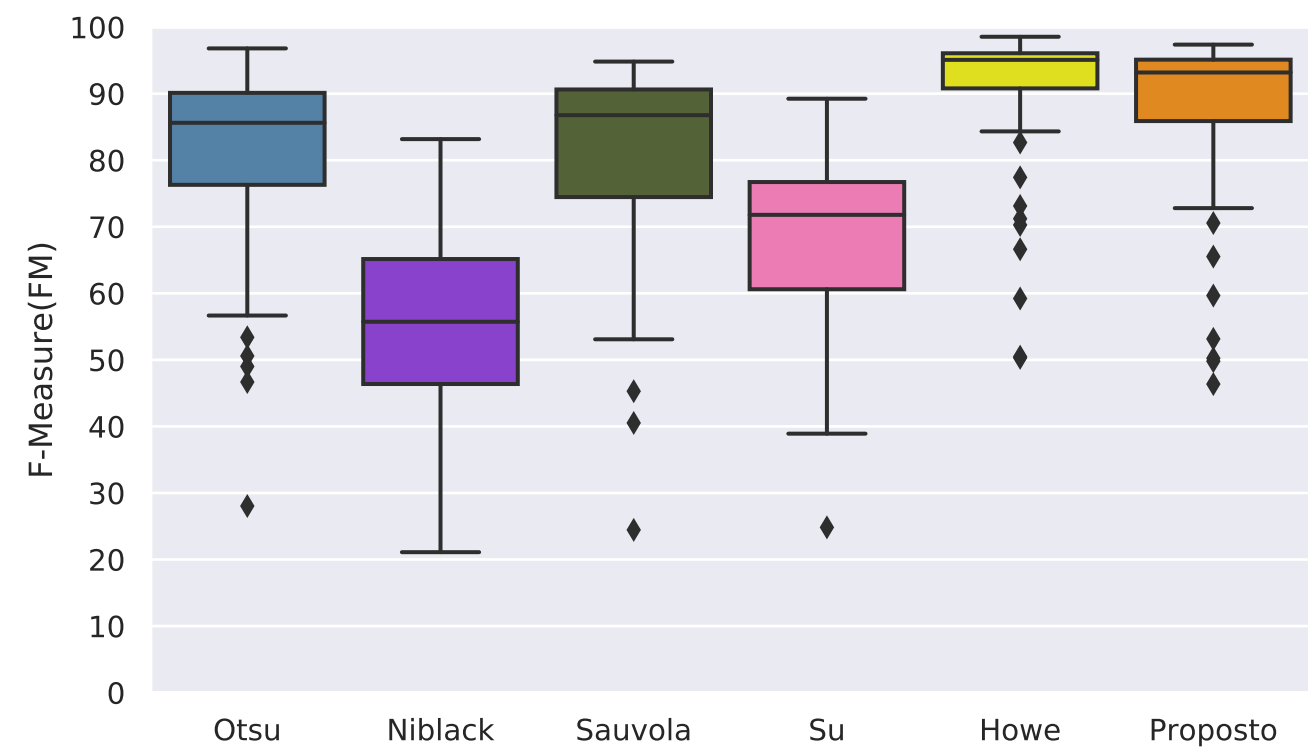

Figura 5.10: Desempenho dos métodos do estado de arte e o proposto segundo o $F M(\%)(\uparrow)$ 
Segundo o Pseudo-FMeasure, pode-se observar na Figura 5.11 que se conseguiram valores semelhantes entre o Howe e o método proposto.

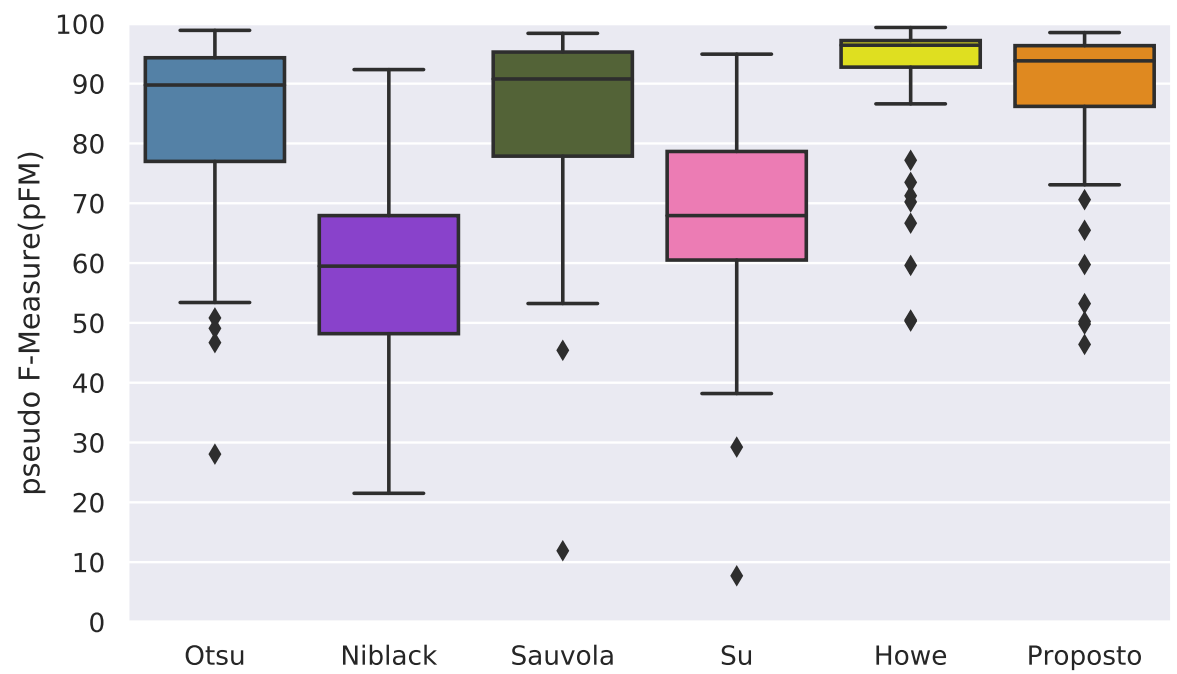

Figura 5.11: Desempenho dos métodos do estado da arte e o proposto segundo o PseudoFM(pFM)(\%)( $\uparrow)$

A Figura 5.12 apresenta o desempenho dos métodos segundo o Peak Signal to Noise Ratio, obtendo o melhor desempenho o método de Howe.

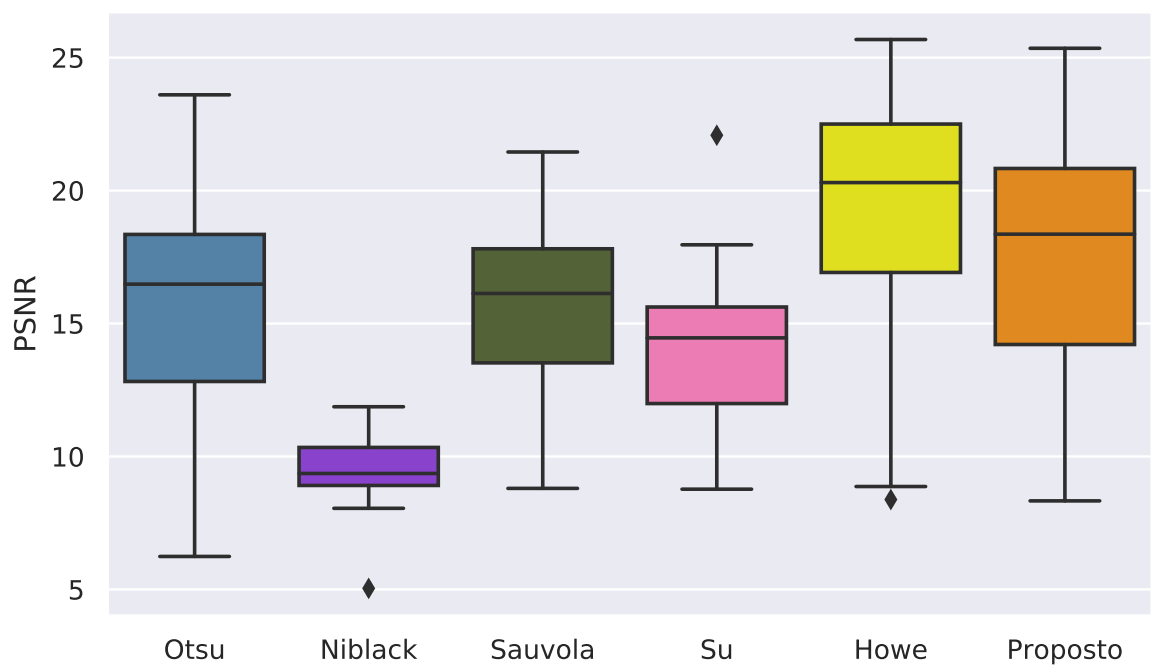

Figura 5.12: Comparação dos metodos do estado da arte e o proposto segundo o PSNR( $\uparrow)$ 


\subsubsection{Segundo o OCR}

Para esta comparação selecionamos o classificador que foi treinando com o conjunto de características "ambas" (todas as características), do Caso 3.1 como método proposto, por ter a melhor performance. A Figura 5.13 apresenta que tanto o método proposto quanto o Howe conseguem a melhor porcentagem de casamento de caracteres dos textos a partir de imagens binarizadas.

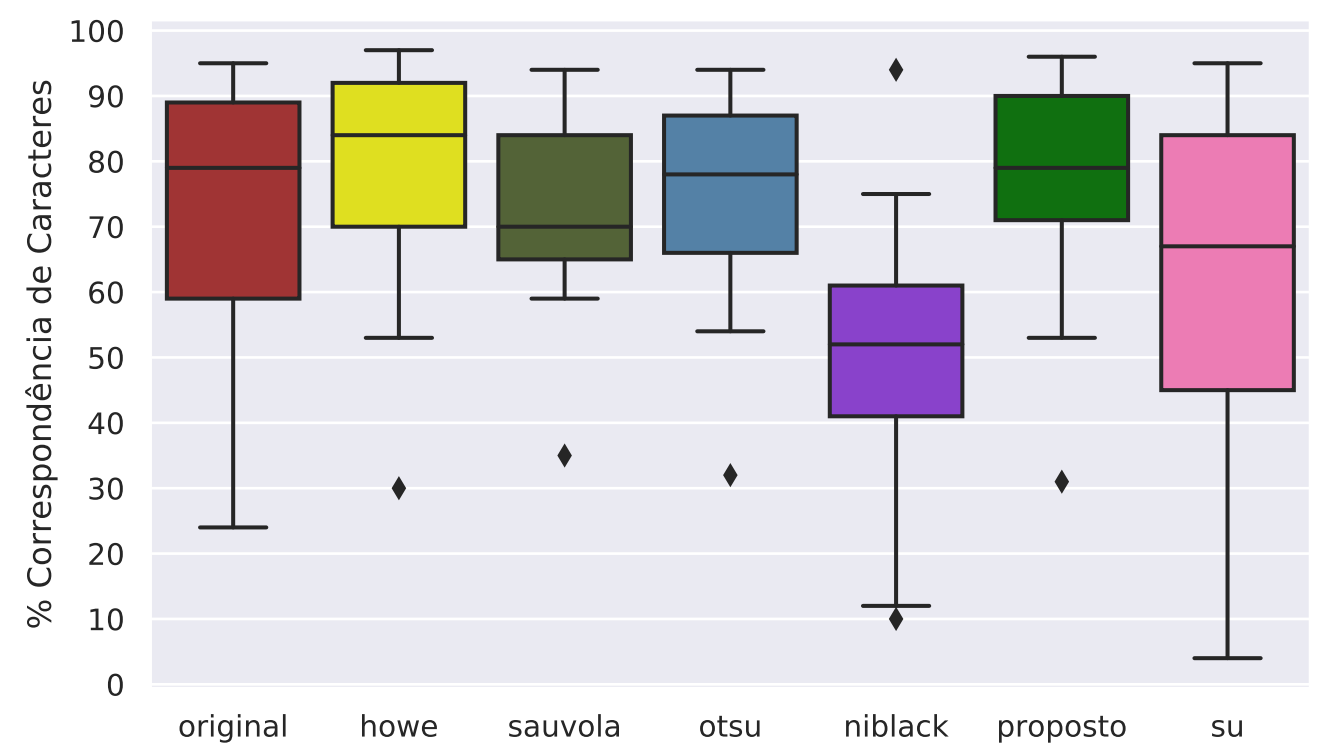

Figura 5.13: Porcentagem de casamento de texto obtido do método proposto e os métodos do estado da arte.

\subsection{Discussão de resultados}

Na comparação do método proposto com os métodos do estado da arte na Seção 5.4, observamos que o método proposto tem resultados semelhantes com o método do Howe tanto nas métricas do DIBCO quanto no OCR. Isto acontece pelo seguinte:

- Usamos um classificador linear, o SVM Linear, onde os parâmetros aprendidos dos modelos ajustados foram:

- Para o classificador que foi treinado com o conjunto de características "heuristicos e intensidade" do Caso 3.1, que obteve a melhor performance com respeito às métricas do $\mathrm{DIBCO}$, que denotamos por:

$$
A(x)=W^{T} X+b
$$


isto é:

$$
A(x)=\left[\begin{array}{c}
-0.0050857 \\
-0.0326264 \\
0.0 \\
-0.4866466 \\
-0.1645731 \\
-0.5746861
\end{array}\right]^{T}\left[\begin{array}{c}
f(x) \\
X^{O t s u}(f)(x) \\
X^{N i b k}(f)(x) \\
X^{S a u}(f)(x) \\
X^{S u}(f)(x) \\
X^{H o}(f)(x)
\end{array}\right]+(-0.70614297)
$$

O $W$ representa a importância de cada um das características em termos de contribuição global. Como pode-se ver, o Howe $\left(X^{H o}(f(x))\right)$ tem o maior peso, por isso é que os resultados do método proposto se aproximam dele. Junto ao Sauvola $\left(X^{\operatorname{Sau}}(f(x))\right)$ e ao $\operatorname{Su}\left(X^{S u}(f(x))\right)$, eles são as três melhores características em termos de contribuição para o modelo.

- Para o classificador que foi treinado com o conjunto de características "ambas" (todas as características, que são, a textura,a intensidade e os heurísticos) do Caso 3.1, ele obteve a melhor performance segundo o OCR, denotado por:

$$
B(x)=W^{T} X+b
$$

isto é:

$$
B(x)=\left[\begin{array}{c}
-0.0000942 \\
-0.0001234 \\
-0.0000424 \\
-0.2656394 \\
-0.1813072 \\
-0.5339285 \\
0.1537787 \\
-0.0868955 \\
-0.0565564
\end{array}\right]^{T}\left[\begin{array}{c}
f(x) \\
X^{O t s u}(f)(x) \\
X^{N i b k}(f)(x) \\
X^{S a u}(f)(x) \\
X^{S u}(f)(x) \\
X^{H o}(f)(x) \\
X^{R I(-1)}(f)(x) \\
X^{R D I}(0)(f)(x) \\
X^{R D I}(1)(f)(x)
\end{array}\right]+(-0.67905)
$$

No caso do modelo $B(x)$, o Howe $\left(X^{H o}(f)(x)\right)$ tem novamente o maior peso na contribuição global. Por isso que o modelo proposto tem resultados muito parecidos com o método do Howe. Seguem o Sauvola $\left(X^{\operatorname{Sau}}(f)(x)\right)$, o $\mathrm{Su}\left(X^{S u}(f)(x)\right)$ e o Random Darkness Index $(-1)\left(X^{R D I(-1)}(f)(x)\right)$ como as melhores características em termos de contribuição.

Nos dois modelos, o maior peso é do Howe, fazendo que os resultados da comparação dos métodos do estado da arte e nosso método proposto são muito parecidos.

- Notamos que, uma imagem binarizada a partir do modelo $B(x)$, obtém melhor performance segundo o OCR, quer dizer, o texto extraido pelo Tesseract é melhor pois obtem uma porcentagem de casamentos mais alta, mesmo não obtendo os melhores resultados segundo as métricas do DIBCO. Isto acontece porque o modelo deste classificador tem um peso considerável para a característica de textura Random Darkness Index $(-1)\left(X^{R D I(-1)}(f)(x)\right)$ que resalta os caracteres do texto (Figura 3.2), então a imagem binarizada fica melhor definida.

A Figura 5.14 apresenta binarizações a partir de uma imagem tipografada que 
apreesenta um carimbo no fundo. Note que o método de Otsu não consegue tirar o carimbo; o Niblack obtém o texto mais limpo porém com muito ruído no fundo; o Sauvola também não consegue tirar o carimbo; no entanto o Su, o Howe e nosso método conseguem tirar o carimbo, sendo que o Howe remove também pixeis do texto. A vantagem do método proposto sobre o Su é que ele consegue devolver um texto mais bem definido.

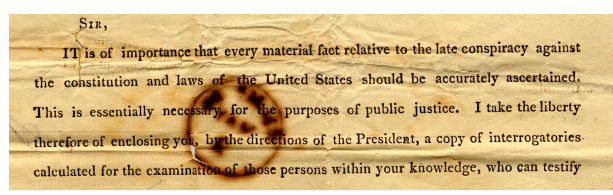

(a) Imagem tipografada

$$
\text { Sir, }
$$

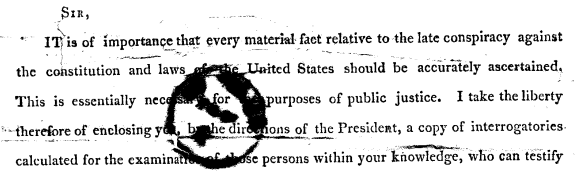

(c) Otsu

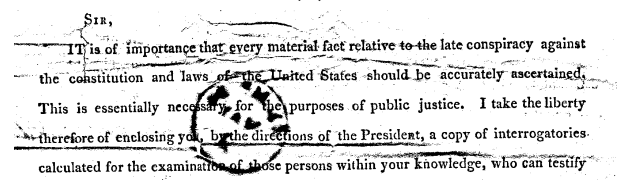

(e) Sauvola

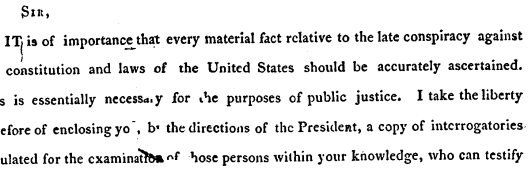

(g) Howe

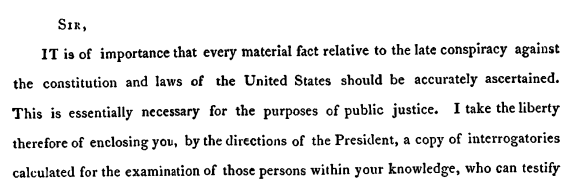

(b) $G T$

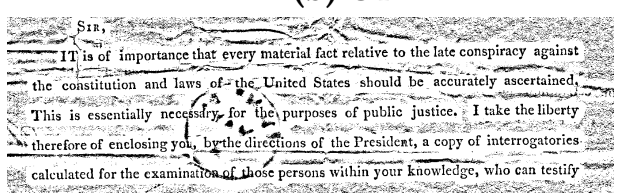

(d) Niblack (f) $\mathrm{Su}$

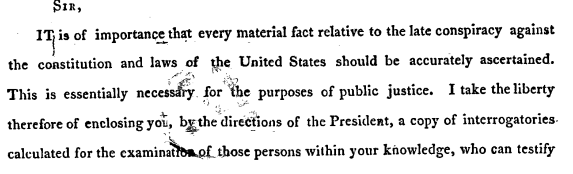

(h) Proposto

Figura 5.14: Imagem tipografada, o seu Ground Truth e as suas binarizações pelos métodos do estado da arte e o método proposto.

A Tabela 5.8 apresenta o desempenho do método proposto em relação aos métodos do estado de arte com respeito ao OCR. A primeira coluna apresenta os métodos, a segunda coluna as imagens, a terceira coluna os resultados das métricas DIBCO, a quarta coluna o texto extraído pelo OCR e a quinta coluna o resultado do casamento com o GT. Note que embora o método do Howe consiga maiores valores nas métricas do DIBCO, o método Proposto consegue reconhecer melhor o texto pois consegue um casamento maior, assim como o Otsu. 


\begin{tabular}{|c|c|c|c|c|}
\hline Método & Imagens & $\begin{array}{l}\text { Métricas } \\
\text { do DIBCO }\end{array}$ & Texto obtido pelo OCR & Matching \\
\hline $\begin{array}{l}\text { Imagem } \\
\text { original }\end{array}$ & 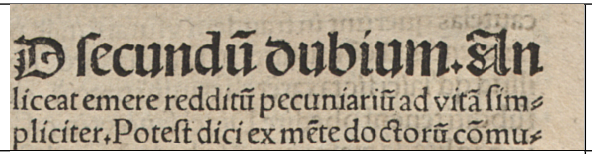 & & $\begin{array}{l}\text { 3» fecundü. oubíum.sin líceat } \\
\text { emere reddítii pecuníarittad } \\
\text { vita fímz plícíter,Poteft díci ex } \\
\text { métedoctorü comu» }\end{array}$ & $76 \%$ \\
\hline Otsu & 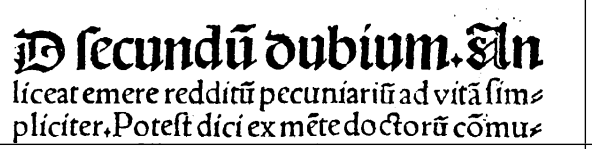 & $\begin{array}{c}F M: 96.60 \\
\text { pFM: } \mathbf{9 8 . 4 9} \\
P S N R: 18.54\end{array}$ & $\begin{array}{l}\text { D secundii dubiumxIln } \\
\text { liceat emere reddirä pecunjariä } \\
\text { ad vitä Hm- pliciter.P9xeft·dici ex } \\
\text { mäte do ckko rä c6"mu- }\end{array}$ & $79 \%$ \\
\hline Niblack & 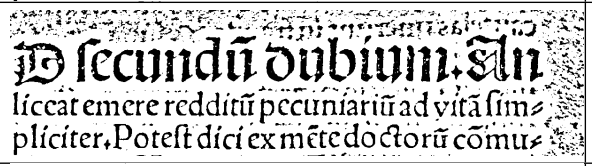 & $\begin{array}{c}F M: 78.96 \\
\text { PFM: } 85.44 \\
P S N R: 10.45\end{array}$ & $\begin{array}{l}\text { ji« «« "7 NOT-km Kost-: } \\
\text { D sccundu dulnunz.Mk« } \\
\text { liccåt emcre kcddttsi pccuniariä ad } \\
\text { vitäfijjp "plicitenpgteft dick emecc } \\
\text { do Zions cöhujz } \\
\end{array}$ & $57 \%$ \\
\hline Sauvola & 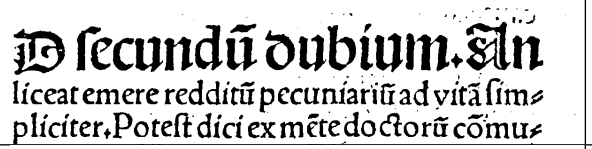 & $\begin{array}{c}F M: 94.82 \\
\text { pFM: } 97.17 \\
P S N R: 16.67\end{array}$ & $\begin{array}{l}\text { ZB secundu dubxumksjjn liceak } \\
\text { emere reddikii pecuniakiä ad vitä } \\
\text { Hm- p licirenpqxefkdici ex m } \\
\text { Ecgjdo dorä c6««m u- }\end{array}$ & $68 \%$ \\
\hline Su & 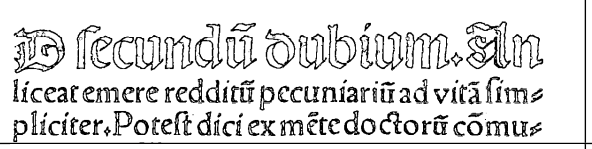 & $\begin{array}{c}F M: 74.80 \\
\text { PFM: } 68.03 \\
P S N R: 10.67\end{array}$ & $\begin{array}{l}\text { FB ALTMde INDEMNITij liceac } \\
\text { emere reddlxrcfr pecuniairää ad } \\
\text { vjtä Em- plljcikerkppxelkchi ex } \\
\text { mste dodo rä chuH }\end{array}$ & $56 \%$ \\
\hline Howe & 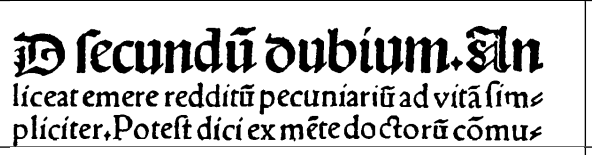 & $\begin{array}{c}\text { FM: } \mathbf{9 6 . 9 2} \\
\text { pFM: } 97.39 \\
\text { PSNR: 18.85 }\end{array}$ & $\begin{array}{l}\text { D secundsi dahin-usw } \\
\text { liceat emere redditci pecuniariä } \\
\text { ad vitä Hm- plicitenpoteft dici ex } \\
\text { mZte do dort-I estim- }\end{array}$ & $74 \%$ \\
\hline Proposto & 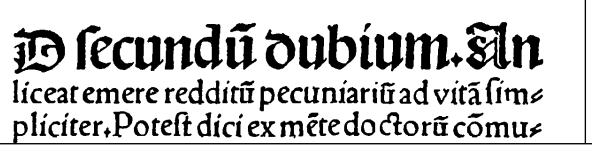 & $\begin{array}{c}F M: 96.80 \\
\text { pFM: } 97.18 \\
P S N R: 18.67\end{array}$ & $\begin{array}{l}\text { D secundsi dubium.I-1n } \\
\text { liceak emere redditki pecuniariä } \\
\text { ad vitä Hm- plicitenpoteft dici ex } \\
\text { mZte do dort-i cömu- }\end{array}$ & $79 \%$ \\
\hline
\end{tabular}

Tabela 5.8: Binarização de uma imagem tipografada pelo método proposto e os métodos do estado da arte, o desempenho dos métodos segundo as métricas do DIBCO a partir, o texto extraido pelo Tesseract a partir das imagens correspondentes, e o resultado do casamento com o texto GT. 


\section{Capítulo 6}

\section{Conclusões}

Neste trabalho, estudamos o estado da arte para resolver o problema de segmentação (binarização) de imagens de documentos antigos. Implementamos alguns dos melhores métodos heurísticos, que geralmente resolvem o problema para certas imagens de entrada e que precisam de ajuste de parâmetros, assim como alguns métodos de aprendizado, que requerem conjuntos de testes padronizados e dados ground truth.

A solução proposta baseia-se no aprendizado de máquina utilizando métodos heuristicos com a finalidade de melhorar o resultado da binarização, e descritores de textura baseado em uma propriedade intrínsica chamada de Relative Darkness Index dos Padrões Locais Ternarios.

O resultado do método proposto foi avaliado em termos de métricas padronizadas da competição mundial de binarização de documentos (DIBCO) e, também em termos de um sistema OCR. Isto é, o método de binarização proposto é integrado como uma etapa preliminar num sistema OCR.

Para tornar possível a avaliação pelo OCR, foi criado os ground truth dos textos a partir da transcrição manual dos documentos de testes tipografados. O idioma dos textos não estão apenas em inglês, mas também em outros idiomas como, o alemão fraktur, o latim, o holandês, o francês, o esloveno, o croata e o inglês.

Foi mostrado que com as características dos métodos heurísticos, os resultados da segmentação tem bom desempenho segundo as métricas do DIBCO, mas nem sempre são os melhores em termos do OCR. Isso quer dizer as métricas de avaliação do DIBCO para imagens binarizadas não se correlacionam totalmente com o desempenho real no OCR.

Adicionar descritores de textura, o Relative Darkness Index, especificamente o $X^{R D I(-1)}(f(x))$, melhora o desempenho do OCR em termos de texto reconhecido em aproximadamente $10 \%$ quando o classificador é treinado tanto com imagens manuscritas, quanto com imagens tipografadas.

Utilizar o método proposto de binarização como etapa preliminar num sistema OCR, como o Tesseract, aumenta o reconhecimento de caracteres em aproximadamente $5 \% \mathrm{em}$ relação ao reconhecimento de caracteres a partir da imagem original. 
Verificou-se que a solução proposta obteve melhor desempenho em relação às métricas do DIBCO quando se trabalha apenas com características heurísticas e intensidade, obtendo um F-Measure(FM) em média 86, 51\% e mediana de 93, 18\%, um Pseudo-FMeasure(pFM) em média de 87,35\% e mediana de 93, 81, um PSNR em média de 17, 72 e mediana de 18, 36 e, por último $D R D$ em média de 0,31 e mediana de 0,24.

Em relação aos métodos do estado da arte, o método proposto consegue melhor desempenho que Otsu Otsu, 1979, que Niblack Niblack, 1985, que Sauvola Sauvola e Pietikëinen, 2000 e que Su Su et al., 2013. Porém tem desempenho menor que Howe Howe, 2013, a vantagem do método proposto sobre o Howe é que ele não perde pixeis do texto, isto é, a taxa de Falsos Negativos (texto confundidos como fundo) é minima em relação ao método do Howe, que em regiões com ruido elevado apaga o texto. Outra vantagem em relação ao método de Howe é que os caracteres ficam mais grossos e definidos, pois também utilizamos em nosso modelo características de textura, e o modelo atribui um pesso significativo para a característica de borda obtida pelo RDI, o que é significativo quando se avalia em termos de OCR.

Nós participamos na competição do DIBCO $2017^{1}$, apreesentamos uma versão antiga do nosso método. A descrição dos métodos que participaram da competição, incluido o nosso, estão descritos por Pratikakis (PratikAKis, ZAGoris et al., 2017), também mostra o resultado da competição.

Durante o trabalho foi feito um visualizador de imagens que nos permite observar imagens e compará-las visualmente, ela está descrita no Anexo A e disponibilizada no https: //github.com/yulenn/Vizualizador-de-imagens para a comunidade.

\subsection{Limitações e pesquisas futuras}

Ao examinarmos os coeficientes do modelo aprendido, percebemos que o coeficiente do Niblack tem um peso muito baixo, isso significa que não tem uma contribuição significativa para o modelo, como trabalho futuro pode-se testar a importancia das características ou relações entre elas.

Também utilizar outros classificadores além do classificadore linear , por exemplo, um ensemble de classificadores ou uma regresão linear.

Regularizar o modelo de outra forma além do 11,12 ou elastic-net. Isso retringiria os pesos do modelo para evitar o sobreajuste do Howe.

\footnotetext{
${ }^{1}$ https://vc.ee.duth.gr/dibco2017/
} 


\section{Apêndice A}

\section{Visualizador de imagens}

Durante o desenvolvimento do trabalho foi feito um visualizador de imagens que nos permite observar imagens e compará-las visualmente.

\section{A.1 Tela inicial}

A Fig. A.1 apresenta a tela inicial do visualizador onde o usuário irá fornecer as seguintes informações:

- O tipo de imagem que queremos observar (manuscrita ou tipografada).

- O diretório onde colocamos as imagens que serão visualizadas (Results folder) (por padrão colocamos o nome "results).

- Para facilitar a comparação, o botão (checkbutton) Difference of images pode ser escolhido. Isso irá fazer uma operação de subtração de imagens (explicada com detalhes abaixo).

- Com o botão Browse escolhemos a imagem de interesse.

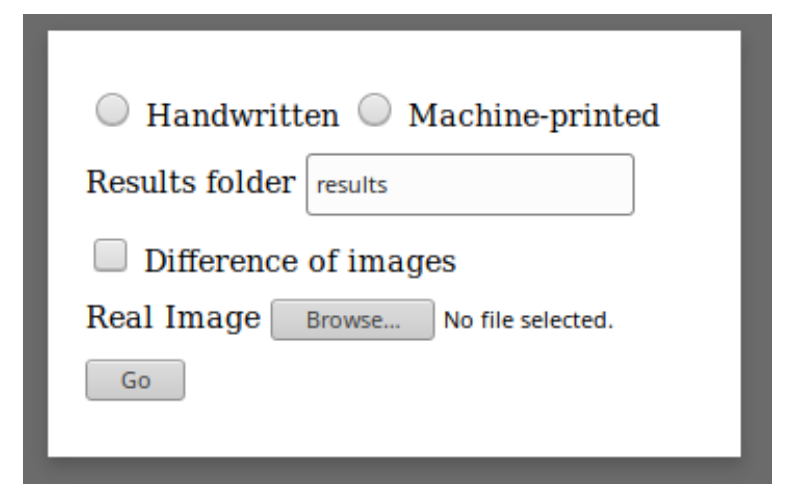

Figura A.1: Tela inicial do visualizador 


\section{A.2 Visualizáção numa escala maior (zoom)}

Nesta seção vamos apresentar um exemplo de como usar o visualizador para comparar imagens. para isso usaremos uma imagem manuscrita.

Primeiramente, na tela inicial, fazemos o seguinte:

- Escolhermos a opção Handwritten.

- Escolhemos uma imagem manuscrita do qual queremos ver os resultados da binarização.

- Acionamos o botão Go.

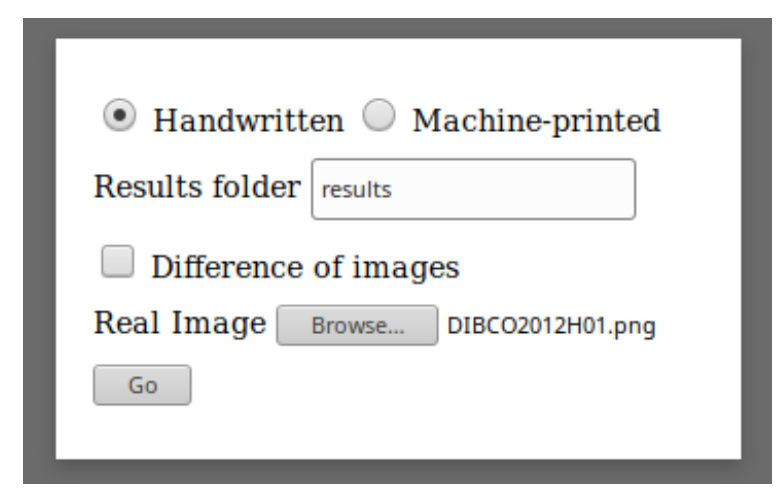

Figura A.2: Tela inicial com a configuração para vizualizar uma imagem manuscrita.

A Fig. A.3 apresenta a segunda tela do visualizador. A tela é dividida em duas partes. Na parte da esquerda, acima, é mostrada a imagem escolhida anteriormente pelo botão Browse. Imediatamente à direita dessa imagem, é mostrada a imagem GT dela. Abaixo dessas imagens, são mostradas até seis imagens de resultados, que devem ser nomeadas como m1.png, m2.png, m3.png, m4.png, m5.png e m6.png. Na segunda parte da tela (lado direito), pode-se escolher quaisquer duas imagens das apresentadas no lado esquerdo e visualizá-las numa escala maior (um zoom delas). Na parte de baixo da ampliação, é apresentada uma tabela de até três colunas, que no nosso caso correspondem às medidas de precisão, revocação e FM das imagens binarizadas, além da quantidade de pixeis. Caso queira-se apresentar esses valores, deve-se preparar um arquivo CSV com essas informações e deixá-lo no mesmo diretório. 


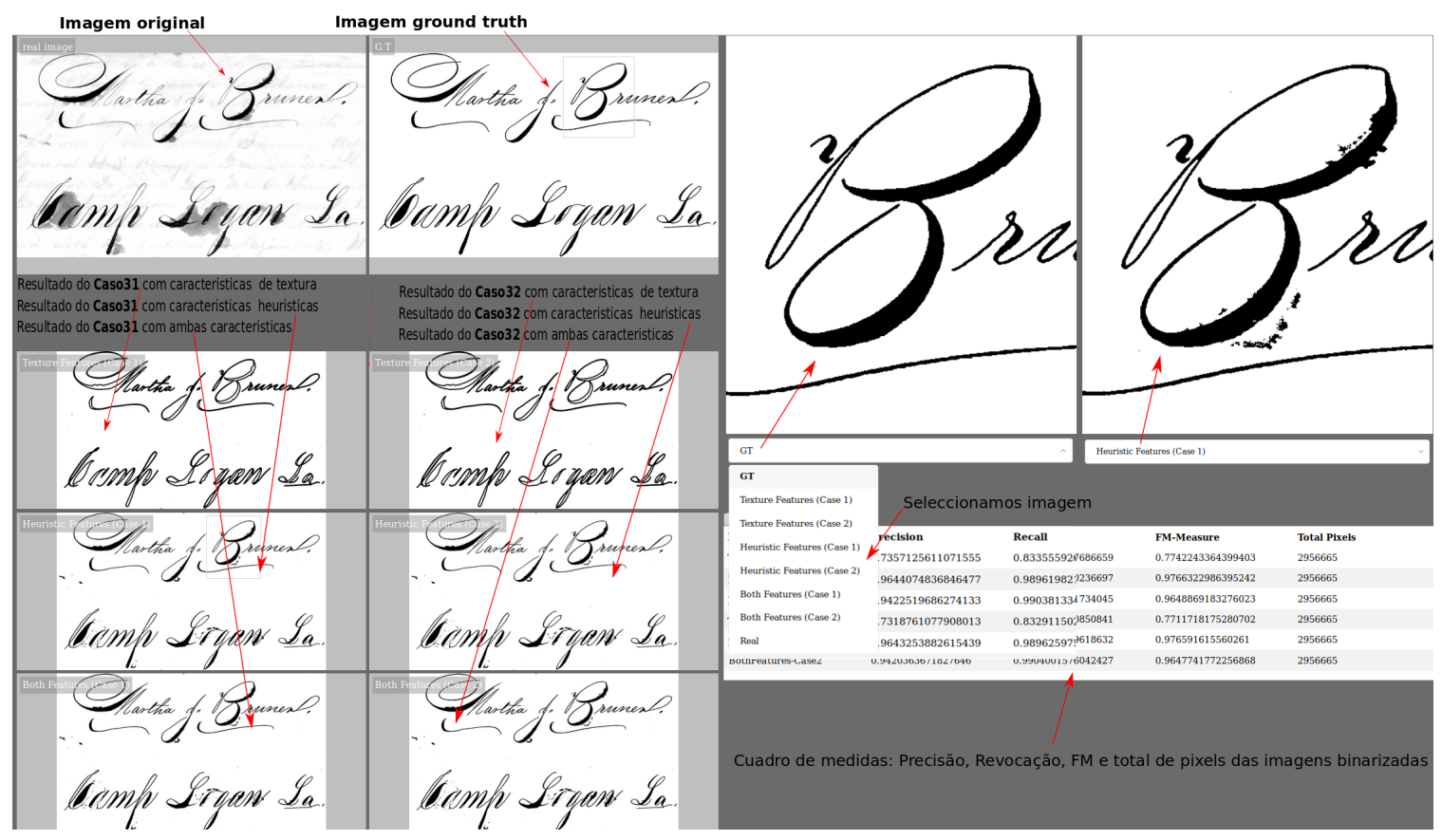

Figura A.3: Visualização e zoom de uma imagem manuscrita

\section{A.3 Visualização da subtração de imagens (diferen- ças)}

A subtração de imagens nos permite compará-las e facilita a visualização das diferenças entre elas. Caso o botão Difference of images (Fig. A.4) tenha sido escolhido, o visualizador calcula a substração das duas imagens selecionadas e pinta com outra cor os pixeis que são diferentes. Os pixeis em vermelho são os Falsos Negativos (pixeis do texto que foram reconhecidos como fundo) e os pixeis em azul são os Falsos Postivos (pixeis do fundo que foram reconhecidos como texto). A Fig. A.5 apreesenta esse caso.

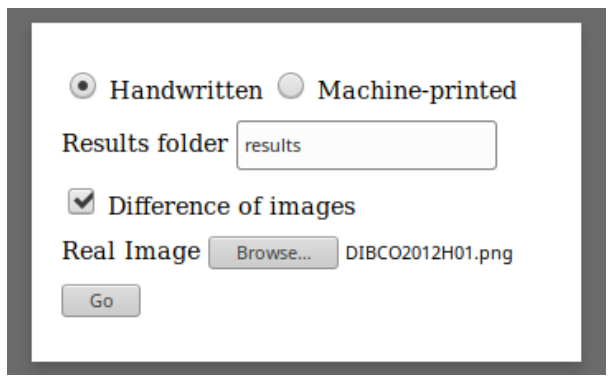

Figura A.4: Configuração da tela inicial para a visualização da diferença de imagens.

A Fig. A.6 mostra um usuário interagindo com o visualizador para enxergar melhor as diferenças. Note que, quando colocamos o mouse acima da imagem de diferença, enxergamos uma ampliação da região abaixo do mouse. 


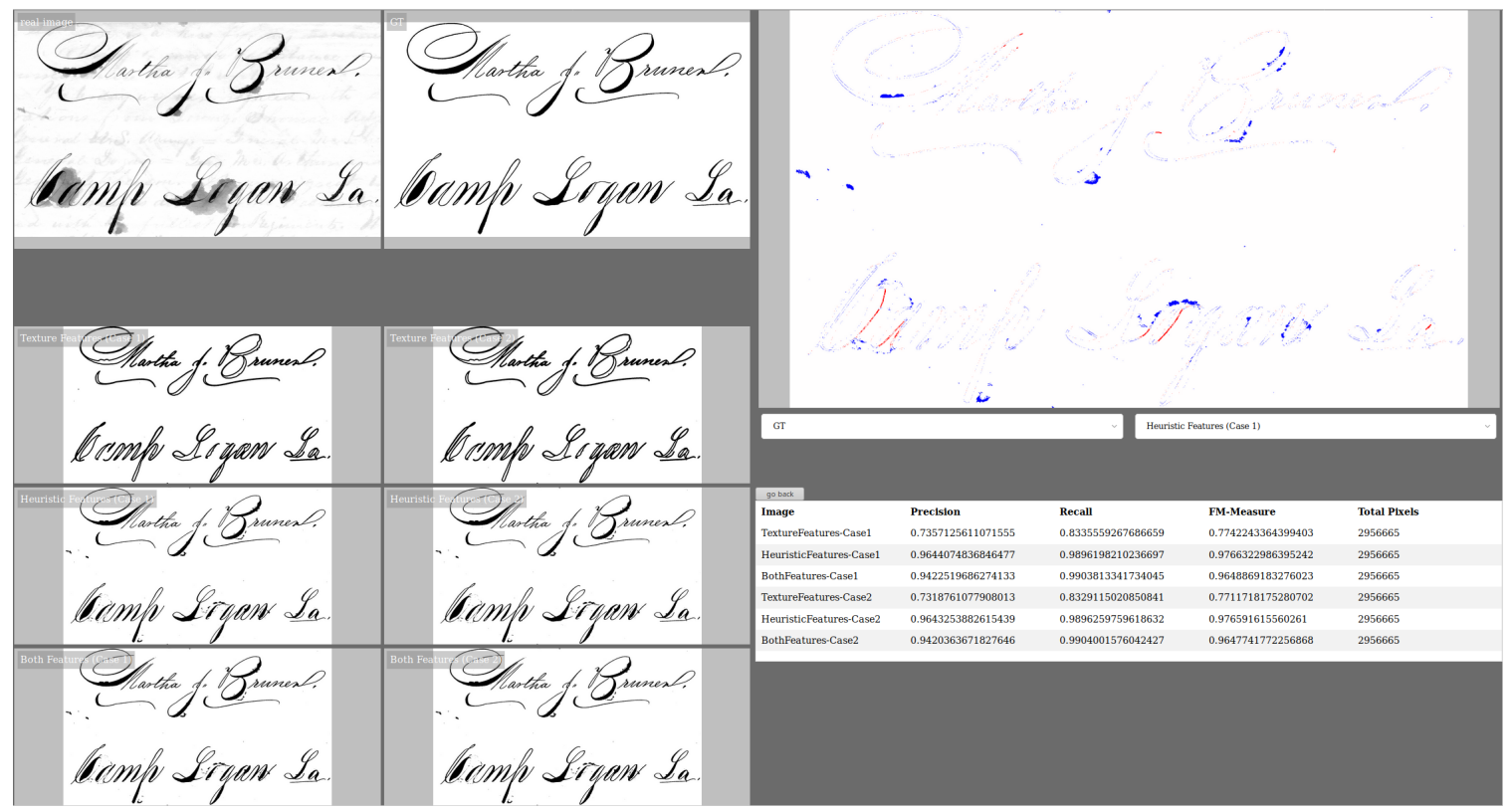

Figura A.5: Visualização da diferença de imagens.

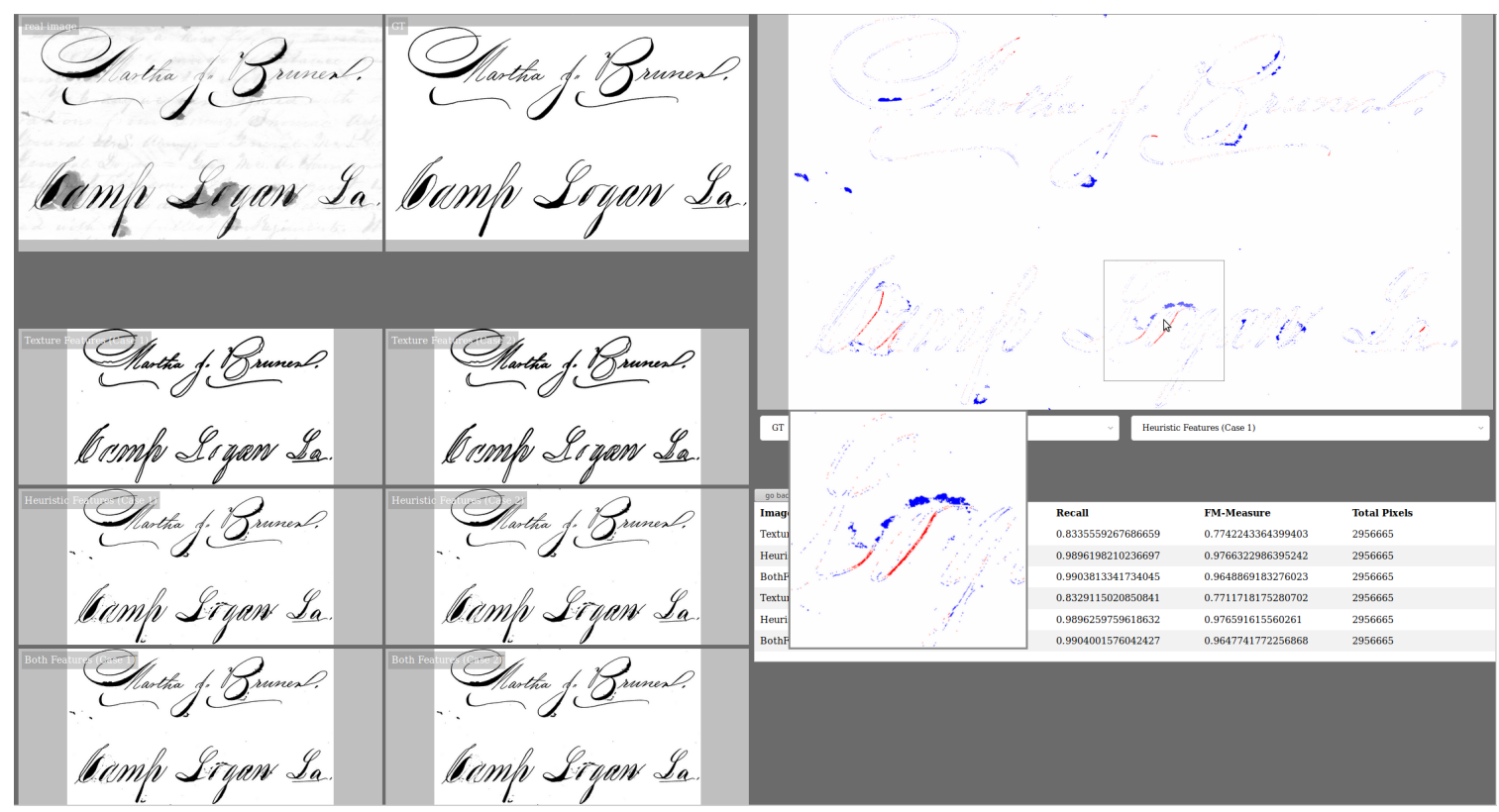

Figura A.6: Visualização da diferença de imagens com uma apliação de uma certa região.

\section{A.4 Visualização de imagens tipografadas e dos textos extraidos}

No caso das imagens tipografadas (Fig. A.7), além das suas binarizações, pode-se visualizar o seu texto correspondente. Para a imagem GT, é o texto fiel à imagem de interesse. Para as outras imagens, é o texto reconhecido pelo Tesseract.

A Fig. A.8 é semelhante às anteriores, mas agora apresenta as binarizações e os textos 
das imagens selecionadas.

Handwritten $\bullet$ Machine-printed

Results folder results

$\checkmark$ Difference of images

Real Image Browse... DIBC02013PR08.png

Go

Figura A.7: Tela inicial para visualizar uma imagem tipografada.

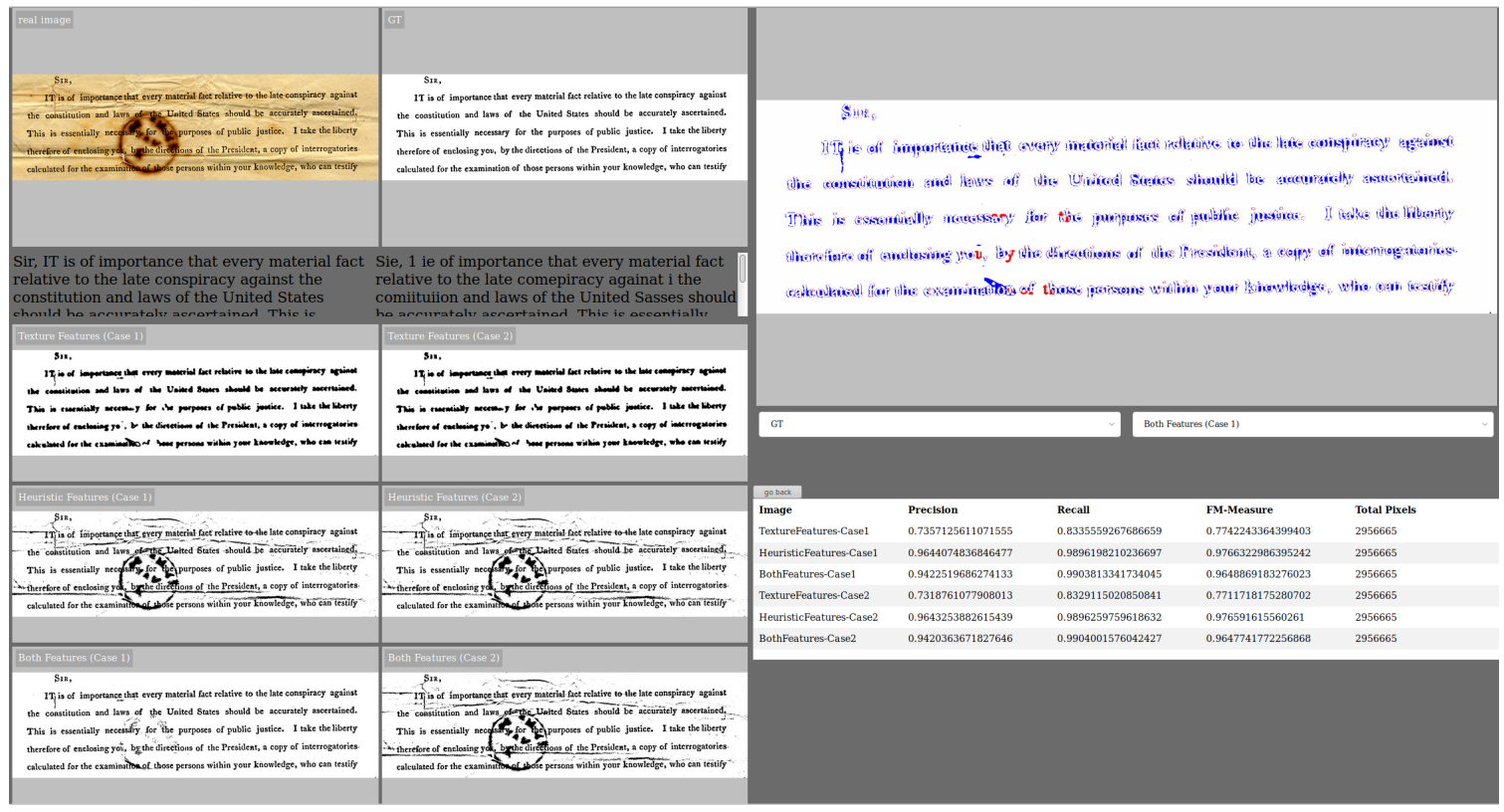

Figura A.8: Visualização e diferença para uma imagem tipografada. 



\section{Bibliografia}

[Afzal et al. 2015] Muhammad Zeshan Afzal et al. "Document image binarization using lstm: a sequence learning approach". Em: Proceedings of the 3rd International Workshop on Historical Document Imaging and Processing. ACM. 2015, pgs. 79-84 (citado na pg. 14).

[Ajitha e Kannan 2014] K Ajitha e P Kannan. "A survey on degraded document image binarization techniques”. Em: International fournal of Advanced Research in Computer Engineering \& Technology 3.11 (2014), pgs. 3805-3808 (citado na pg. 9).

[Alginahi 2004] Yasser Alginahi. Computer analysis of composite documents with non-uniform background. University of Windsor, 2004 (citado na pg. 13).

[Bertalmio et al. 2000] Marcelo Bertalmio, Guillermo Sapiro, Vincent Caselles e Coloma BAllester. "Image inpainting". Em: Proceedings of the 27th annual conference on Computer graphics and interactive techniques. ACM Press/AddisonWesley Publishing Co. 2000, pgs. 417-424 (citado na pg. 13).

[Bernsen 1986] John Bernsen. "Dynamic thresholding of gray-level images”. Em: (jan. de 1986) (citado na pg. 12).

[Bоттоu 2010] Léon Botтou. "Large-scale machine learning with stochastic gradient descent”. Em: Proceedings of COMPSTAT’2010. Springer, 2010, pgs. 177-186 (citado na pg. 20).

[CANnY 1986] John CANny. "A computational approach to edge detection". Em: IEEE Transactions on pattern analysis and machine intelligence 6 (1986), pgs. 679-698 (citado nas pgs. 12, 18, 26).

[Chamchong e Fung 2010] Rapeeporn Chamchong e Chun Che Fung. "Optimal selection of binarization techniques for the processing of ancient palm leaf manuscripts”. Em: Systems Man and Cybernetics (SMC), 2010 IEEE International Conference on. IEEE. 2010, pgs. 3796-3800 (citado na pg. 13).

[CaO e Govindaraju 2009] Huaigu Cao e Venu Govindaraju. "Preprocessing of lowquality handwritten documents using markov random fields". Em: IEEE Transactions on Pattern Analysis and Machine Intelligence 31.7 (2009), pgs. 1184-1194 (citado na pg. 12). 
[Calvo-Zaragoza e Gallego 2017] Jorge Calvo-Zaragoza e Antonio-Javier GalLEGO. "A selectional auto-encoder approach for document image binarization". Em: arXiv preprint arXiv:1706.10241 (2017) (citado na pg. 14).

[Chou et al. 2010] Chien-Hsing Chou, Wen-Hsiung Lin e Fu Chang. “A binarization method with learning-built rules for document images produced by cameras". Em: Pattern Recognition 43.4 (2010), pgs. 1518-1530 (citado na pg. 13).

[Chauhan et al. 2016] Shivani Chauhan, Ekta Sharma, Amit Doegar et al. "Binarization techniques for degraded document images-a review". Em: Reliability, Infocom Technologies and Optimization (Trends and Future Directions)(ICRITO), 2016 5th International Conference on. IEEE. 2016, pgs. 163-166 (citado na pg. 9).

[Chaкi et al. 2014] Nabendu Chaki, Soharab Hossain Shaikh e Khalid Saeed. "A comprehensive survey on image binarization techniques”. Em: Exploring Image Binarization Techniques. Springer, 2014, pgs. 5-15 (citado na pg. 9).

[Calvo-Zaragoza, Vigliensoni et al. 2017] Jorge Calvo-Zaragoza, Gabriel VigliENSONI e Ichiro FujINAGA. "Pixel-wise binarization of musical documents with convolutional neural networks". Em: Machine Vision Applications (MVA), 2017 Fifteenth IAPR International Conference on. IEEE. 2017, pgs. 362-365 (citado na pg. 14).

[Chi e Wong 2001] Z Chi e KW Wong. "A two-stage binarization approach for document images”. Em: Intelligent Multimedia, Video and Speech Processing, 2001. Proceedings of 2001 International Symposium on. IEEE. 2001, pgs. 275-278 (citado na pg. 13).

[Duda et al. 2012] Richard O Duda, Peter E Hart e David G Stork. Pattern classification. John Wiley \& Sons, 2012 (citado na pg. 15).

[Dixit e Shirdhonkar 2015] Umesh D Dixit e MS Shirdhonkar. "A survey on document image analysis and retrieval system”. Em: International fournal on Cybernetics \& Informatics (IfCI) 4.2 (2015), pgs. 259-270 (citado na pg. 1).

[GÉron 2017] Aurélien GÉron. Hands-on machine learning with Scikit-Learn and TensorFlow: concepts, tools, and techniques to build intelligent systems. "O'Reilly Media, Inc.", 2017 (citado na pg. 30).

[Geurts et al. 2006] Pierre Geurts, Damien Ernst e Louis Wehenkel. "Extremely randomized trees”. Em: Machine learning 63.1 (2006), pgs. 3-42 (citado na pg. 13).

[Basilis Gatos et al. 2009] Basilis Gatos, Konstantinos Ntirogiannis e Ioannis PraTIKAKIs. "Icdar 2009 document image binarization contest (dibco 2009)". Em: Document Analysis and Recognition, 2009. ICDAR'09. 10th International Conference on. IEEE. 2009, pgs. 1375-1382 (citado na pg. 23). 
[Goodfellow et al. 2016] Ian Goodfellow, Yoshua Bengio, Aaron Courville e Yoshua Bengio. Deep learning. Vol. 1. MIT press Cambridge, 2016 (citado nas pgs. 14, 29).

[Basilios Gatos et al. 2006] Basilios Gatos, Ioannis Pratikakis e Stavros J Perantonis. “Adaptive degraded document image binarization”. Em: Pattern recognition 39.3 (2006), pgs. 317-327 (citado na pg. 12).

[Guo et al. 2008] Xinjian Guo, Yilong YIn, Cailing Dong, Gongping YAng e Guangtong ZHou. "On the class imbalance problem". Em: Natural Computation, 2008. ICNC'08. Fourth International Conference on. Vol. 4. IEEE. 2008, pgs. 192-201 (citado na pg. 30).

[Rafael C Gonzalez e Richard E Woods 2002] Rafael C Gonzalez e Richard E Woods. “Thresholding”. Em: Digital Image Processing (2002), pgs. 595-611 (citado na pg. 10).

[Rafael C. Gonzalez e Richard E. Woods 2006] Rafael C. Gonzalez e Richard E. WooDs. Digital Image Processing (3rd Edition). Upper Saddle River, NJ, USA: PrenticeHall, Inc., 2006. ISBN: 013168728X (citado na pg. 18).

[Huttenlocher et al. 1999] Daniel Huttenlocher, Pedro Felzenszwalb e William RUCKLIDGE. "Digipaper: a versatile color document image representation”. Em: Image Processing, 1999. ICIP 99. Proceedings. 1999 International Conference on. Vol. 1. IEEE. 1999, pgs. 219-223 (citado na pg. 1).

[Hidalgo et al. 2005] J Luis Hidalgo, Salvador España, María José Castro e José Alberto PÉREz. "Enhancement and cleaning of handwritten data by using neural networks". Em: Iberian Conference on Pattern Recognition and Image Analysis. Springer. 2005, pgs. 376-383 (citado na pg. 13).

[Howe 2011] Nicholas R Howe. "A laplacian energy for document binarization”. Em: Document Analysis and Recognition (ICDAR), 2011 International Conference on. IEEE. 2011, pgs. 6-10 (citado nas pgs. 4, 5, 16, 18).

[Howe 2013] Nicholas R Howe. "Document binarization with automatic parameter tuning”. Em: International fournal on Document Analysis and Recognition (IfDAR) 16.3 (2013), pgs. 247-258 (citado nas pgs. 5, 6, 12, 18, 49, 56).

[Ismail et al. 2018] Saad M Ismail, Siti Norul Huda Sheikh Abdullah e Fariza Fauzi. "Statistical binarization techniques for document image analysis". Em: fournal of Computer Science 14.1 (2018), pgs. 23-36 (citado nas pgs. 4, 11).

[JaIn 1989] Anil K JaIn. Fundamentals of digital image processing. Prentice-Hall, Inc., 1989 (citado na pg. 12).

[Kittler et al. 1985] Josef Kittler, John Illingworth e J Föglein. "Threshold selection based on a simple image statistic". Em: Computer vision, graphics, and image processing 30.2 (1985), pgs. 125-147 (citado na pg. 9). 
[Kaur e Mahajan 2014] Er Jagroop Kaur e Rajiv Mahajan. "Improved degraded document image binarization using guided image filter”. Em: International journal of Advance research in Computer Science and Software Engineering 4.9 (2014) (citado na pg. 9).

[Kefali et al. 2014] Abderrahmane Kefali, Toufik Sari e Halima Bahi. "Foregroundbackground separation by feed-forward neural networks in old manuscripts”. Em: Informatica 38.4 (2014) (citado na pg. 13).

[LeVenshtein 1966] Vladimir I Levenshtein. "Binary codes capable of correcting deletions, insertions, and reversals”. Em: Soviet physics doklady. Vol. 10. 8. 1966, pgs. 707-710 (citado nas pgs. 12, 29).

[H. Lu et al. 2004] Haiping Lu, Alex C Кот e Yun Q SHI. "Distance-reciprocal distortion measure for binary document images". Em: IEEE Signal Processing Letters 11.2 (2004), pgs. 228-231 (citado nas pgs. 5, 28).

[S. Lu et al. 2010] Shijian Lu, Bolan Su e Chew Lim TAN. "Document image binarization using background estimation and stroke edges". Em: International journal on document analysis and recognition 13.4 (2010), pgs. 303-314 (citado na pg. 12).

[Likforman-Sulem et al. 2007] Laurence Likforman-Sulem, Abderrazak Zahour e Bruno TACONET. "Text line segmentation of historical documents: a survey". Em: International journal on document analysis and recognition 9.2 (2007), pgs. 123-138 (citado na pg. 2).

[Mishra et al. 2011] Anand Mishra, Karteek Alahari e CV Jawahar. "An mrf model for binarization of natural scene text”. Em: Document Analysis and Recognition (ICDAR), 2011 International Conference on. IEEE. 2011, pgs. 11-16 (citado na pg. 12).

[More e Dighe 2016] Prachi K More e DD Dighe. "A review on document image binarization technique for degraded document images". Em: International Research fournal of Engineering and Technology (IRJET) 3.03 (2016), pgs. 1132-1138 (citado na pg. 9).

[Murray e Grubesic 2002] Alan T Murray e Tony H Grubesic. "Identifying nonhierarchical spatial clusters". Em: International fournal of Industrial Engineering 9 (2002), pgs. 86-95 (citado na pg. 13).

[Moghaddam et al. 2013] Reza Farrahi Moghaddam, Fereydoun Farrahi Moghaddam e Mohamed Cheriet. "Unsupervised ensemble of experts (eoe) framework for automatic binarization of document images". Em: Document Analysis and Recognition (ICDAR), 2013 12th International Conference on. IEEE. 2013, pgs. 703-707 (citado na pg. 13).

[Murphy et al. 2006] Kevin P Murphy et al. "Naive bayes classifiers". Em: University of British Columbia 18 (2006) (citado na pg. 13). 
BIBLIOGRAFIA

[NAVARro 2001] Gonzalo Navarro. "A guided tour to approximate string matching". Em: ACM computing surveys (CSUR) 33.1 (2001), pgs. 31-88 (citado na pg. 29).

[Ntirogiannis, Basilios Gatos et al. 2008] Konstantinos Ntirogiannis, Basilios GATOS e Ioannis PrATIKAKIs. "An objective evaluation methodology for document image binarization techniques”. Em: Document Analysis Systems, 2008. DAS'08. The Eighth IAPR International Workshop on. IEEE. 2008, pgs. 217-224 (citado nas pgs. 26, 27).

[Ntirogiannis, Basilis Gatos et al. 2014] Konstantinos Ntirogiannis, Basilis Gatos e Ioannis Pratikakis. "Icfhr2014 competition on handwritten document image binarization (h-dibco 2014)”. Em: Frontiers in Handwriting Recognition (ICFHR), 2014 14th International Conference on. IEEE. 2014, pgs. 809-813 (citado nas pgs. 13, 23).

[Niblack 1985] Wayne Niblack. An introduction to digital image processing. Strandberg Publishing Company, 1985 (citado nas pgs. 10, 16, 17, 49, 56).

[Ouafek e Kholladi 2018] Naouel Ouafek e Mohamed-Khireddine Kholladi. “A binarization method for degraded document image using artificial neural network and interpolation inpainting". Em: Optimization and Applications (ICOA), 2018 4th International Conference on. IEEE. 2018, pgs. 1-5 (citado nas pgs. 4, 9, 13).

[Oтsu 1979] Nobuyuki Oтsu. "A threshold selection method from gray-level histograms". Em: IEEE transactions on systems, man, and cybernetics 9.1 (1979), pgs. 62-66 (citado nas pgs. 5, 6, 9, 16, 17, 49, 56).

[Pastor-Pellicer et al. 2015] Joan Pastor-Pellicer, S España-Boquera, Francisco Zamora-Martínez, M Zeshan Afzal e Maria Jose Castro-Bleda. "Insights on the use of convolutional neural networks for document image binarization". Em: International Work-Conference on Artificial Neural Networks. Springer. 2015, pgs. 115-126 (citado na pg. 14).

[Pratikakis, Basilis Gatos et al. 2010] Ioannis Pratikakis, Basilis Gatos e Konstantinos NTIRogianNis. "H-dibco 2010-handwritten document image binarization competition”. Em: Frontiers in Handwriting Recognition (ICFHR), 2010 International Conference on. IEEE. 2010, pgs. 727-732 (citado nas pgs. 23, 27).

[Pratikakis, Basilis Gatos et al. 2011] Ioannis Pratikakis, Basilis Gatos e Konstantinos NTIRogiannis. "Icdar 2011 document image binarization contest (dibco 2011)". Em: Document Analysis and Recognition (ICDAR), 2011 International Conference on. IEEE. 2011, pgs. 1506-1510 (citado nas pgs. 23, 24).

[Pratikakis, Basilis Gatos et al. 2012] Ioannis Pratikakis, Basilis Gatos e Konstantinos NTIRogiannis. "Icfhr 2012 competition on handwritten document image binarization (h-dibco 2012)". Em: Frontiers in Handwriting Recognition (ICFHR), 2012 International Conference on. IEEE. 2012, pgs. 817-822 (citado na pg. 23). 
[Pratikakis, Basilis Gatos et al. 2013] Ioannis Pratikakis, Basilis Gatos e Konstantinos Ntirogiannis. "Dibco 2013-document image binarization contest". Em: International Conference on Document Analysis and Recognition. 2013, pgs. 11021107 (citado na pg. 23).

[Pratikakis, Zagoris et al. 2016] Ioannis Pratikakis, Konstantinos Zagoris, George BARLAS e Basilis Gatos. "Icfhr2016 handwritten document image binarization contest (h-dibco 2016)". Em: 2016 15th International Conference on Frontiers in Handwriting Recognition (ICFHR). IEEE. 2016, pgs. 619-623 (citado nas pgs. 14, 23).

[Pratikakis, Zagoris et al. 2017] Ioannis Pratikakis, Konstantinos Zagoris, George BARLAS e Basilis Gatos. "Icdar2017 competition on document image binarization (dibco 2017)". Em: 2017 14th IAPR International Conference on Document Analysis and Recognition (ICDAR). IEEE. 2017, pgs. 1395-1403 (citado nas pgs. 23, 26, 56).

[READ s.d.] READ. URL: https://read.transkribus.eu/ (citado na pg. 24).

[Stathis et al. 2008] Pyrrhos Stathis, Ergina Kavallieratou e Nikos Papamarkos. "An evaluation technique for binarization algorithms." Em: f. UCS 14.18 (2008), pgs. 3011-3030 (citado na pg. 27).

[Su et al. 2012] Bolan Su, Shijian Lu e Chew Lim TAN. "A learning framework for degraded document image binarization using markov random field”. Em: Pattern Recognition (ICPR), 2012 21st International Conference on. IEEE. 2012, pgs. 32003203 (citado na pg. 13).

[Su et al. 2013] Bolan Su, Shijian Lu e Chew Lim TAN. "Robust document image binarization technique for degraded document images". Em: IEEE transactions on image processing 22.4 (2013), pgs. 1408-1417 (citado nas pgs. 16, 18, 49, 56).

[Sauvola e Pietikäinen 2000] Jaakko Sauvola e Matti Pietikäınen. "Adaptive document image binarization”. Em: Pattern recognition 33.2 (2000), pgs. 225-236 (citado nas pgs. $5,6,10,12,16,17,49,56)$.

[Sezgin e Sankur 2004] Mehmet Sezgin e Bülent Sankur. "Survey over image thresholding techniques and quantitative performance evaluation”. Em: fournal of Electronic imaging 13.1 (2004), pgs. 146-166 (citado na pg. 11).

[TAN e Triggs 2010] Xiaoyang TAN e Bill Triggs. "Enhanced local texture feature sets for face recognition under difficult lighting conditions". Em: IEEE transactions on image processing 19.6 (2010), pgs. 1635-1650 (citado na pg. 16).

[Varghahan et al. 2011] Behrooz Zali Varghahan, Mehdi Chehel Amirani e Sara Minandoost. "Enhancement and cleaning of handwritten data by using neural networks and threshold technical". Em: Application of Information and Communication Technologies (AICT), 2011 5th International Conference on. IEEE. 2011, pgs. 1-4 (citado na pg. 13). 
[VATs et al. 2017] Ekta VATs, Anders Hast e Prashant Singh. "Automatic document image binarization using bayesian optimization". Em: Proceedings of the 2017 Workshop on Historical Document Imaging and Processing. ACM (2017, in press). 2017 (citado na pg. 5).

[Vo et al. 2018] Quang Nhat Vo, Soo Hyung Kim, Hyung Jeong YANG e Gueesang LEE. "Binarization of degraded document images based on hierarchical deep supervised network”. Em: Pattern Recognition 74 (2018), pgs. 568-586 (citado nas pgs. 9, 14).

[Weinman et al. 2014] Jerod J Weinman, Zachary Butler, Dugan Knoll e Jacqueline FEILD. "Toward integrated scene text reading". Em: IEEE transactions on pattern analysis and machine intelligence 36.2 (2014), pgs. 375-387 (citado na pg. 1).

[Westphal et al. 2018] Florian Westphal, Niklas Lavesson e Håkan Grahn. "Document image binarization using recurrent neural networks". Em: 2018 13th IAPR International Workshop on Document Analysis Systems (DAS). IEEE. 2018, pgs. 263-268 (citado nas pgs. 9, 14).

[Wu et al. 2016] Yue Wu, Premkumar Natarajan, Stephen Rawls e Wael AbdAlmaGEED. "Learning document image binarization from data". Em: Image Processing (ICIP), 2016 IEEE International Conference on. IEEE. 2016, pgs. 3763-3767 (citado nas pgs. 13, 16). 